NBER WORKING PAPER SERIES

\title{
A MODEL OF SECULAR STAGNATION: THEORY AND QUANTITATIVE EVALUATION
}

\author{
Gauti B. Eggertsson \\ Neil R. Mehrotra \\ Jacob A. Robbins \\ Working Paper 23093 \\ http://www.nber.org/papers/w23093 \\ NATIONAL BUREAU OF ECONOMIC RESEARCH \\ 1050 Massachusetts Avenue \\ Cambridge, MA 02138 \\ January 2017
}

This paper replaces an earlier version of a paper released in 2014 under the title "A Model of Secular Stagnation." We thank the Institute for New Economic Thinking for financial support. We also thank Olivier Blanchard, John Cochrane, Michael Dotsey, Emmanuel Farhi, Jesus Fernandez-Villaverde, Pablo Guerron-Quintana, Benjamin Keen, Pat Kehoe, John Leahy, Emi Nakamura, Paolo Pesenti, and Lawrence Summers for helpful discussions and conference and seminar participants at the Bank of Canada, Bank of England, Bank for International Settlements, Bank of Japan, Bank of Finland, Boston University, Brown, Central Bank of Austria, Cornell, Chicago Booth, Georgetown, European Central Bank, Rutgers, the Federal Reserve Banks of Boston, Dallas, Minneapolis, and New York, Harvard, LSE, LUISS Guido Carli, NBER Summer Institute MEFM and EFG meetings, Northwestern, Princeton, Royal Economic Society meetings, and UTDT for comments. We would also like to thank Alex Mechanick for excellent research assistance. The views expressed herein are those of the authors and do not necessarily reflect the views of the National Bureau of Economic Research.

NBER working papers are circulated for discussion and comment purposes. They have not been peer-reviewed or been subject to the review by the NBER Board of Directors that accompanies official NBER publications.

(C) 2017 by Gauti B. Eggertsson, Neil R. Mehrotra, and Jacob A. Robbins. All rights reserved. Short sections of text, not to exceed two paragraphs, may be quoted without explicit permission provided that full credit, including $\odot$ notice, is given to the source. 
A Model of Secular Stagnation: Theory and Quantitative Evaluation

Gauti B. Eggertsson, Neil R. Mehrotra, and Jacob A. Robbins

NBER Working Paper No. 23093

January 2017, Revised February 2017

JEL No. E31,E32,E5,E52,E58,E6,E62

\begin{abstract}
$\underline{\text { ABSTRACT }}$ to restore higher rates.

Gauti B. Eggertsson

Department of Economics

Brown University

64 Waterman Street

Providence, RI 02912

and NBER

gauti_eggertsson@brown.edu

Neil R. Mehrotra

Federal Reserve Bank of Minneapolis

90 Hennepin Avenue

Minneapolis, MN 55401

neil_mehrotra@brown.edu

Jacob A. Robbins

Department of Economics

Brown University

64 Waterman Street

Providence, RI 02906

Jacob_Robbins@brown.edu
\end{abstract}

This paper formalizes and quantifies the secular stagnation hypothesis, defined as a persistently low or negative natural rate of interest leading to a chronically binding zero lower bound (ZLB). Output-inflation dynamics and policy prescriptions are fundamentally different from those in the standard New Keynesian framework. Using a 56-period quantitative life cycle model, a standard calibration to US data delivers a natural rate ranging from $-1: 5 \%$ to $-2 \%$, implying an elevated risk of ZLB episodes for the foreseeable future. We decompose the contribution of demographic and technological factors to the decline in interest rates since 1970 and quantify changes required

A online appendix is available at http://www.nber.org/data-appendix/w23093 
Figure 1: Short and long term interest rates
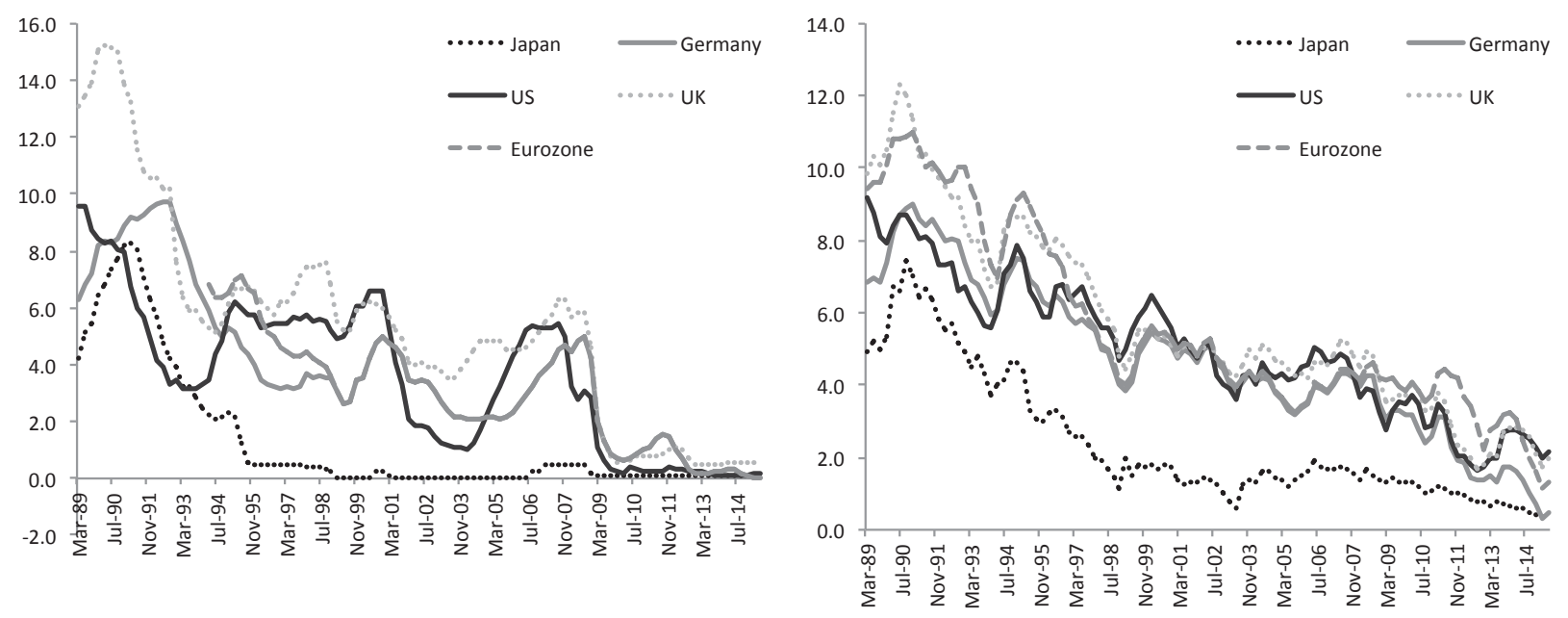

\section{Introduction}

The zero lower bound (ZLB) on the short-term nominal interest rate became a binding constraint in the United States in 2008 in the midst of the financial crisis. Accordingly, low interest rates are often tied to that event, and it may seem natural to presume that as the crisis of 2008 moves into the rear view mirror so too will the low interest rate environment. This perspective seems vindicated by the recent interest rate increases by the Federal Reserve in the fourth quarter of 2016. However, as shown in Figure 1, the low interest rate in 2008 was not just an anomaly that arose solely because of the financial crisis. Instead, it is the culmination of a 25-year trend across major industrial economies. In Japan, rates have been zero since the mid-1990s and remain there today. Furthermore, while recent increases in the Federal Funds rate may give rise to optimism in the US, rates remain at zero in Europe with no end in sight. The fact that rates remain so low should raise concern that the ZLB will remain a significant constraint on US monetary policy in the future should economic conditions deteriorate.

This paper contemplates the possibility that the fall in interest rates observed over the past 25 years in the industrialized world represents a permanent change - a "new normal." We propose a model that allows for ZLB episodes of arbitrary duration due to a persistent fall in interest rates (as observed in Figure 1) driven by slow-moving secular forces that are unlikely to reverse themselves. We also perform a quantitative assessment to ascertain the plausibility of a decline in the natural (full employment) interest rate to negative values using a quantitative life cycle model calibrated to current US data.

This paper should be read as a formalization of the secular stagnation hypothesis, originally proposed by Hansen (1939), who, a decade into the Great Depression with interest rates still at 
zero, argued that the US economy faced a permanent shortfall in aggregate demand. This idea was recently resurrected by Lawrence Summers, who argued that one should think of secular stagnation as the hypothesis that the natural rate of interest (the equilibrium real interest rate consistent with output at potential) is permanently negative (see Summers (2013) and Summers (2014)). We formalize this idea by constructing a series of analytic and quantitative overlapping generation models (OLG) of varying degrees of complexity in which the steady-state, full-employment real interest rate is permanently negative. This leads under certain conditions to a chronically binding ZLB, subpar growth, and inflation below target; we define these characteristics as a secular stagnation.

The policy implications of our framework differ in important ways from the standard ZLB literature. Perhaps most importantly, a policy of simply waiting for a ZLB episode to end is not a good strategy in a secular stagnation; there is no deus ex machina for recovery as presumed in the existing literature (see Krugman (1998) and Eggertsson and Woodford (2003), where the exogenous shocks that give rise to the ZLB must ultimately revert). The absence of an automatic recovery has fundamental implications for monetary policy. Unlike in Eggertsson and Woodford (2003), forward guidance loses most of its power, for two reasons. First, agents do not necessarily anticipate a future date at which the ZLB is not binding. Second, aggregate demand (or the intertemporal IS equation) is not as "forward looking" - sensitive to expectations about future income - in our setting relative to the standard model. Raising the inflation target may be an option to accommodate a negative natural rate of interest. This policy, however, suffers from two major drawbacks. First, an increase in the inflation target must be sufficiently large. For example, if the natural rate of interest is $-4 \%$, the inflation target must be $4 \%$ or higher. Small changes in the inflation target have no effect, capturing Krugman's observation of the "law of the excluded middle" or "timidity trap" when trying explain why the Japanese economy might not respond to a higher inflation target announced by the Bank of Japan unless it was sufficiently aggressive (see Krugman (2014)). Second, even with a high enough increase in the inflation target, the secular stagnation equilibrium is not eliminated. Hence, an increase in the inflation target allows for a better outcome, but it does not guarantee it because it cannot exclude a secular stagnation equilibrium. ${ }^{1}$

Fiscal policy is more effective in addressing the problems raised by secular stagnation, and an aggressive enough fiscal expansion does not suffer from multiplicity of steady states - it eliminates the secular stagnation steady state altogether. However, the effects of fiscal policy are more subtle than in the standard New Keynesian treatment of the ZLB. Increases in government spending can carry zero or negative multipliers in our model, depending on the distribution of taxes across generations. The key for successful fiscal policy is that it must reduce the oversupply of

\footnotetext{
${ }^{1}$ In fact, theory provides no obvious way to determine whether the high or low steady state will be chosen because they both pass standard equilibrium selection tests, such as local determinacy.
} 
savings and raise the natural rate of interest. Fiscal policy that instead increases desired savings by, for example, reducing future disposable income through tax increases, can exacerbate a secular stagnation. In the standard NK model, government spending multipliers are above one irrespective of the financing mechanism and may be unboundedly large for reasons related to the forward-looking intertemporal IS curve. These mechanisms are considerably attenuated in our framework.

In addition to allowing for the possibility of arbitrarily long periods of negative interest rates, our model accounts for and can quantify a host of new forces that affect the natural rate of interest. These forces come naturally into play in our analysis since we abandon the representative agent framework of the standard NK model. Essentially any force that alters the relative supply of savings and investment can have an effect on the interest rate. We show how a slowdown in population growth or an increase in life expectancy puts downward pressure on the natural rate. Rising income inequality or a fall in the relative price of investment goods may also reduce the natural rate. A slowdown in productivity growth can also play an important role. ${ }^{2}$

Many existing narratives of the Great Recession in the US have emphasized the effect of debt deleveraging caused by the housing crisis on restraining aggregate demand and causing the ZLB to bind (see, for example, Mian and Sufi (2014), Eggertsson and Krugman (2012), Guerrieri and Lorenzoni (2011), and Mehrotra (2017)). For this reason, we incorporate financial frictions in our baseline model. In earlier models, even a permanent shock that tightens credit to financially constrained households results in only a temporary ZLB episode. Once the deleveraging cycle runs its course, the natural rate of interest rises, aggregate demand rises, and the ZLB episode ends. In stark contrast, in our model a deleveraging cycle need not culminate in a rise in the natural rate, and there is no guarantee of a recovery once deleveraging ends. Indeed, our model predicts that, as the deleveraging cycle runs its course, interest rates continue to fall as the young borrowers who transition to saving in middle age have greater disposable income. Incorporating financial frictions in our model also gives some structure to the idea that secular stagnation conditions may have existed prior to 2008 but were masked by the tech bubble in the late 1990s and the subsequent housing bubble in the early 2000s as suggested by Summers (2014).

While the first main contribution of this paper is an analytic framework that lays out the theoretical ingredients needed to characterize secular stagnation, the second main contribution is building a medium-scale life cycle model to explore whether persistently negative natural interest rates are quantitatively realistic. We build a 56-period OLG model with capital and calibrate it to match the US economy in 2015, assuming that the output gap at that time is either (i) zero, or (ii) corresponds to the deviation of output from its pre-2008 trend - two natural (and extreme) benchmarks. In our calibrated model, this gives us a range for the natural rate of interest from

\footnotetext{
${ }^{2}$ It should be noted that the elasticity of the interest rate to changes in productivity growth differs in an OLG setting relative to the standard representative agent model.
} 
$-1.47 \%$ to $-2.20 \%$.

Our quantitative model is able to generate a permanently negative natural rate of interest using parameters that are standard in the macro literature and match key moments from the US data. The main drivers of negative natural interest rates are an aging population, low fertility, and sluggish productivity growth. While this trend may reverse itself, if current projections for fertility and productivity hold, our analysis suggests that the natural rate of interest will be low or negative for the foreseeable future. ${ }^{3}$ Though productivity growth has experienced unexpected periods of acceleration and deceleration since the 1970s, the demographic factors accounting for a low natural rate of interest are unlikely to abate.

We use our model to understand the decline in interest rates seen in the data. We take our 2015 calibration and revert observable demographic and productivity factors to their 1970s value. Over this period, our model generates a 4.02\% decrease in the real interest rate from 1970 to 2015, which matches the actual decrease of $4.09 \%$ experienced in the real Federal Funds rate over that period. The reductions in fertility, mortality, and the rate of productivity growth play the largest role; each alone can account for a fall in the real interest rate of $-1.84 \%,-1.92 \%$, and $-1.90 \%$, respectively. The main factor that has tended to counterbalance these forces is an increase in government debt, which accounts for a $2.11 \%$ increase in the real interest rate. Changes in the labor share, the relative price of investment goods, and variation in consumer debt capacity play a quantitatively smaller role (the first two decrease rates by $-0.50 \%$ and $-0.44 \%$, while the last raises rates by $0.13 \%$ ).

We also evaluate quantitatively the assumptions under which one should expect real interest rates to revert to a more normal level of $1 \%$ - the assumption maintained by current Federal Reserve projections. At a 1\% steady-state real interest rate, the ZLB is much less likely to pose a problem for business cycle stabilization (see, for example, Williams (2016)). A key determinant of whether interest rates are likely to increase is whether the rate of productivity growth, which has slowed markedly since the 1970s, returns to its long-run rate of $2 \%$ per year. This experiment makes clear that the lively debate between Robert Gordon and others about the likely evolution of productivity is crucial in determining whether secular stagnation will remain a problem. Gordon (2012) takes a very pessimistic view of the evolution of future productivity, while Brynjolfsson and McAfee (2014), for example, take a more optimistic view. Our simulations suggest that the stakes are high in that debate for the future conduct of monetary policy, as it may determine the extent to which the ZLB remains an issue for macroeconomic stabilization.

Our paper is organized as follows. In Section 2, we relate the paper to the existing literature. In Section 3, we present our baseline model, starting with a simple endowment economy to explore

\footnotetext{
${ }^{3}$ Of course, a negative natural rate of interest in steady state does not exclude the possibility that we may see a short-term rise in the nominal interest rate due to temporary business cycle factors. Instead, it suggests that there are plausible conditions under which one should expect recurrent and chronic ZLB episodes going forward that can be of arbitrary duration.
} 
interest rate determination in an OLG model with no nominal frictions. Section 4 adds price level determination. Sections 5 and 6 incorporate nominal rigidities and show how negative real interest rates can create a demand recession. Section 7 evaluates monetary and fiscal policy responses in a secular stagnation. Section 8 presents a 56-generation life cycle model with capital accumulation and borrowing constraints to allow for a quantitative evaluation of the secular stagnation hypothesis.

\section{Related Literature}

It may seem somewhat surprising that the idea of secular stagnation has not already been studied in detail in the relatively large literature on the liquidity trap. This literature already invites the possibility that the zero bound on the nominal interest rate is binding for some period of time due to a drop in the natural rate of interest. The reason for this omission, we suspect, is that secular stagnation does not emerge naturally from the current vintage of models in use in the literature. This, however - and perhaps unfortunately - has less to do with economic reality than with the limitations of these models. Most analyses of the current crisis take place within representative agent models (see, e.g., Krugman (1998), Eggertsson and Woodford (2003), Christiano, Eichenbaum and Rebelo (2011), and Werning (2012) for a few well-known examples) where the long-run real interest rate is directly determined by the inverse of the discount factor of the representative agent. Zero lower bound episodes are caused by temporary shocks to the discount factor triggering temporary reductions in the real interest rate that eventually must revert back to a positive long-run level. ${ }^{4}$ The second generation of these models, as in Eggertsson and Krugman (2012), that more explicitly incorporate financial frictions and deleveraging cannot generate permanently negative rates either, since the steady-state real interest rate is tied to the discount rate of the representative saver.

Our model differs fundamentally from this earlier generation of models. As has been understood since Samuelson (1958), with an OLG structure the discount factor of a representative saver is no longer the sole determinant of the natural rate of interest, and a negative natural rate that lasts for an arbitrarily long time is now a possibility. ${ }^{5}$ Our contribution is to introduce the zero lower bound in a framework where the natural rate of interest is influenced by a broader set of factors than in the typical infinite-horizon model. As we argue, these differences are nontrivial for thinking about monetary and fiscal policy at the zero lower bound. Furthermore, an OLG

\footnotetext{
${ }^{4} \mathrm{~A}$ permanent shock to the household's discount factor is not possible since the maximization problem of the representative household is no longer well defined. One possible alternative in the representative agent framework is a rise in uncertainty large enough to make the risk-free rate negative, as in Abel et al. (1989).

${ }^{5}$ For a more recent reference that provides a good overview of the results in the literature, see Blanchard and Weil (2001).
} 
structure allows for a richer set of factors to influence the real interest rate, which is essential for understanding the sources and potential persistence of the decline in the natural rate.

A recent literature has emphasized that existing New Keynesian models of the zero lower bound tend to generate inflation and output dynamics at odds with recent ZLB episodes; NK models predict a sharp collapse in output and deflationary spirals for particularly long-lasting ZLB episodes (see, e.g., Cochrane (2016)). By contrast, our model does not suffer from these counterfactual dynamics. In a secular stagnation steady state, inflation is persistently below target and output falls below trend, which matches the observed dynamics of output, inflation, and interest rates in the US, Eurozone, and Japan. Similarly, our model also does not suffer from the "forward guidance puzzle" - the idea that interest rate changes very far in the future have implausibly large effects on output and inflation today, as discussed in Del Negro, Giannoni and Patterson (2012). The intertemporal IS equation in our model is not as forward looking, exhibiting endogenous discounting as in McKay, Nakamura and Steinsson (2016) due to life cycle considerations as opposed to occasionally binding borrowing constraints in their model.

A literature related to our work that explores the deflation steady state in a standard NK model is found in Benhabib, Schmitt-Grohé and Uribe (2001), Schmitt-Grohé and Uribe (2017), and Benigno and Fornaro (2015). A key difference to this strand of the literature is that, in these papers, the ZLB is binding due to self-fulfilling expectations rather than the fundamental factors we consider here. Moreover, the ZLB steady state in these models is locally indeterminate. In contrast, the secular stagnation equilibrium in our model satisfies normal determinacy conditions. This allows us to consider well-defined comparative statics, and our steady state is immune from criticism as in Christiano, Eichenbaum and Johannsen (2016), who argue that indeterminate ZLB episodes driven by self-fulfilling expectations can be ruled out on the grounds that they are not "learnable" and hence it is unclear how expectations can coordinate on this steady state (see Gibbs (2017)).

Other closely related work includes Kocherlakota (2013), who also considers a permanent liquidity trap. The focus in that paper is on falling land prices as a trigger for the crisis, while our focus is on the forces usually associated with secular stagnation: population dynamics, income inequality, a decline in the relative price of investment goods, and a debt deleveraging shock. ${ }^{6}$ Likewise, Caballero and Farhi (2014) characterize a long-lasting ZLB episode resulting from a scarcity of safe assets. This work is more closely focused on explaining falling rates during the Great Recession as opposed to long-term interest rate trends, the focus of the secular stagnation hypothesis. It is worth stressing, however, that the safety trap mechanism is not inconsistent with

\footnotetext{
${ }^{6}$ In the context of the Japanese crisis, Krugman (1998) suggested that population dynamics might be driving some of the decline in the natural rate of interest, although he did not explore this possibility explicitly. Carvalho and Ferrero (2014) quantify this force in a medium-scale DSGE model in the Japanese context and argue that demographic pressures were a significant contributor. Another recent contribution in the same vein but focusing on US age dynamics is Gagnon, Johannsen and Lopez-Salido (2016).
} 
the forces we emphasize as driving secular stagnation. Indeed, building on an earlier version of this paper, Caballero and Farhi (2014) explicitly incorporate the supply side of our model and show that many of the same policy conclusions apply. In separate work, the simple model in this paper is extended to an open economy setting (Eggertsson et al. (2016)), where the open economy dimensions of secular stagnation are analyzed. Open economy factors are particularly relevant when thinking about the global savings glut identified in Bernanke (2005) as a source of low interest rates in the early 1990s, as well as in understanding policy spillovers from current account imbalances and monetary/fiscal policy interactions across countries in a global secular stagnation (see also Coeurdacier, Guibaud and Jin (2015) for the role of demographics and low interest rates in a global context).

\section{Endowment Economy}

We start by considering a simple overlapping-generations economy to analyze the determination of interest rates in an OLG setting. Households live for three periods. They are born in period 1 (young), enter middle age in period 2 (middle age), and retire in period 3 (old). Consider the case in which no aggregate saving is feasible (that is, there is no physical capital) but that generations can borrow and lend to one another. Moreover, imagine that only the middle-aged and old generations receive any income in the form of an endowment: $Y_{t}^{m}$ and $Y_{t}^{o}$. In this case, the young will borrow from the middle-aged households, which, in turn, will save for retirement. The old will not save, but will fully consume their remaining income and assets. We assume, however, that there is a limit on the amount of debt the young can borrow. Generally, we would like to think of this as reflecting some sort of incentive constraint, but for the purposes of this paper it will simply take the form of an exogenous time-varying constant $D_{t}$ (as in the "debtors" in Eggertsson and Krugman (2012)).

More concretely, consider the representative household of a cohort born at time $t$. This household has the following utility function:

$$
\max _{C_{t}^{y}, C_{t+1}^{m}, C_{t+2}^{o}} \mathbb{E}_{t}\left\{\log \left(C_{t}^{y}\right)+\beta \log \left(C_{t+1}^{m}\right)+\beta^{2} \log \left(C_{t+2}^{o}\right)\right\}
$$

where $C_{t}^{y}$ is the consumption of the household when young, $C_{t+1}^{m}$ its consumption when middle aged, and $C_{t+2}^{o}$ its consumption while old. We assume that borrowing and lending take place via one-period riskless bonds denoted $B_{t}^{i}$, where $i=y, m, o$ at an interest rate $r_{t}$. Given this structure, 
we can write the budget constraints facing households born at time $t$ in each period as

$$
\begin{aligned}
C_{t}^{y} & =B_{t}^{y} \\
C_{t+1}^{m} & =Y_{t+1}^{m}-\left(1+r_{t}\right) B_{t}^{y}+B_{t+1}^{m} \\
C_{t+2}^{o} & =Y_{t+2}^{o}-\left(1+r_{t+1}\right) B_{t+1}^{m} \\
\left(1+r_{t}\right) B_{t}^{i} & \leq D_{t},
\end{aligned}
$$

where equation (1) corresponds to the budget constraint for the young where consumption is financed by borrowing. Equation (2) gives the budget constraint of the middle-aged household that receives the endowment $Y_{t}^{m}$, repays what was borrowed, and saves $B_{t+1}^{m}$ for retirement. Finally, equation (3) corresponds to the budget constraint when the household is old, consuming savings and interest and any endowment received in the last period. ${ }^{7}$

The inequality (4) corresponds to the exogenous borrowing limit (as in Eggertsson and Krugman (2012)). We assume that the collateral constraint is tight enough so that it binds for the young: ${ }^{8}$

$$
C_{t}^{y}=B_{t}^{y}=\frac{D_{t}}{1+r_{t}}
$$

where the amount of debt that the young can borrow depends on their ability to repay in the middle period and, therefore, includes interest payments. As a result, a drop in the real interest rate increases borrowing by the young.

The old at any time $t$ are hand to mouth and will consume their income:

$$
C_{t}^{o}=Y_{t}^{o}-\left(1+r_{t-1}\right) B_{t-1}^{m}
$$

The middle aged, however, are at an interior solution and their consumption-saving choices satisfy a standard Euler equation given by

$$
\frac{1}{C_{t}^{m}}=\beta \mathbb{E}_{t} \frac{1+r_{t}}{C_{t+1}^{o}}
$$

We assume that the size of each generation is given by $N_{t}$. Let us define the growth rate of the new cohort by $1+g_{t}=\frac{N_{t}}{N_{t-1}}$. Equilibrium in the bond market requires that borrowing of the young equals the savings of the middle aged so that $N_{t} B_{t}^{y}=-N_{t-1} B_{t}^{m}$ or

$$
\left(1+g_{t}\right) B_{t}^{y}=-B_{t}^{m}
$$

\footnotetext{
${ }^{7}$ The addition of a warm-glow bequest motive would not affect our qualitative results because the steady-state real interest may remain negative. Thwaites (2015) shows that bequests do not materially impact determination of real interest rates in an OLG setting. However, in the full life cycle model, we include an explicit bequest motive.

${ }^{8}$ For the constraint to be binding, it must be the case that $\frac{Y_{t}^{m}+Y_{t+1}^{o} /\left(1+r_{t}\right)}{1+\beta(1+\beta)}>D_{t-1}$. We check in our numerical experiments that the relevant condition is satisfied.
} 
Figure 2: Equilibrium in the asset market

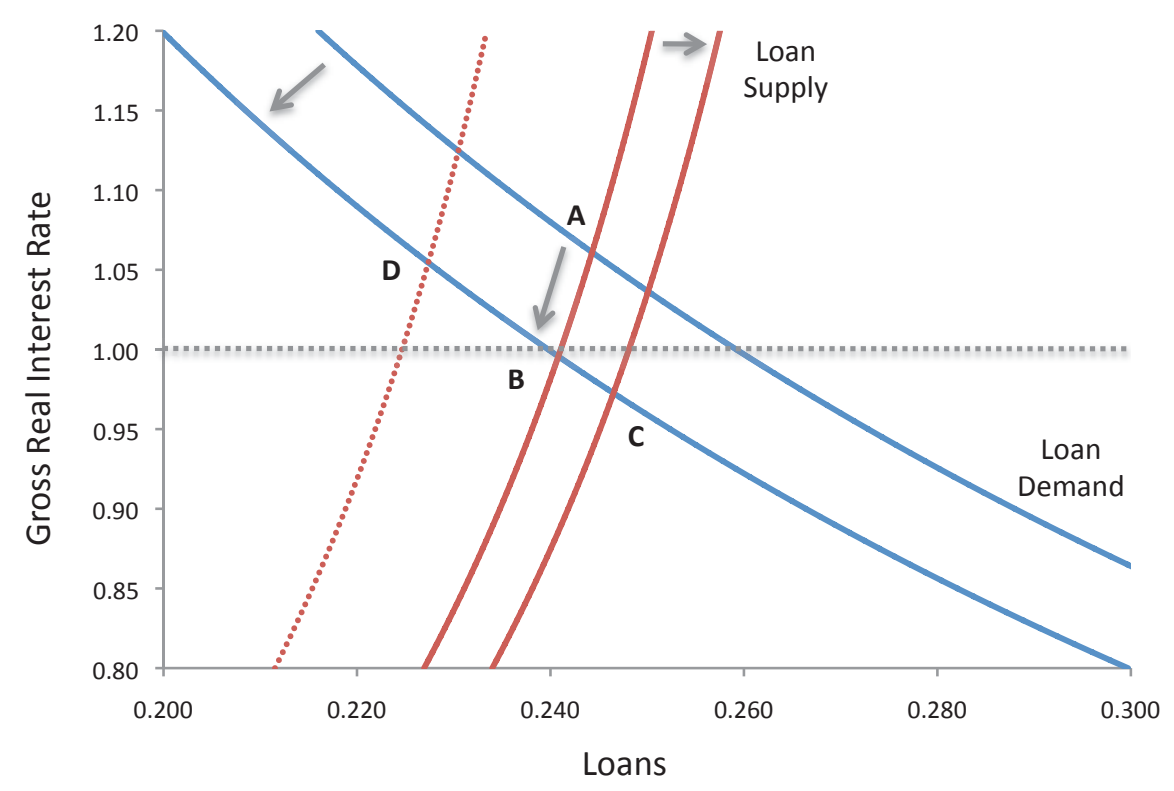

An equilibrium is now defined as a set of stochastic processes $\left\{C_{t}^{y}, C_{t}^{o}, C_{t}^{m}, r_{t}, B_{t}^{y}, B_{t}^{m}\right\}$ that solve $(1),(2),(5),(6),(7)$, and (8) given an exogenous process for $\left\{D_{t}, g_{t}\right\}$.

To analyze equilibrium determination, let us focus on equilibrium in the market for savings and loans given by equation (8) using the notation $L_{t}^{s}$ and $L_{t}^{d}$; the left-hand side of (8) denotes the demand for loans, $L_{t}^{d}$, and the right-hand side its supply, $L_{t}^{s}$. Hence the demand for loans (using (5)) can be written as

$$
L_{t}^{d}=\frac{1+g_{t}}{1+r_{t}} D_{t}
$$

while an expression for loan supply, assuming perfect foresight, can be derived by combining the household budget constraints and the middle-generation Euler equation:

$$
L_{t}^{s}=\frac{\beta}{1+\beta}\left(Y_{t}^{m}-D_{t-1}\right)-\frac{1}{1+\beta} \frac{Y_{t+1}^{o}}{1+r_{t}} .
$$

The real interest rate, depicted in Figure 2, is then determined by the intersection of the loan demand, $L_{t}^{d}$, and loan supply, $L_{t}^{s}$ :

$$
1+r_{t}=\frac{1+\beta}{\beta} \frac{\left(1+g_{t}\right) D_{t}}{Y_{t}^{m}-D_{t-1}}+\frac{1}{\beta} \frac{Y_{t+1}^{o}}{Y_{t}^{m}-D_{t-1}} .
$$

In contrast to the standard representative agent model, the real interest rate will now, in general, depend on a host of factors in addition to the discount factor: the income profile over the life cycle, the debt limit, and population growth all influence the real interest rate. 


\subsection{Productivity, Population Growth, and Inequality}

In our OLG setting, any factor that affects the relative supply or demand for loans changes the interest rate. Unlike in the standard representative agent model used in business cycle analysis, these forces can have permanent effects on the interest rate, and we should expect these dynamics to play out over an extended period. Importantly, there is nothing that prevents the real interest rate in expression (2) from being either positive or negative. Below, we offer a few examples of the forces that may affect the equilibrium interest rate; this list is far from exhaustive, and in the quantitative section we take a firmer stand on which of these forces best account for declining US interest rates.

Let us first consider a potential fall in total factor productivity growth, which has been commonly associated with discussions of secular stagnation (this hypothesis is most forcefully articulated by Gordon (2015)). For this exercise, we assume that the income of the middle aged and the old is proportional to the aggregate endowment $Y_{t}$, which in turn is proportional to productivity such that $Y_{t}=A_{t} \tilde{Y}$. Moreover, as the debt limit reflects the extent to which the middle-aged agents can replay their debt, we assume that it grows with the middle-aged income so that the debt limit relevant to the young at time $t$ is given by $D_{t}=A_{t+1} \tilde{D}$. The loan demand and supply can then be written in terms of renormalized variables, as shown. ${ }^{9}$

Consider now the effect of a slowdown in productivity. First, lower productivity growth shifts out the supply of savings since lower expected future income induces the middle-aged generation to increase retirement savings. Second, the expectation of lower future productivity tightens the borrowing constraint of the young, leading to a backward shift in the demand for loans. The new equilibrium is shown in point $C$ in Figure 2, which now depicts the renormalized variables. It should be noted that, unlike in the representative agent model, it is not required for productivity growth to be negative in order for the real interest rate to become negative. ${ }^{10}$ Instead, interest rates depend on how income is distributed over the life cycle, as well as on the interaction between productivity growth and the income distribution.

The mechanism by which a reduction in population growth lowers the interest rate is straight-

\footnotetext{
${ }^{9}$ The demand and supply for loans can now be written as

$$
\begin{aligned}
\tilde{L}_{t}^{d} & =\frac{1+g_{t}}{1+r_{t}} \frac{A_{t}}{A_{t-1}} \tilde{D} \\
\tilde{L}_{t}^{s} & =\frac{\beta}{1+\beta}\left(\tilde{Y}^{m}-\tilde{D}\right)-\frac{1}{1+\beta} \frac{\tilde{Y}^{o}}{1+r_{t}} \frac{A_{t+1}}{A_{t}},
\end{aligned}
$$

where tilde denotes that the original variable has been divided by productivity.

${ }^{10}$ In the representative household model (without population growth) the real interest rate is given by

$$
1+r_{t}=\beta^{-1} \frac{A_{t+1}}{A_{t}},
$$

so productivity would need to decline at a rate greater than the inverse of the discount factor for the interest rate to be negative. While productivity growth is low in many advanced countries, it is not negative.
} 
forward and can be seen directly by inspecting the expression for loan demand. As the number of young decreases relative to the middle aged (a decline in $g_{t}$ ), loan demand falls, shifting back the $L_{t}^{d}$ curve and lowering the real interest rate to point B in Figure 2. In the quantitative model, we will also consider changes in mortality risk, which have a relatively intuitive effect on the real interest rate. As mortality risk decreases, individuals save more for retirement, increasing the supply of savings and lowering the interest rate.

Our model can also be used to consider the impact of an increase in inequality on interest rates. Generically, the effect of an increase in inequality is ambiguous. There are plausible conditions, however, under which higher inequality will in fact reduce the natural rate of interest. We provide one such example in Appendix B, in which a fraction of the middle-aged population are credit constrained. In this case, shifting income from the low-skilled, credit-constrained households to the high-skilled middle-aged households reduces the real interest rate. In general, the condition needed for inequality to reduce rates is that those with higher incomes at a given age save more than those with lower incomes. ${ }^{11}$

A fourth force often associated with secular stagnation is a persistent fall in the relative price of investment goods. As investment goods become cheaper, less savings is needed to finance a given level of investment in the capital stock, thereby reducing overall demand. Since our example does not include capital, we will defer this discussion to Section 8.

\subsection{Deleveraging}

One of the main narratives about the source of the 2008 crisis is that it was triggered by a debt deleveraging shock (see, e.g., Mian and Sufi (2014)). Households took on excessive levels of mortgage debt in the mid-2000s, and the 2008 crisis corresponded to an abrupt correction whereby households were forced to pay down high levels of debt - often referred to as a "Minsky moment." Eggertsson and Krugman (2012) (hereafter EK) model this as permanent tightening in the household collateral constraint $D_{t}$. A key prediction of EK and related models is that once agents in the economy pay down their debt to the new sustainable level the debt deleveraging ends and interest rates return to their precrisis level. However, in our framework, this prediction is overturned, and the end of a debt deleveraging cycle does not lead to a normalization of interest rates.

Point B in Figure 2 shows the equilibrium level of the real interest rate on impact after a deleveraging shock. As we can see, the shock leads directly to a reduction in the demand for loans

\footnotetext{
${ }^{11}$ Most realistic models of bequests, for example, argue that the preference for leaving a bequest increases with income, implying an increase in bequests is associated with higher inequality. See Dynan, Skinner and Zeldes (2004) for a discussion of other mechanisms, such as the persistence of skill types across generations. We have also experimented with a production structure where skill-biased technological change (as in Krusell et al. (2000)) increases inequality and found plausible conditions under which skill-biased technical change puts downward pressure on the real interest rate. We leave a fuller analysis of this subject for future research.
} 
since the demand curve shifts inward. The supply of loanable funds is unchanged since the debt repayment of the middle-aged generation depends on the lagged value of collateral constraint, $D_{t-1}$.

On impact, the young are now spending less at a given interest rate, while the middle aged and old are spending the same. Since the endowment must be fully consumed in our economy, this fall in spending by the young then needs to be made up by inducing some agents to spend more. This adjustment takes place via a reduction in the real interest rate that induces more spending. ${ }^{12}$ So far, the mechanism described in our model is exactly the same as in EK. A deleveraging shock triggers a drop in spending by borrowers at the existing rate of interest. The real interest rate then falls to keep the aggregate level of spending the same.

In EK, the economy reaches a new steady state in the next period, in which, once again, the real interest rate is determined by the discount factor of the representative savers in the economy. In that setting, the loan supply curve shifts back so that the real interest rate is exactly the same as before (as seen in point D). Loan supply shifts back in EK because borrower deleveraging reduces interest income accruing to savers, which implies that their supply of savings falls in equilibrium. In contrast, in our model there is no representative saver; instead, households are both borrowers and savers at different stages in their lives. The fall in the borrowing of young households in period $t$ then implies that in the next period — when that agent becomes a saver - each household has more resources to save since disposable income is higher. At time $t+1$, the supply of savings $L_{t}^{s}$ shifts outward as shown in Figure 2. In sharp contrast to EK, where the economy settles back into the old steady state after a one-period transition, the economy in our model reaches a new steady state with a permanently lower real rate of interest. The new interest rate may be negative, depending on the size of the shock. This process can serve as a powerful and persistent propagation mechanism for the original deleveraging shock. More generally, even if the drop in $D_{t}$ is not permanent, the natural rate of interest will inherit the dynamics of the drop in $D_{t}$, which may be of arbitrary duration. One interesting implication of these dynamics is that policies that are implemented in the midst of a deleveraging crisis, such as macroprudential policies, run the risk of permanently depressing the natural rate of interest.

\footnotetext{
${ }^{12}$ The drop in the real interest rate stimulates spending via two channels. First, as equation (11) shows, a fall in the real interest rate makes consumption today more attractive to the middle aged, thus increasing their spending. Observe that the $L_{t}^{s}$ curve is upward sloping in the real interest rate; in general, the slope of the savings curve depends upon the elasticity of intertemporal substitution. If preferences exhibit very weak substitution effects and if the endowment is received only by the middle-aged generation, it is possible to have a downward sloping $L_{t}^{s}$ curve. However, our view is that the empirically relevant case is when savings are increasing in the interest rate. Second, for the credit-constrained young generation, a reduction in the real interest rate relaxes their borrowing constraint. A lower interest rate allows them to take on more debt, $B_{t}^{y}$, for any given value of $D_{t}$. Since borrowing is limited by their ability to repay in the next period, changes in the interest rate that affect the size of the total repayment affect borrowing today.
} 


\section{Price Level Determination}

We now introduce perfectly flexible nominal prices. We will show that this introduces a kink in the model: If the steady-state equilibrium interest rate is negative, then there is no equilibrium consistent with inflation below a certain level. For example, if the real interest rate is $-3 \%$, then inflation must be greater than $3 \%$ in a steady state that respects the zero lower bound on nominal interest rates. This will have fundamental implications when we introduce realistic nominal frictions; the unwillingness or inability of the central bank to accommodate a high enough inflation rate will result in a demand shortfall and output contraction.

As is standard in the literature, we introduce a nominal price level by assuming that one-period nominal debt denominated in money is traded and that the government controls the nominal rate of return on this asset. ${ }^{13}$ The saver in our economy (the middle-generation household) now has access to risk-free nominal debt that is indexed in dollars, in addition to one-period risk-free real debt. ${ }^{14}$ This assumption gives rise to a consumption Euler equation, which is the nominal analog of the Euler equation (7):

$$
\frac{1}{C_{t}^{m}}=\beta E_{t} \frac{1}{C_{t+1}^{o}}\left(1+i_{t}\right) \frac{P_{t}}{P_{t+1}},
$$

where $i_{t}$ is the nominal rate and $P_{t}$ is the price level. We impose a non-negativity constraint on nominal rates. Implicitly, we assume that the existence of money precludes the possibility of a negative nominal rate. At all times,

$$
i_{t} \geq 0
$$

Equations (7) and (14) imply (assuming perfect foresight) the standard Fisher relation

$$
1+r_{t}=\left(1+i_{t}\right) \frac{P_{t}}{P_{t+1}}
$$

where again the equilibrium real interest rate $r_{t}$ is determined by equation (11). The Fisher equation simply states that the real interest rate should be equal to the nominal rate deflated by the growth rate of the price level (inflation). ${ }^{15}$

\footnotetext{
${ }^{13}$ There are various approaches to microfounding a demand for money by using money in the utility function or cash-in-advance constraints. For completeness, we explicitly add money in the utility function to our model in Appendix F.

${ }^{14}$ For simplicity, we assume that this asset trades in zero net supply, so that, in equilibrium, the budget constraints already considered are unchanged. However, we relax this assumption once we incorporate fiscal policy. Strictly speaking, what is needed, once money is explicitly incorporated as in Appendix F with explicit fiscal policy rules, is that net government nominal debt (inclusive of money) be in zero supply. As we show, our conclusions are unchanged when one considers a strictly positive level of government debt.

${ }^{15}$ Again, we can define an equilibrium as a collection of stochastic processes $\left\{C_{t}^{y}, C_{t}^{o}, C_{t}^{m}, r_{t}, i_{t}, B_{t}^{y}, B_{t}^{m}, P_{t}\right\}$ that solve (1), (2), (5), (6), (7), and (8) and now also (14) and (15) given an exogenous process for $\left\{D_{t}, g_{t}\right\}$ and a specification for monetary policy like an interest rate rule.
} 
From (15) and (16), it follows that if the real rate of interest is permanently negative, then there is no equilibrium consistent with a stable price level. To see this, assume such an equilibrium and that $P_{t+1}=P_{t}=P^{*}$. Then the Fisher equation implies that $i_{t}=r_{t}<0$, violating the zero bound. Hence, a constant price level — price stability — cannot be sustained when $r_{t}$ is negative. ${ }^{16}$

Let us denote the growth rate of the price level (inflation) by $\Pi_{t}=\frac{P_{t+1}}{P_{t}}=\bar{\Pi}$. The zero bound and the Fisher equation then imply that, for an equilibrium with constant inflation to satisfy the $\mathrm{ZLB}$, there is a bound on the inflation rate given by $\Pi(1+r)=1+i \geq 1$ or

$$
\bar{\Pi} \geq \frac{1}{1+r},
$$

which implies that steady-state inflation is bounded from below by the real interest rate due to the zero bound. We term this the natural lower bound on inflation.

At a positive real interest rate, the natural bound is of little relevance. If, as is common in the literature using representative agent models, the real interest rate in steady state is equal to the inverse of the discount factor, then the natural bound says that $\Pi \geq \beta$. Under a standard calibration, this implies a bound on the steady-state inflation rate of about $-2 \%$ to $-4 \%$. This is, of course, well below the inflation target of most central banks, making this bound of little empirical relevance.

With permanently negative real rates, however, this bound takes on a greater practical significance. If the real interest rate is negative, it implies that, under flexible prices, steady-state inflation must be positive. Suppose, for example, that the natural rate of interest is $-4 \%$ in Europe; this implies the natural lower bound on inflation is $4 \%$. But what happens if the European Central Bank (ECB) refuses to allow inflation to rise above $2 \%$ ? With flexible prices, this possibility cannot be contemplated in the model; it does not admit an equilibrium. If the real interest rate is negative, the inflation rate has to be positive. The ECB must target inflation above $4 \%$ in the example above.

This is an unappealing result. A key question we want to ask our model is, what happens if the natural rate of interest is negative and the central bank does not provide enough inflation, causing the zero lower bound to become binding? So far, our model is not able to answer this question because there is simply no equilibrium under this scenario. A straightforward solution, and one that fits the data, is to employ nominal rigidities in the price system. Once we introduce nominal frictions, then the central bank can indeed set inflation below the natural lower bound on inflation. In this case, however, the refusal of the central bank to allow inflation to rise to or overshoot its target results in an output gap and the nominal interest rate stuck permanently at zero.

\footnotetext{
${ }^{16}$ For this result, it is important that we rule out bubbles and that fiscal policy keeps the real value of government liabilities constant. With passive fiscal policy and positive government liabilities, the price level could fall sharply on impact to increase the real value of debt and raise the natural rate of interest back to zero. After impact, the nominal rate will be at zero and the central bank will keep prices stable. This possibility will become more transparent once fiscal policy is explicitly introduced. We thank Jaume Ventura for pointing this out.
} 


\section{Aggregate Supply}

In this section, we incorporate nominal rigidities into our baseline model. The presence of nominal rigidities carries important implications for adjustment when the natural rate falls negative. We show that if the natural rate of interest is negative and the central bank does not set a sufficiently high inflation target, an employment and output gap emerges.

While it is common for models to feature short-term pricing rigidities, our model will incorporate a form of long-run rigidity. Since our modeling choice is uncommon, some initial discussion is warranted before we proceed to our exact specification. There is a broad consensus among economists that, with permanently high levels of inflation, expectations about future inflation will ultimately adjust so there is no long-run trade-off between inflation and unemployment. This empirical prediction was indeed largely borne out during the 1970s in the United States. Our model will incorporate this neutrality of high inflation in the form of a long-run vertical aggregate supply curve when inflation is sufficiently high (see the top half of the aggregate supply curve in Figure 3).

In contrast, a similar consensus has not emerged for long-run neutrality in a low inflation/deflation environment. Tobin (1972) argued that, during the Great Depression, firms were reluctant to cut nominal wages despite high unemployment. Tobin argued that this behavior suggests a permanent, long-run trade-off between inflation and unemployment at low levels of inflation. Others have built on and formalized Tobin's analysis in the form of an upward sloping long-run Phillips curve (see, for example, Akerlof, Dickens and Perry (1996), Kim and Ruge-Murcia (2009), Fagan and Messina (2009), Benigno and Ricci (2011), Coibion, Gorodnichenko and Wieland (2012), and Daly and Hobijn (2014)). We incorporate this notion of aggregate supply in our model, leading to an upward sloping Phillips curve (see the bottom half of the aggregate supply curve in Figure 3).

Alternative microfoundations for introducing nominal rigidities will provide similar qualitative results as long as the models feature a long-run trade-off between inflation and output. ${ }^{17}$ Here, we opt for capturing this trade-off by introducing downward nominal wage rigidity; this specification has the virtue of capturing the neutrality of inflation when it is high, yet simultaneously giving rise to meaningful trade-offs at low inflation rates.

A large body of evidence documents the presence of downwardly nominally rigid wages, even in the face of high unemployment. This notion dates back as far as Malthus, who noted that "it very rarely happens that the nominal price of labour universally falls" (Malthus (1798)). Bewley (1999) interviewed firm executives directly and explicitly documented their reluctance to cut nominal wages. More recently, substantial nominal wage rigidity has been studied in US administrative data by Fallick, Lettau and Wascher (2011), in worker surveys by Barattieri, Basu and

\footnotetext{
${ }^{17}$ In Appendix E, we provide perhaps the most standard way of specifying rigidities: the New Keynesian Calvo model.
} 
Gottschalk (2014), and in cross-country data by Schmitt-Grohé and Uribe (2016). Our specification is closely related to the supply side of Schmitt-Grohé and Uribe (2016), and our calibrated level of wage rigidity in our quantitative analysis (see Section 8) matches closely their estimates for the degree of wage rigidity. ${ }^{18}$

We simplify our exposition by assuming that only the middle-aged generation receives income, now as payment for labor supplied instead of as an exogenous endowment.The budget constraint for young agents is again given by equations (1) and (4), but now we replace the budget constraint of the middle-aged generation (2) and old generation (3) with the following:

$$
\begin{aligned}
C_{t+1}^{m} & =\frac{W_{t+1}}{P_{t+1}} L_{t+1}+\frac{Z_{t+1}}{P_{t+1}}-\left(1+r_{t}\right) B_{t}^{y}+B_{t+1}^{m} \\
C_{t+2}^{o} & =-\left(1+r_{t+1}\right) B_{t+1}^{m},
\end{aligned}
$$

where $W_{t+1}$ is the nominal wage rate, $P_{t+1}$ the aggregate price level, $L_{t+1}$ the labor supply of the middle-aged generation, and $Z_{t+1}$ the profits of the firms. For simplicity, we assume that the middle-aged generation will supply a constant level of labor $\bar{L}$ inelastically. Note that if the firms do not hire all available labor supplied, then labor demand $L_{t}$ may be lower than labor supply $\bar{L}$ due to rationing. Under these assumptions, each of the generations' consumption-saving decisions remains the same as before. ${ }^{19}$

On the firm side, we assume that firms are perfectly competitive and take prices as given. They hire labor to maximize period-by-period profits. Their problem is given by

$$
\begin{aligned}
& Z_{t}=\max _{L_{t}} P_{t} Y_{t}-W_{t} L_{t} \\
\text { s.t. } \quad Y_{t} & =L_{t}^{\alpha} .
\end{aligned}
$$

The firms' labor demand condition is then given by

$$
\frac{W_{t}}{P_{t}}=\alpha L_{t}^{\alpha-1}
$$

So far we have described a perfectly frictionless production side, and, if this were the end, our model would be analogous to what we have already considered in the endowment economy. Output would be given by $Y_{t}=L_{t}^{\alpha}=\bar{L}^{\alpha}$ and the labor demand condition (22) would fix the real wage.

Now, consider a world in which households will never accept working for wages that fall below their wage in the previous period, so nominal wages at time $t$ cannot be lower than what

\footnotetext{
${ }^{18}$ Relative to their specification, ours allows us to vary the degree to which wages are downwardly rigid or flexible and to show that increasing flexibility does not lead to stabilization, illustrating the basic failure of the price mechanism in restoring full employment in a secular stagnation. Also see Shimer (2012) and Kocherlakota (2013) for further discussion of how wage rigidities can explain labor dynamics during the Great Recession.

${ }^{19}$ The rationing approach followed here and in Schmitt-Grohé and Uribe (2016) is essentially of the same form as in the general disequilibrium model of Barro and Grossman (1971); for a review of this literature, see Bénassy (1993).
} 
they were at time $t-1$. Or, slightly more generally, imagine that the household would never accept lower wages than a wage norm given by $\tilde{W}_{t}=\gamma W_{t-1}+(1-\gamma) W_{t}^{f l e x}$ where

$$
W_{t}^{f l e x}=P_{t} \alpha \bar{L}^{\alpha-1} .
$$

If $\gamma=1$, the wage norm is simply last period's nominal wages and wages are perfectly downwardly rigid; if $\gamma=0$, we obtain the flex-price nominal wage. Formally, wages in our economy are given by

$$
W_{t}=\max \left\{\tilde{W}_{t}, W_{t}^{\text {flex }}\right\} \text { where } \tilde{W}_{t}=\gamma W_{t-1}+(1-\gamma) W_{t}^{\text {flex }} .
$$

Nominal wages in our economy can never fall below the wage norm $\tilde{W}_{t}$. If labor market clearing requires nominal wages lower than the previous nominal wage rate, then the labor market will not clear, and labor is rationed. ${ }^{20}$

To close the model, we specify a monetary policy rule. We posit that the central bank sets the nominal rate according to a standard Taylor rule:

$$
1+i_{t}=\max \left(1,\left(1+i^{*}\right)\left(\frac{\Pi_{t}}{\Pi^{*}}\right)^{\phi_{\pi}}\right),
$$

where $\phi_{\pi}>1 ; \Pi^{*}$ and $i^{*}$ are parameters of the policy rule that we hold constant. This rule states that the central bank attempts to keep inflation at the inflation target $\Pi^{*}$ and the nominal rate at $i^{*}$ so long as the nominal rate implied by the rule is not constrained by the zero bound. ${ }^{21}$

It should be noted that the results we present in this paper do not depend on the particulars of the Taylor rule. We are interested in exploring what happens in an inflation-targeting regime when the natural rate of interest is negative and the central bank's inflation target is low enough that it cannot be reached even at a zero nominal rate. A simpler way of thinking about the policy regime we have in mind - an equivalent one for our purposes to the Taylor rule specified above — is that we are assuming that the central bank will set inflation equal to its target $\Pi^{*}$ at all times (without needing to concern ourselves with how exactly this is accomplished) except for when this implies a negative nominal interest rate. In this case, the nominal interest rate is zero and inflation falls below target (see Eggertsson et al. (2016) for an example of this specification of the policy regime). ${ }^{22}$

\footnotetext{
${ }^{20}$ If labor market clearing requires nominal wages higher than the past nominal wage rate, nominal wages will rise to their market clearing level, equating labor demand and supply.

${ }^{21}$ In Appendix F, we introduce money explicitly into our model and show that our results are not affected so long as fiscal policy keeps consolidated government liabilities constant.

${ }^{22}$ The key assumption here is that, at the ZLB, we do not allow for the possibility that the inflation rate is higher than the inflation target. Essentially, the central bank would not tolerate such an outcome since it could always raise the nominal interest rate in that scenario. The only equilibria then consistent with the policy regime would be those in which inflation is below target because the central bank is constrained by the ZLB. Of course, there are equilibria consistent with higher inflation targets that do accommodate a negative natural rate of interest. We see these equilibria as those that emerge from different policy regimes that are willing to accept a higher inflation target (see Section 7).
} 
Equilibrium in the economy with nominal rigidities is defined as follows:

Definition 1. A competitive equilibrium is a sequence of quantities $\left\{C_{t}^{y}, C_{t}^{o}, C_{t}^{m}, B_{t}^{y}, B_{t}^{m}, L_{t}, Y_{t}, Z_{t}\right\}$ and prices $\left\{P_{t}, W_{t}, W_{t}^{\text {flex }}, r_{t}, i_{t}\right\}$ that satisfy (1) , (5), (6), (7), (8), (14) , (15), (18), (20), (21), (22), (23), (24), and (25) given an exogenous process for $\left\{D_{t}, g_{t}\right\}$ and initial values for $W_{-1}$ and $B_{-1}^{m}$.

We start by characterizing the steady state of the model, which can be shown graphically based on two relationships between output and inflation in a steady state: aggregate supply and aggregate demand. The aggregate supply specification of the model consists of two regimes: one in which the real wage equals the market-clearing real wage (if $\Pi \geq 1$ ) and the other when the bound on nominal wages is binding $(\Pi<1)$. Intuitively, positive inflation in the steady state means that wages behave as if they are flexible, since nominal wages must rise to keep real wages constant. If $\Pi \geq 1$, then labor demand equals the exogenous level of labor supply $\bar{L}$, defining the full-employment level of output $Y^{f}$ :

$$
Y=\bar{L}^{\alpha}=Y^{f} \text { for } \Pi \geq 1
$$

This is shown in Figure 3 as a solid vertical segment.

If there is deflation in the steady state $(\Pi<1)$, the wage norm binds ( $W=\tilde{W})$ and the real wage exceeds the market-clearing real wage. ${ }^{23}$ We can then derive a relationship between output and inflation tracing the lower segment of the AS curve:

$$
\frac{\gamma}{\Pi}=1-(1-\gamma)\left(\frac{Y}{Y^{f}}\right)^{\frac{1-\alpha}{\alpha}} \text { for } \Pi<1 .
$$

Equation (27) is simply a nonlinear Phillips curve. The intuition is straightforward: As inflation increases, real wages fall and firms hire more labor. Importantly, this Phillips curve relationship is not a short-run relationship; instead, it describes the behavior of steady-state inflation and output. The aggregate supply curve is shown in Figure 3, with the vertical segment given by (26) and the upward sloping segment given by (27) and the kink point at $\Pi=1$. $^{24}$

Turning to the aggregate demand relation, we again have two regimes: one in which the zero bound is not binding and the other in which it is binding. When the nominal rate is unconstrained, we obtain the $\mathrm{AD}$ curve by combining the real interest rate equation, Fisher relation, and monetary policy rule - equations (11), (16), and (25) - to get

$$
Y=D+\frac{(1+\beta)(1+g) D \Gamma^{*}}{\beta} \frac{1}{\Pi^{\phi_{\pi}-1}} \text { for } i>0
$$

\footnotetext{
${ }^{23}$ With a steady-state deflation rate of $\Pi$, we can use equation (24) to find the steady-state wage rate of $w=$ $\frac{(1-\gamma) \alpha \bar{L}^{\alpha-1}}{1-\gamma \Pi^{-1}}$.

${ }^{24}$ The AS and AD diagrams and numerical examples in this section assume the following parameter values: $\beta=$ $0.985, \gamma=0.94, \alpha=0.7, \Pi^{*}=1.01, \phi_{\pi}=2, D=0.28$, and $g=0.9 \%$.
} 
where $\Gamma^{*} \equiv\left(1+i^{*}\right)^{-1}\left(\Pi^{*}\right)^{\phi_{\pi}}$ is the composite policy parameter in the monetary policy reaction function. The upper portion of the AD curve in Figure 3 depicts this relationship. As inflation increases, the central bank raises the nominal interest rate by more than one for one (since $\phi_{\pi}>1$ ), which, in turn, increases the real interest rate and reduces demand.

At the zero lower bound, we combine the same set of equations, but now impose $i=0$. We obtain the following expression relating output and inflation:

$$
Y=D+\frac{(1+\beta)(1+g) D}{\beta} \Pi \text { for } i=0 .
$$

In this case, the AD curve is upward sloping. The logic should again be relatively straightforward for those familiar with the literature on the liquidity trap: As inflation increases, the nominal interest rate remains constant, thus reducing the real interest rate. This change in the real rate raises consumption demand, as shown by the bottom portion of the AD curve in Figure 3.

The kink in the aggregate demand curve occurs at the inflation rate at which monetary policy is constrained by the zero lower bound. That is, the AD curve depicted in Figure 3 will become upward sloping when the inflation rate is sufficiently low that the implied nominal rate the central bank would like to set is below zero. Mathematically, we can derive an expression for this kink point by solving for the inflation rate that equalizes the two arguments in the max operator of equation (25):

$$
\Pi_{k i n k}=\left(\frac{1}{1+i^{*}}\right)^{\frac{1}{\phi_{\pi}}} \Pi^{*} .
$$

The location of the kink in the AD curve depends on both parameters of the policy rule: the inflation target $\Pi^{*}$ and the targeted real interest rate $i^{*}$.

In what follows, it will be useful to define the natural rate of interest: - the interest rate at which output is at its full-employment level. The natural rate can be obtained by evaluating equation (11) at the full-employment level of output $Y^{f}$ :

$$
1+r_{t}^{f}=\frac{1+\beta}{\beta} \frac{\left(1+g_{t}\right) D_{t}}{Y^{f}-D_{t-1}}
$$

It is useful to note that the full-employment interest rate corresponds exactly to the real interest rate we derived in the endowment economy. Hence, any of the forces that we showed affect the real interest rate in the endowment economy will directly affect the full-employment real interest rate in the more general setup.

\section{Full Employment and Secular Stagnation}

Equilibrium output and inflation is determined by the intersection of the aggregate demand and aggregate supply curves. We first consider a normal equilibrium at which the natural rate of 
Figure 3: Steady-state aggregate demand and aggregate supply curves

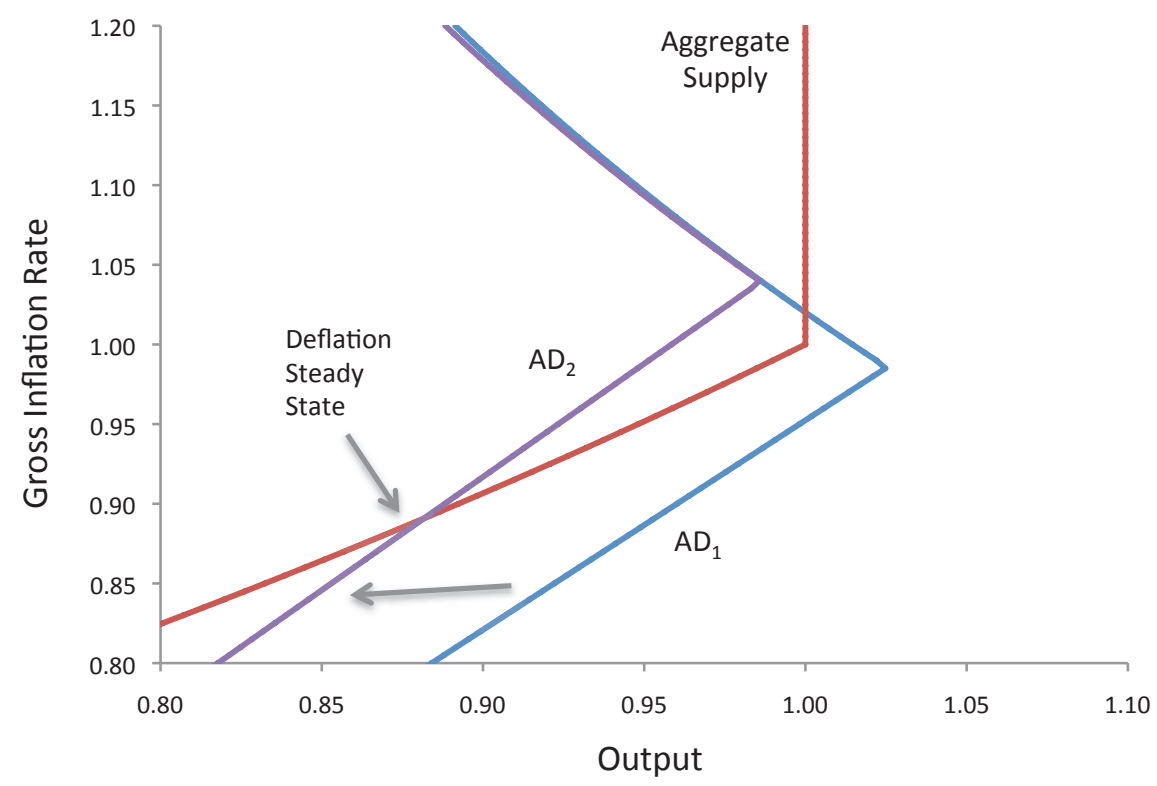

interest is positive. We assume that the central bank aims for a positive inflation target (that is, $\Pi^{*}>1$ ) and that the nominal interest rate target is consistent with the inflation target: $1+i^{*}=$ $\left(1+r^{f}\right) \Pi^{*}$. With $r_{f}>0$, the aggregate demand curve intersects the aggregate supply curve on the vertical segment of the AS curve. The exact intersection point is determined by the inflation target. ${ }^{25}$ This full-employment equilibrium is displayed in Figure 3. Under our assumed policy rule, the equilibrium depicted in Figure 3 is unique for a small enough inflation target and a high enough $\gamma \cdot{ }^{26}$

The making of a secular stagnation equilibrium is shown in Figure 3. Here, we illustrate the effect of a tightening in the collateral constraint $D_{t} \cdot{ }^{27}$ We assume the shock is large enough to move the natural rate of interest negative and, indeed, below the inflation target: $1+r_{t}^{f}<\left(\Pi^{*}\right)^{-1}$. As can be seen from equation (28), a reduction in D reduces output for any given inflation rate. This fall in output stems from the decline in consumption by the young households, who cannot borrow as much as before to finance their consumption early in life. In the normal equilibrium, this drop in spending would be compensated by a drop in the real interest rate, restoring spending to its pre-shock level. However, the zero lower bound prevents this adjustment. Hence, the shock moves the economy off the full-employment segment of the AS curve to a deflationary steady state where the nominal interest rate is zero. Here, steady-state deflation raises steady-state real wages

\footnotetext{
${ }^{25}$ If the central bank targets zero inflation $\left(\Pi^{*}=1\right)$ the intersection is at the kink of the AS curve.

${ }^{26}$ Uniqueness is guaranteed if $\gamma=1$. As $\gamma$ approaches zero, more equilibria are possible. We discuss these additional equilibria in Section 7 when they appear in a more general setting.

${ }^{27}$ Or, equivalently, we could consider a fall in the rate of population or productivity growth.
} 
Figure 4: Adjustment mechanisms: wage flexibility and hysteresis
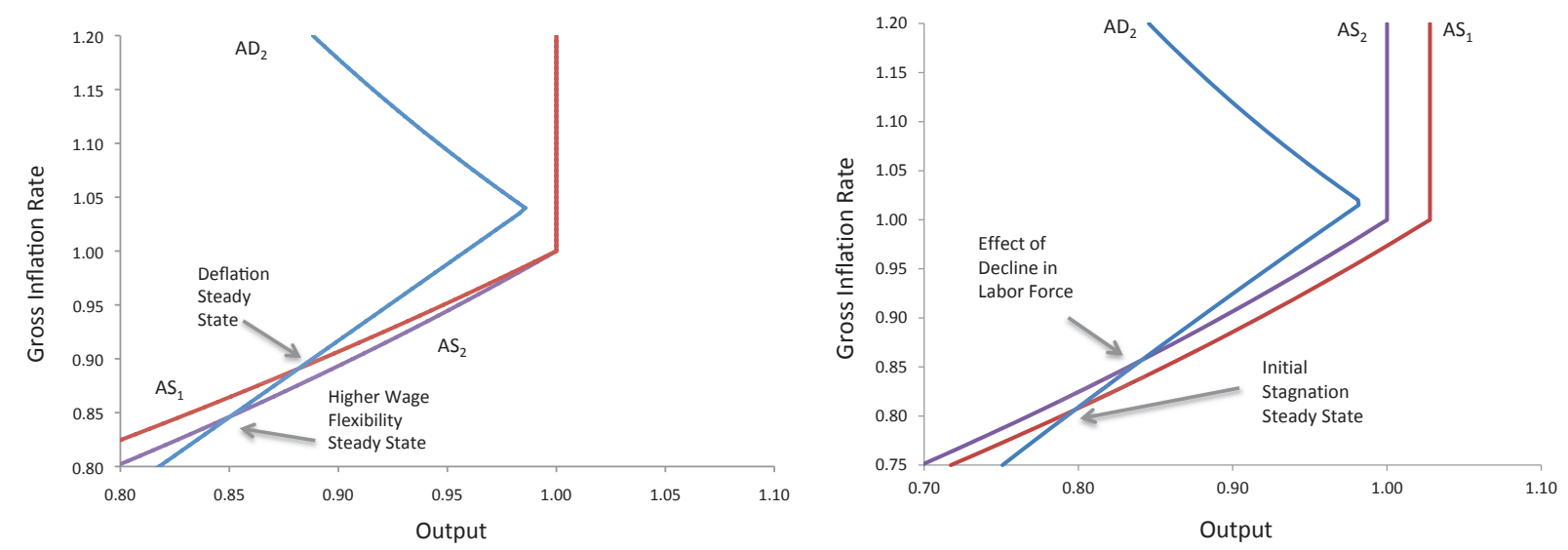

above their market-clearing level, thus depressing demand for labor and contracting output. ${ }^{28}$

Proposition 1. If $\gamma>0, \Pi^{*}=1$, and $i^{*}=r^{f}<0$, then there exists a unique, locally determinate secular stagnation equilibrium.

Proof. See Appendix D.

As shown in Appendix C, if we linearize the model around the unique secular stagnation steady state, the dynamic system is locally determinate. The determinacy of the secular stagnation steady state in our model stands in contrast to the indeterminacy of the deflation steady state analyzed in Schmitt-Grohé and Uribe (2013) and Benigno and Fornaro (2015). ${ }^{29}$ Indeterminacy of equilibrium has been one justification for disregarding the deflation steady state and restricting analysis to the determinate positive interest rate steady state in New Keynesian models. As shown in Proposition 1, the AD curve must be steeper than the AS curve at the intersection point that implies the local determinacy condition. Importantly, local determinacy implies that an economy in secular stagnation may continue to experience well-defined (unique bounded) business cycle fluctuations in unemployment and output around a permanently depressed growth path.

Our model delivers a permanent steady-state slump with no pull towards full employment. A natural question is, what forces can move the economy back to full employment, absent any government intervention? First, and perhaps obviously, if the shock that pushes the natural rate negative is only temporary, then the full-employment equilibrium can be attained. To the extent that the shocks leading to negative real interest rates are slow moving (such as demographic factors) there is less reason to be optimistic about this adjustment mechanism.

\footnotetext{
${ }^{28}$ As we show, outright deflation is not central to the mechanism. If wages are indexed to the inflation target, then an inflation rate that falls below target results in real wages that exceed the market-clearing level and output falls below the full-employment level.

${ }^{29}$ For further discussion of the stability properties in Benhabib, Schmitt-Grohé and Uribe (2001), see Bullard (2010).
} 
Figure 5: Data versus model transition paths: US, Japan, and the Eurozone
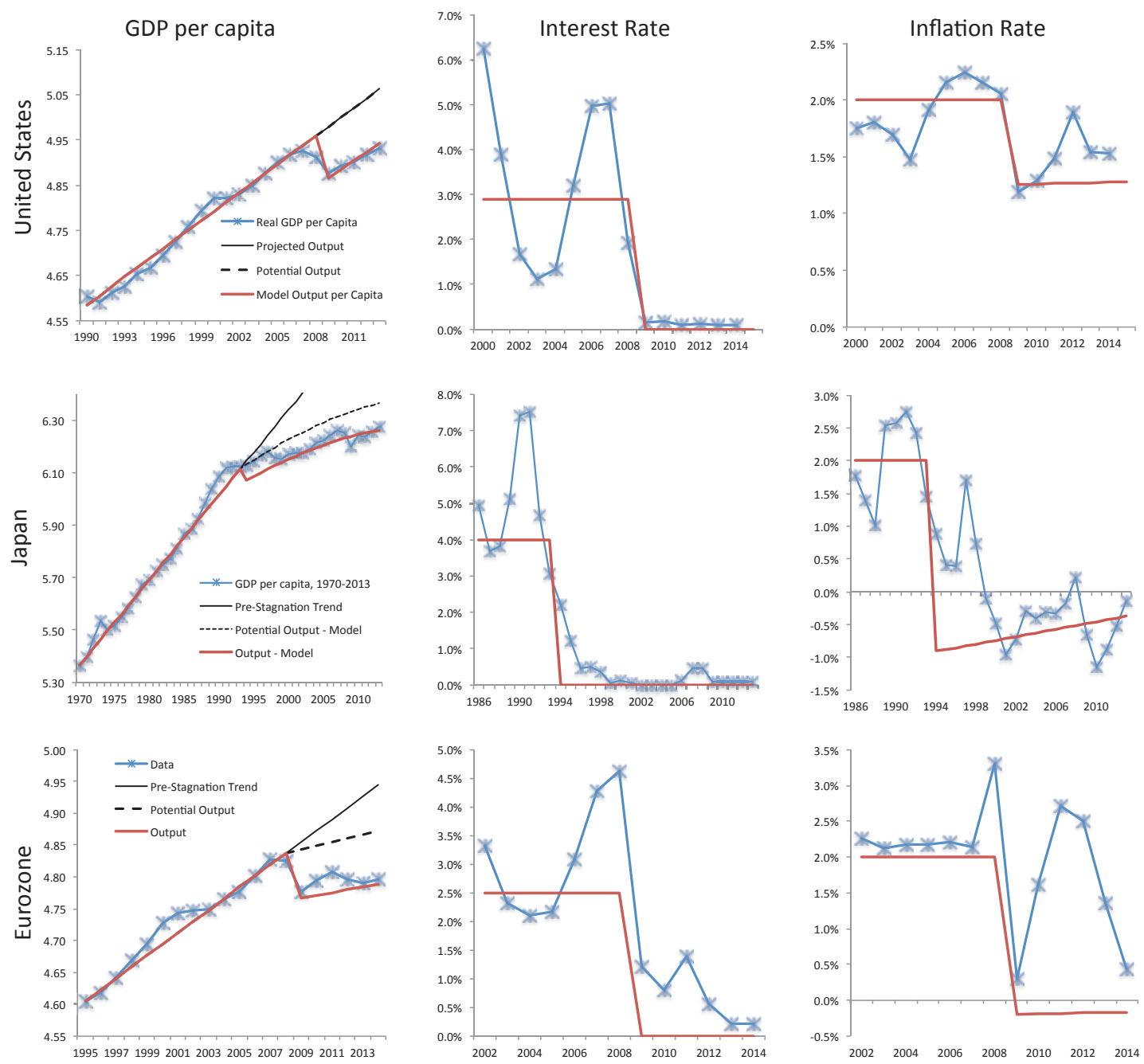
A key friction in triggering unemployment was the fact that wages were downwardly rigid. A natural question, then, is whether an increase in the flexibility of the wage adjustment process will push the economy back to full employment. The answer to this question is, surprisingly, no. This result emerges because an increase in price/wage flexibility triggers a drop in expected inflation, increasing the real interest rate. This cannot be offset by interest rate cuts due to the zero bound. As wages become more flexible (a decrease in the parameter $\gamma$ ), the slope of the AS curve steepens (see the left-hand panel of Figure 4). For any given deflation steady state, a decrease in $\gamma$ will shift the steady state along the AD curve, increasing the rate of deflation, raising real wages, and therefore increasing the shortfall in output. This result echoes the paradox of flexibility shown in Eggertsson and Krugman (2012) and considered in a more general setting in Bhattarai, Eggertsson and Schoenle (2014).

Finally, a third adjustment mechanism is a reduction in the labor force led by discouraged workers (or workers whose skills have deteriorated) after prolonged spells of unemployment. Labor force participation fell markedly in the US, and the duration of unemployment remains elevated despite recent reductions in the unemployment rate. A reduction in the labor force reduces downward pressures on wages and weakens deflationary pressure. If the contraction of the labor force proceeds far enough, the output gap is eliminated, and the AD curve intersects the AS curve at the new, lower full-employment level of output. ${ }^{30}$

In Figure 5, we present data on the evolution of output, inflation, and the short-term nominal interest rate in the US, Japan, and the Eurozone. We calibrate our simple three-period model and show how our model generates dynamics consistent with the observed behavior of these macro aggregates. The key message of the figure is that our model has, in principle, no difficulty generating a persistent fall in inflation, interest rates at the ZLB, and output persistently below trend. These features are in stark contrast to the standard New Keynesian model in which the model explodes (i.e., a determinate equilibrium no longer exists) if the natural rate of interest is expected to be negative for a long enough period (see, e.g., Eggertsson and Singh (2016)). Even though highly stylized, a straightforward calibration of our simple model does a good job of capturing the transition dynamics of output and interest rates in these stagnation episodes. To conserve space, we defer the description of the calibration underlying Figure 5 to Appendix $H$, which allows us to focus on a richer quantitative life cycle model. ${ }^{31}$

\footnotetext{
${ }^{30}$ Under hysteresis mechanisms, the AS curve shifts inward along the transition path. Unemployment falls and inflation rises back toward target, while nominal interest rates stay at the ZLB. Relative to the pre-stagnation trend, output remains depressed. In this extension, there is no returning to the pre-trend level of employment. Hysteresis mechanisms need not work solely through the labor market. See Garga and Singh (2016) for a model with hysteresis effects on productivity growth.

${ }^{31}$ To capture the slowdown in GDP per capita growth and the absence of outright deflation in the US and Eurozone, we extend our basic model to incorporate hysteresis effects on productivity growth and a more general wage norm where nominal wages are indexed to productivity growth and the inflation target. See Appendix G.
} 
Figure 6: Monetary and fiscal policy responses
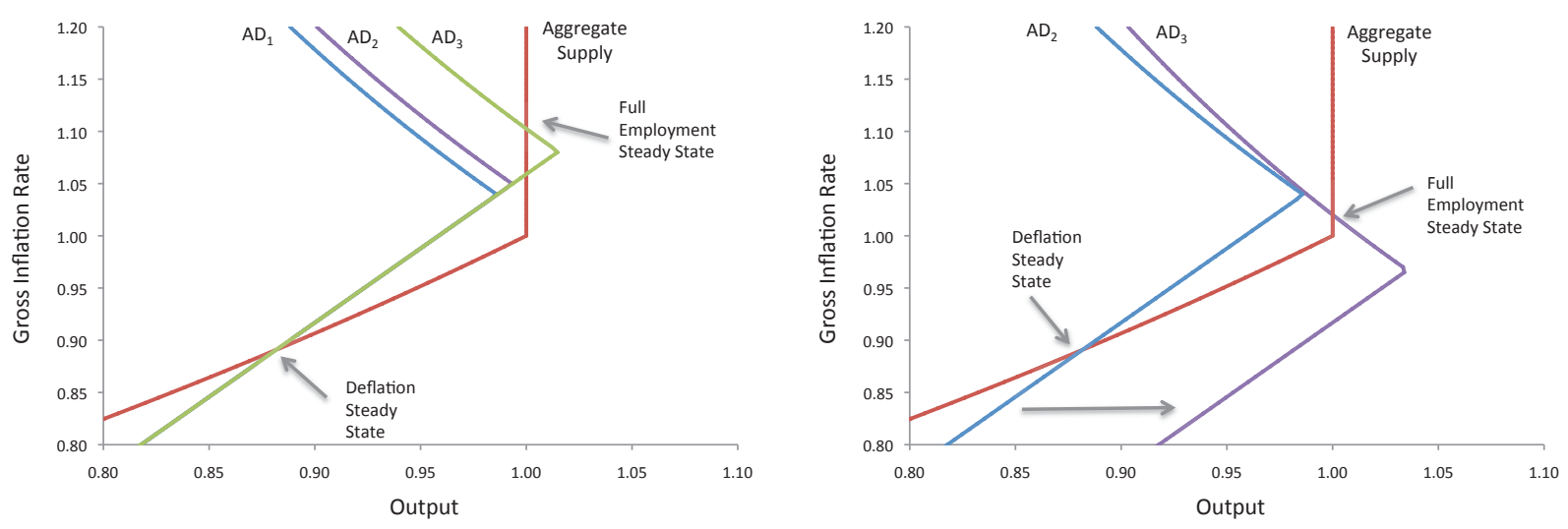

\section{Monetary and Fiscal Policy}

We now consider monetary and fiscal policy in a secular stagnation. As we show in this section, the policy implications of our model for both monetary and fiscal policy are starkly different from those of existing New Keynesian models of the zero lower bound.

Let us first consider the effect of an increase in the inflation target $\Pi^{*}$. This change has no effect on the AS curve but instead shifts the AD curve. Specifically, a rise in the inflation target shifts out the kink point in the AD curve, as shown in the left-hand panel of Figure 6. In this figure, the initial inflation target is set at $1 \%$. As the inflation target increases, the kink point moves upward, effectively shifting up the downward sloping portion of the AD curve. $A D_{1}$ shows the original aggregate demand curve with a unique secular stagnation steady state. $A D_{2}$ shows the effect of a modest increase in the inflation target, while $A D_{3}$ shows the effect of a large increase in the inflation target. Notice that $A D_{3}$ now intersects the aggregate supply curve at three points.

$A D_{2}$ illustrates the perils of too small an increase in the inflation target. For a sufficiently negative natural rate of interest, a small increase in the inflation target will not shift the AD curve enough to intersect the full-employment line. The contention that a small increase in the inflation target will be ineffective has been labeled by Krugman variously as the "timidity trap" or, in reference to Japan in the late 1990s, the "law of the excluded middle." Our framework readily captures this idea. Formally, the inflation target needs to be high enough so that $\left(1+r^{f}\right) \Pi^{*} \geq 1$; otherwise, the kink point in the AD curve occurs to the left of the full-employment line.

With a sufficiently large increase in the inflation rate (as shown by $A D_{3}$ ), our model admits three distinct steady states. The first steady state at the top intersection of the two curves is the normal, full-employment equilibrium at which point inflation is equal to the inflation target of the central bank $\Pi^{*}$. At this point the nominal interest rate is positive because the inflation target is large enough to accommodate the negative natural rate - that is, $\left(1+r^{f}\right) \Pi^{*}>1$. However, there is another equilibrium at full employment that is consistent with the policy rule. This is the 
second intersection of the two curves, where $i=0$ and $\Pi<\Pi^{*}$. This steady state, however, is locally indeterminate. ${ }^{32}$ Importantly, even with a sufficiently large increase in the inflation target, the secular stagnation steady state remains; an increase in the inflation target does not eliminate this equilibrium. Furthermore, this steady state is locally determinate.

This multiplicity shows that monetary policy is less effective in our environment than in models that feature temporary liquidity traps, such as those in Krugman (1998) or Eggertsson and Woodford (2003). In those models, a permanent increase in the inflation target will always have an effect because, by assumption, one can always reach the higher inflation target at some point in the future. Working backwards, a commitment of this sort will always have expansionary effects during a liquidity trap, and, provided the inflation target is high enough, it may even eliminate the demand slump altogether. Since the trap is permanent in our model, however, this backward induction breaks down; there is no future date at which one can be certain that the higher inflation target is reached (even if the policy regime is fully credible in the sense that people do not expect the government to deviate from the policy rule). For the same reason, a commitment to keep nominal rates low for a long period in a secular stagnation is of limited use and does not by itself guarantee a recovery. Indeed, interest rate commitments of the type pursued by the Federal Reserve during the crisis (often referred to as "forward guidance") would be irrelevant in shifting the economy out of the deflationary equilibrium since households are expecting rates to stay at zero forever. Even if a recovery were anticipated, the expansionary effect of a commitment to keep interest rates lower in the future is far less effective, given discounting in the Euler equation due to finite lifetimes. ${ }^{33}$ Though an increase in the inflation target could make a full-employment steady state feasible, our model is silent on how a government could coordinate expectations on the favored full-employment equilibrium.

The fact that we have two locally determinate steady states suggests there is no obvious reason why a higher inflation target should bring about full employment for an economy at the secular stagnation steady state. ${ }^{34}$ Moreover, as shown by Gibbs (2017), both the full-employment and

\footnotetext{
${ }^{32}$ This steady state is akin to the deflation steady state in Benhabib, Schmitt-Grohé and Uribe (2001).

${ }^{33}$ See McKay, Nakamura and Steinsson (2016) for a discussion.

${ }^{34}$ One suggestion, proposed by John Cochrane in discussing this paper, is that the government can select between the two determinate steady states by raising nominal interest rates since, with a high enough inflation target, the nominal interest rate is positive. The main problem with this interpretation is that it presumes the Taylor rule is a structural policy regime that can be changed by increasing the nominal rate, so that increasing interest rates today will necessarily imply an increase in the nominal interest rate forever. If one instead interprets the Taylor rule as a reducedform representation of a policy regime that aims at targeting a certain level of inflation $\Pi^{*}$, then an increase in the nominal interest rate at time $t$ need not imply anything about future policy commitment. If an increase in the nominal interest rate at time $t$ only changes the interest rate at that time, without affecting expectations, then it will have a contractionary effect via the aggregate demand channel. This could be modeled more formally as optimal policy under discretion (Markov Perfect Equilibrium), for example, whereby the policy objective of the government is to minimize the deviation of inflation from a target.
} 
secular stagnation steady-state are learnable and survive under deviations from rational expectations. $^{35}$

Given the drawbacks of monetary policy, we turn to fiscal policy. We extend our model to incorporate taxes and denote taxes on each generation by $T_{t}^{i}$, where $i=y, m$, or $o$. We first consider the effect of fiscal policy on the natural rate (i.e., in the endowment economy) before reincorporating nominal frictions. The budget constraints can now be written taking taxes into account:

$$
\begin{aligned}
C_{t}^{y}+T_{t}^{y} & =B_{t}^{y} \\
C_{t+1}^{m}+\left(1+r_{t}\right) B_{t}^{y} & =Y_{t+1}^{m}-T_{t+1}^{m}-B_{t+1}^{m} \\
C_{t+2}^{o} & =Y_{t+2}^{o}+\left(1+r_{t+1}\right) B_{t+1}^{m}-T_{t+2}^{o} .
\end{aligned}
$$

Public debt now enters the asset market-clearing condition:

$$
-N_{t-1} B_{t}^{m}=N_{t} B_{t}^{y}+N_{t-1} B_{t}^{g}
$$

where $B_{t}^{g}$ is government debt (normalized in terms of the size of the middle-aged generation). In previous sections, the only demand for borrowing came from the young households; now the government also may want to borrow so that loan demand is given by the right-hand side of equation (34):

$$
L^{d}=\frac{1+g}{1+r} D+B^{g}
$$

We have omitted the time subscript to indicate that we are evaluating the steady state. Meanwhile, the supply of loans can be derived in exactly the same way as before, yielding

$$
L^{s}=-B^{m}=\frac{\beta}{1+\beta}\left(Y^{m}-D-T^{m}\right)-\frac{1}{1+\beta} \frac{Y^{o}-T^{o}}{1+r} .
$$

Relative to the earlier specification, loan supply must now also track tax payments. The government's budget constraint is the final equation needed to determine asset market equilibrium:

$$
T^{m}+B^{g}+\frac{1}{1+g} T^{o}+(1+g) T^{y}=G+(1+r) \frac{1}{1+g} B^{g},
$$

where $G$ is government spending (normalized in terms of the size of the middle-aged generation). The equilibrium real interest rate is once again the interest rate that equalizes loan supply $L^{s}$ and loan demand $L^{d}$ and takes the same form as we saw previously in Section 3 and as was illustrated by Figure 2. The key difference is that now the real interest rate can be affected by fiscal policy, shifting the loan supply and loan demand curves in Figure 2. A fiscal policy regime corresponds

\footnotetext{
${ }^{35}$ Another consideration against raising the inflation target and accommodating a negative natural rate of interest is that very low rates could spur asset-price bubbles and raise financial stability concerns. See Galí (2014) and Asriyan et al. (2016) for further discussion.
} 
to a choice of the level and distribution of taxation and government spending $\left(T^{o}, T^{m}, T^{y}, G, B^{g}\right)$ subject to the government's budget constraint. The overall effect of fiscal policy on the real interest rate then depends on the contribution of all the fiscal variables. Equating (35) and (36), and taking account of the budget constraint (37), we have two equations and six unknown variables $\left(T^{o}, T^{m}\right.$, $T^{y}, G, B^{g}$, and $\left.1+r\right)$. Hence, we need four restrictions on the fiscal policy instruments to determine the interest rate. Previously, we implicitly assumed that $T^{o}=T^{m}=T^{y}=0, G=0$, which implies $B^{g}=0$ from the government budget constraint, leaving equations (35)-(36) to pin down the real interest rate $1+r$.

Consider now a more general policy regime that will help us clarify a number of results. ${ }^{36}$ The tax on the young and government spending are exogenously given by $T^{y}=T^{*}$ and $G=G^{*}$. Similarly, the overall level of real government debt is exogenously given by $B_{*}^{g}$. Finally, we assume that taxes on the middle aged and the old satisfy the following relation:

$$
T^{m}=\frac{1}{\beta} \frac{1}{1+r} T^{o}=T,
$$

where the level of taxation $T$ adjusts so that the budget constraint (37) is satisfied. The distribution of taxation condition given by (38) ensures that now there is no effect of fiscal policy on the supply of loans given by (36).

We first consider an increase in public debt $B_{*}^{g}$. Under the fiscal rule we have considered, an increase in public debt only affects loan demand, shifting out the demand for debt and raising the natural rate. In this respect, increasing government debt is a natural way of avoiding a secular stagnation. ${ }^{37}$ Who receives the proceeds from this increase in government debt? The conditions above show that this does not matter so long as equation (38) is satisfied. The increase in government debt could be directed to the young or toward government spending, or be distributed to the middle aged and the old in accordance with the fiscal rule (38). The effect of public debt also shows that if a central bank kept the nominal level of money constant in a secular stagnation with deflation, eventually the natural rate would have to rise (see Appendix F for more details). We can similarly explore the effect of increasing government spending, funded via taxes, or various tax redistribution schemes. The effect of those policies can be gauged by analyzing how the policy shifts loan demand and loan supply in Figure 2. We will be a bit more specific about these types of policy experiments in the full life cycle model.

A critical reason for why an increase in government debt raised the natural rate of interest is that it is expected to be permanent. To make this clear, let us consider the following policy regime.

\footnotetext{
${ }^{36}$ While this particular policy regime is clearly special, we think it helps illustrate how relatively cleanly fiscal policy operates in this environment.

${ }^{37}$ The ability of an increase in the public debt in an OLG economy to undo the effect of credit frictions (that is, the effect of borrowing constraints) is similar to examples presented in Woodford (1990).
} 
Table 1: Government purchases multiplier at the zero lower bound

\begin{tabular}{lcc}
\hline \hline Financing & Multiplier & Value \\
\hline Increase in public debt & $\frac{1+\beta}{\beta} \frac{1}{1-\kappa \psi}$ & $>2$ \\
Tax on the young & 0 & 0 \\
Tax on the middle-aged & $\frac{1}{1-\kappa \psi}$ & $>1$ \\
Tax on the old & $-\frac{1+g}{\beta} \frac{1}{1-\kappa \psi}$ & $<0$ \\
\hline
\end{tabular}

$G_{t}=T_{t}^{y}=B_{t-1}^{g}=0$ and

$$
\begin{aligned}
T_{t}^{m} & =-B_{t}^{g} \\
T_{t+1}^{o} & =\left(1+r_{t}\right) B_{t}^{g} .
\end{aligned}
$$

The thought experiment here is that an increase in the public debt results in a lump-sum transfer to the middle aged in period $t$. The old are then taxed by the same amount in the next period (plus interest) to return the debt to its original level. ${ }^{38}$ A temporary increase in the public debt is completely irrelevant for the interest rate: The increase in debt in period $t$ is met by an increase in the middle-aged savings to pay off the future tax. The point is that the effect of an increase in the public debt considered in the previous policy regime depends critically on agents' expectations about future fiscal policy. In particular, it depends upon the expectation of the middle aged that they will not be taxed to pay down the debt in the future. ${ }^{39}$

So far, we have only considered the effect of fiscal policy on the real interest rate in the endowment economy. Our results, however, carry over to the full model with endogenous production. Fiscal policy that leads to a change in the real interest rate in the endowment economy is equivalent to a policy that changes the natural rate of interest in the model with production. It therefore corresponds directly to a shock that shifts the AD curve, as shown in the right-hand panel of Figure 6, displaying the effect of an increase in government spending via debt issuance. Thus, fiscal policies that raise the natural rate of interest correspond to an outward shift in the aggregate demand curve, while policies that reduce the natural rate correspond to an inward shift of the AD curve. Importantly, in contrast to monetary policy, where an increase in the inflation target only allowed for the possibility of a "good equilibria" and suffered from multiple steady states, fiscal policy can eliminate the secular stagnation equilibrium since it shifts the entire AD curve (see Figure 6).

To derive some analytic results for the effect of fiscal policy on output, let us generalize equation (29) by combining equations (35) and (36), together with equations (16) and (25), and assum-

\footnotetext{
${ }^{38}$ For simplicity, we set population growth to zero.

${ }^{39}$ Since money and public debt are perfect substitutes at the zero lower bound, a temporary helicopter drop would also have the same effect. A helicopter drop is only effective to the extent that the rise in consolidated government liabilities is permanent.
} 
ing $i=0$, to yield

$$
Y=D+T^{m}+\frac{1+\beta}{\beta} B^{g}+\left(\frac{(1+g)(1+\beta)}{\beta} D-\frac{1}{\beta} T^{o}\right) \Pi,
$$

where we now see how fiscal instruments directly affect aggregate demand at a zero interest rate. Tracing out exactly how aggregate demand shifts requires being specific about the policy regime. In Table 1, we derive analytically the steady-state multiplier of government spending at the zero lower bound under different financing conditions, under the policy regime we specified before (except we relax equation (38) when government spending is financed by the middle aged or old). ${ }^{40}$

Observe that, away from the ZLB, the multiplier is zero since labor is supplied inelastically; once all workers are employed, government purchases will reduce private consumption one to one without any effect on output. At the zero bound, however, the multiplier is generally different from 0 as seen in Table 1 and critically depends on the way in which government spending is financed. ${ }^{41}$

First, we consider the case in which spending is financed via an issuance of public debt. Financing via an increase in the public debt results in the largest multiplier shown in Table 1 . Using the formula in Table 1, we see that because $\beta$ is less than 1, and $\kappa$ can be no lower than zero (when wages are perfectly fixed), this multiplier has to be larger than 2. As we increase the value of $\kappa$, the multiplier becomes larger and can even be unboundedly large - a result similar to that in Christiano, Eichenbaum and Rebelo (2011) in the context of the standard New Keynesian model.

However, in contrast to the NK model, government spending multipliers are not always positive at the ZLB. The sign of the multiplier depends on whether fiscal expansions reduce the saving glut in a secular stagnation, which, in turn, depends on how government spending is financed. If instead of being financed by increasing debt, spending is financed via a tax on young households, the multiplier is zero. The collateral constraint is binding in equilibrium so that the young will cut their consumption by exactly the same amount as they are taxed. An increase in government purchases then simply substitutes for existing consumption by the young, leaving output unchanged. If an increase in spending is financed via a tax on middle-generation households, the purchases multiplier is still positive but smaller than if spending is financed via debt as shown in Table 1. We see from the analytic expression that this multiplier always has to be greater than 1 . Finally,

\footnotetext{
${ }^{40}$ The parameters $\kappa$ and $\psi$ - the slope of the AS and AD curves respectively — are given by

$$
\begin{aligned}
& \kappa=\frac{1-\alpha}{\alpha} \frac{1-\gamma}{\gamma} \\
& \psi=\frac{1+\beta}{\beta}(1+g) D .
\end{aligned}
$$

${ }^{41}$ In computing the multiplier, we consider only a small increase in spending (so the zero bound is still binding) and a linear approximation of the model around a zero inflation steady state.
} 
if government purchases are financed via a tax on the old, the multiplier is negative. This negative multiplier obtains because the old generation will cut their spending one for one with the tax (thus offsetting the higher spending by the government). Meanwhile, the middle aged will now increase their saving, having anticipated higher future taxes, which reduces aggregate demand.

Nevertheless, overall the model suggests a relatively positive picture of fiscal policy as it can lead to an increase in demand via either debt policy or tax and spending actions.

\section{A Quantitative Life Cycle Model}

We now turn to a medium-scale quantitative version of the baseline model where we can incorporate a variety of additional features. ${ }^{42}$ The economy consists of a large number of households with identical utility functions. Households enter economic maturity at age 26, after which they work, consume, have children, and trade in asset markets. Households pass away with certainty at age $J$, which we take to be 81 years. Households have children at age 26 , and the population growth rate is determined by the total fertility rate $(\Gamma)$ of every family. Households face a probability of dying stochastically before reaching maximum age $J$. The probability of surviving between age $j$ and $j+1$ is denoted by $s_{j} .{ }^{43}$ The unconditional probability of reaching age $j$ is denoted with a superscript $s^{j} \cdot{ }^{44}$

Households receive utility from two sources: (i) consumption, which is given by a timeseparable, constant elasticity of substitution (CES) utility function $u(\cdot)$ with elasticity parameter $\rho$, and (ii) bequests that are divided equally among all descendants. The bequest motive is also characterized by a CES function $v(\cdot)$ whose argument is the amount of bequests left per descendent, denoted by $x .^{45}$ The utility function for bequests is multiplied by a parameter $\mu \geq 0$ that determines the strength of the bequest motive. Denoting the consumption of households of age $j$ at time $t$ by $c_{j, t}$ and the discount rate by $\beta$, a household that enters economic maturity at time $t$ has lifetime expected utility given by the expression

$$
U_{t}=\sum_{j=26}^{J} s^{j} \beta^{j} u\left(c_{j, t+j-1}\right)+s^{J} \beta^{J} \mu v\left(x_{J, t+J-1}\right) .
$$

A household of age $j$ can trade in a real asset $a_{j, t}$ at time $t$, which is used as productive capital. At time $t+1$, capital will pay a return of $r_{t+1}^{k}$, which is the rental rate of capital, and has a resell value (net of depreciation) of $\xi_{t+1}(1-\delta)$, where $\xi_{t+1}$ is the exogenous relative price of capital in terms of the consumption good. Each household has an identical exogenous labor productivity

\footnotetext{
${ }^{42}$ The model is based on Auerbach and Kotlikoff (1987) and Ríos-Rull (1996).

${ }^{43}$ Age-specific survival rates may also vary over time $t$; however, for notational simplicity, we omit these additional subscripts.

${ }^{44}$ This can be calculated as the product of the one-period survival probabilities: $s^{j}=\Pi_{m=26}^{j} s_{m}$.

${ }^{45}$ Thus the total size of the bequest left by households is the bequest $x$ multiplied by the fertility of the household.
} 
process, or human capital profile, denoted by $h c_{j}$, which changes with age. Households receive no wage income after retirement, which, in our model, occurs after age 65. We assume an inelastic labor supply; hence, wage income is equal to the wage multiplied by the household's age-specific labor productivity $h c_{j}$ net of labor taxes $\left(1-\tau^{w}\right)$.

Households also receive income from the pure profits of firms, denoted by $\pi_{j, t}^{f}$, and we assume that profits are distributed proportionally to labor income. Finally, the household may receive a bequest $q_{j, t}$. Individuals receive bequests $q$ the year after their parents die; thus descendants receive bequests at age $J-24$. For example, if we take $J$ to be 81 , individuals would receive bequests at age 57 . Bequests made $(x)$ are zero at all times except in the final year of life at age $J$. Following Ríos-Rull (1996), we suppose that agents insure themselves against the idiosyncratic risk of early death via one-period annuity contracts.

The flow budget constraint of a household of age $j$ at time $t$ is

$c_{j, t}+\xi_{t} a_{j+1, t+1}+\Gamma_{26, t-j+26} \cdot x_{j, t}=\left(1-\tau^{w}\right) w_{t} h c_{j}+\pi_{j, t}^{f}+\left(r_{t}^{k}+\xi_{t}(1-\delta)\right)\left(a_{j, t}+q_{j, t}+\frac{1-s_{j}}{s_{j}} a_{j, t}\right)$.

Households can borrow against future income, and we impose a borrowing constraint of the same form as in our simple model of Section $3^{46}$ :

$$
a_{j, t} \geq \frac{D_{t}}{1+r_{t}}
$$

There are two types of firms: producers of final goods, and producers of intermediate goods. The final goods firms produce a differentiated good $Y_{t}^{f}$. The final good composite is the CES aggregate:

$$
Y_{t}=\left(\int_{0}^{1}\left(Y_{t}^{f}\right)^{\frac{\theta_{t}-1}{\theta_{t}}} d f\right)^{\frac{\theta_{t}}{\theta_{t}-1}}
$$

Each final goods producer utilizes $Y_{t}^{m}$ of intermediate goods to produce output via a linear technology: $Y_{t}^{f}=Y_{t}^{m}$. The presence of monopolistically competitive final goods firms allows for a time-varying markup given by $\frac{\theta_{t}}{\theta_{t}-1}$; pure profits due to monopoly rents are returned to the households.

There is a perfectly competitive intermediate goods sector that sells its production to the final goods sector. These firms hire workers at wage rate $w_{t}$ and rent capital at rate $r_{t}^{k}$. They operate a CES production function in labor and capital with an elasticity of substitution $\sigma$. The production function is

$$
Y_{t}^{m}=\left(\alpha K_{t}^{\frac{\sigma-1}{\sigma}}+(1-\alpha)\left(A_{t} L_{t}\right)^{\frac{\sigma-1}{\sigma}}\right)^{\frac{\sigma}{\sigma-1}},
$$

where $A_{t}$ is an exogenous, labor-augmenting technological progress, and $0<\alpha<1$.

\footnotetext{
${ }^{46}$ We will assume, in addition, that the borrowing constraint $D_{t}$ grows at the rate of productivity growth and the household's earning potential over the life cycle.
} 
Table 2: Parameters taken from the data and related literature

\begin{tabular}{lccc}
\hline \hline Panel A: Data & Symbol & Value & Source \\
\hline Mortality profile & $s_{j, t}$ & & US mortality tables, CDC \\
Income profile & $h c_{j}$ & & Gourinchas and Parker (2002) \\
Total fertility rate & $n$ & 1.88 & UN fertility data \\
Productivity growth & $g$ & $0.65 \%$ & Fernald (2012) \\
Government spending (\% of GDP) & $G$ & $21.3 \%$ & CEA \\
Public debt (\% of GDP) & $b_{g}$ & $118 \%$ & Flow of Funds
\end{tabular}

Panel B: Related literature

\begin{tabular}{lccc} 
Elasticity of intertemporal substitution & $\rho$ & 0.75 & Gourinchas and Parker (2002) \\
Capital/labor elasticity of substitution & $\sigma$ & 0.6 & Antras (2004) \\
Depreciation rate & $\delta$ & $12 \%$ & Jorgenson (1996) \\
\hline
\end{tabular}

The government purchases some level of output $G_{t}$ and may issue debt. The budget constraint for the government becomes

$$
b_{g, t}=G_{t}+\left(1+r_{t}\right) b_{g, t-1}-T_{t},
$$

where taxes are collected on labor income. We economize on notation by omitting real and nominal bonds as assets above; these assets enter in the same way as in the simpler model (Section 5) so there is both a well-defined real interest rate $r_{t}$ on a risk-free one-period real bond and a nominal interest rate $i_{t}$ on nominal bonds.

Monetary policy and wage rigidity are modeled as in Section 5. The full nonlinear model is solved numerically; we solve for both the stationary equilibrium and perfect foresight transition paths. We outline the computational details and the numerical solution algorithm in Appendix J. ${ }^{47}$

\subsection{Calibration}

We first calibrate our model to match the US economy in 2015. Considerable uncertainty remains as to the size of the output gap in 2015. We consider two polar cases: (i) a zero output gap in 2015 based on Stock and Watson (2012), and (ii) an alternative calibration where the output gap is $-15 \%$, which is what Hall (2016) estimates as the deviation of output from its pre-recession trend in 2015. We consider this latter case as a sensible upper bound on the possible size of the output

\footnotetext{
${ }^{47}$ The equilibrium conditions consist of roughly 170 equations in the stationary equilibrium. Transition dynamics are more complicated as the birthrate over the past 25 years becomes a state variable in that case and agents form expectations over the entire transition path.
} 
gap. $^{48}$

We first consider the case of the zero output gap. We calibrate our model to match the 2015 real interest rate in the US, which was $-1.47 \%$. Since we are assuming a zero output gap, this implies that the natural rate of interest is also $-1.47 \%$. We will thus be on the upper section of the aggregate demand and aggregate supply curves and can continue with our parameterization without reference to nominal frictions.

Our parameters come from three main sources. The first is statistical data about US demographics and the economy that we can match directly, such as mortality rates, fertility levels, productivity growth, and the size of government debt. The second source of parameters we take directly from the related literature that has previously estimated or calibrated these parameters. The third set is chosen to match key moments in the data, such as the investment-to-output ratio. The moments will be matched by minimizing an objective function. We discuss each in turn.

Panel A of Table 2 shows the first category of parameters that are taken directly from observed data. We use mortality data from the Centers for Disease Control (CDC) to directly match US survival tables. The total fertility rate is taken from UN fertility data, and the retirement length is chosen to match the average years of retirement. Government debt to GDP and government spending to GDP are also chosen to match current values. ${ }^{49}$ The rate of productivity growth is a key determinant of the real interest rate. Our baseline uses a productivity growth rate of $0.65 \%$ per year, which we have taken from Fernald (2012). The wage profile $h c_{j}$ is chosen to match the earnings profile estimated from the data by Gourinchas and Parker (2002).

Panel B of Table 2 shows the second category of parameters taken from the related literature. We set the intertemporal elasticity of substitution $\rho$ equal to 0.75 . This parameter has been estimated widely in the literature, with ranges between .25 and $1 .^{50}$ The depreciation rate comes from Jorgenson (1996) and BEA (2004), which have extensive estimates of the depreciation rate of private and governmental nonresidential equipment. ${ }^{51}$ The value of the production elasticity of substitution, $\sigma$, has also been estimated widely in the literature, and generally falls between 0.4 and $1 .{ }^{52}$ As these parameters are not directly observed in the data, we report in Appendix L how

\footnotetext{
${ }^{48}$ To be clear, Hall (2016) does not interpret this gap as reflecting the output gap of the kind we see in the model, but we still think that computing deviation from trend provides a convenient benchmark for contrasting with the opposite extreme - an economy with no output gap.

${ }^{49}$ We set government debt as the sum of federal, state, and local debt as reported by the Council of Economic Advisers and the Census Bureau.

${ }^{50}$ For example, Cooley and Prescott (1995) set $\rho=1$, while Auerbach and Kotlikoff (1987) and Ríos-Rull (1996) set $\rho=.25$.

${ }^{51}$ Since our model does not explicitly incorporate housing, our preferred specification uses depreciation applicable to equipment investment, which generally is higher than for housing. We consider a lower value in the sensitivity analysis in the appendix.

${ }^{52}$ For example, Antras (2004) estimates it is between 0.4 and 0.9, while Oberfield and Raval (2014) estimate an elasticity of 0.7 and Klump, McAdam and Willman (2007) estimate a value between 0.5 and 0.6.
} 
Table 3: Parameters chosen to match targets

\begin{tabular}{lcc}
\hline \hline Targets & Model/Data & Source \\
\hline Natural rate of interest & $-1.47 \%$ & Federal Reserve \\
Investment-to-output ratio & $15.9 \%$ & NIPA \\
Consumer-debt-to-output ratio & $6.3 \%$ & Flow of Funds \\
Labor share & $66.0 \%$ & Elsby (2013) \\
Bequests-to-output ratio & $3.0 \%$ & Hendricks (2001) \\
& & \\
Parameters chosen to match targets & Symbol & Value \\
\hline Rate of time preference & $\beta$ & 0.98 \\
Borrowing limit (\% of annual income) & $D$ & $23.4 \%$ \\
Bequests parameter & $\mu$ & 21.6 \\
Retailer elasticity of substitution & $\theta$ & 4.9 \\
Capital share parameter & $\alpha$ & 0.24 \\
\hline
\end{tabular}

our results change for different parameter choices and we will also comment on them below.

We choose the remaining parameters to match five key data moments as of 2015: a real interest rate of $-1.47 \%$, an investment-to-output ratio of $15.9 \%$, a consumer-debt-to-output ratio of $6.3 \%$, a labor share of $66.0 \%$, and a bequest-to-output ratio of $3 \% .5354$ The parameters chosen this way are the rate of time preference $\beta$, the debt limit $D$, the bequest parameter $\mu$, the capital share parameter $\alpha$, and the retailer elasticity of substitution $\theta$. We select the parameters by minimizing a loss function whose value is the sum of the squared differences between the moments of the model and those we take from the data.

Generically, there is no one-to-one mapping between these remaining parameters and the targets. Hence, we jointly choose all parameters to match the model output to the targets. Nevertheless, each of the parameters above corresponds relatively closely with one of the key moments we are trying to match. The rate of time preference $\beta$ has a direct effect on the real interest rate; as $\beta$ increases, the real interest rate falls. Not unexpectedly, the debt limit most directly affects the level of consumer debt to output, while the bequest parameter $\mu$ mostly directly affects the bequeststo-output ratio. Finally, the capital share parameter $\alpha$ determines the investment-to-output ratio, while inverse profit share $\theta$ controls the labor share.

\footnotetext{
${ }^{53}$ Sources are listed in Table 3.

${ }^{54}$ We choose to target the investment-to-output ratio, rather than the capital output ratio, as this ratio does not require adjustment of the past capital stock for changes in the relative price of capital goods. Investment to output is just a ratio of two nominal, readily measured quantities.
} 


\subsection{Negative Real Interest Rates}

Table 3 shows the results of the calibration procedure with the zero output gap. With the parameters selected by our minimization, each of the model moments perfectly matches those in the data. We document in Appendix $\mathrm{N}$ that the parameters in Table 3 fall directly within the range of parameter values reported in the existing literature. Therefore, we argue that a relatively standard OLG model with capital accumulation calibrated to match US data can generate permanently negative real interest with standard parameter values. ${ }^{55}$

That a standard, conservatively calibrated OLG model can deliver a substantially negative natural rate of interest suggests a reevaluation of the standard estimate of the natural rate for the US. Indeed, there is no reason a priori to expect a normalization of interest rates in the US. Pre-recession estimates for the long-run neutral real interest rate remained between $2 \%$ and $3 \%$ (see Williams (2016)). As long-term rates have continued to fall, the Federal Reserve has adjusted downward its estimates of the neutral rate to between $0.5 \%$ and $1.8 \%$ according to FOMC projections (see FOMC (2016)). Our calibration, however, suggests that, given current productivity and demographic trends, these estimates for the long-run neutral rate remain too optimistic. Our benchmark calibration has the steady-state real interest rate at $-1.47 \%$, or $2.27 \%$ lower than the FOMC estimate as of 2016.

Our results are robust to a variety of additional specifications; in particular, we focus on three parameters taken from the literature. Appendix L calculates the same moments in Table 3 for three alternate specifications: (i) setting depreciation to $8 \%$, (ii) setting the intertemporal elasticity of substitution $\rho$ to 1, and (iii) setting the production elasticity parameter $\sigma$ to 1 (Cobb-Douglas). For each of these specifications, we again minimize the objective function to find $\beta, \alpha, \mu D$, and $\theta$ to match the targets from the data. The results for these alternate specifications are similar to our main specification. The model still hits the targets, but with different values for the calibration parameters that remain well within the ranges from the literature. We report results under these alternative parameterizations for other experiments in Appendix L.

While the model can clearly generate permanently negative real interest rates, it is also of interest to explore if it can explain the reduction observed in the real interest rate over time. Before getting there, however, it is worth asking if our model can also replicate a scenario in which the

\footnotetext{
${ }^{55}$ In Appendix L, we show the optimal consumption path for households over their life cycle. Consumption tracks income over the early part of the life cycle due to borrowing constraints, then declines gradually as households save for retirement. This leads to the classic hump-shaped consumption profile. For comparison purposes, this figure also includes the estimated consumption profile from the Consumer Expenditure Survey, as estimated by Gourinchas and Parker (2002). We also compare the model's population pyramid in Appendix L to the current US pyramid. The fact that we are considering the stationary equilibrium is not innocuous. It does not take into account the dynamics of the aging of the baby boom and the effect on interest rates as the boom filters through the population pyramid. To study these effects, we need to consider transition dynamics, which we turn to shortly.
} 
natural rate of interest is negative enough that the zero bound is binding with output below potential.

\subsection{Secular Stagnation in a Quantitative Life Cycle Model}

We next turn to our calibration for the US economy with a substantial output gap. We keep the first group of parameters (those taken directly from the data) and the second group of parameters (those taken from the literature) the same as in our initial calibration. For our third group of parameters (those we choose to match moments), we keep all parameters unchanged save for the rate of time preference $\beta$. In addition, we must choose the wage rigidity parameter $\gamma$.

We jointly choose $\beta$ and $\gamma$ to match two moments of the US economy in 2015: the inflation rate and the output gap. We model the economy as in a secular stagnation, with an inflation rate of $1.62 \%$ as in the data and an output gap of $-15 \%$, corresponding to the deviation of output from its pre crisis trend in 2015 as documented in Hall (2016). A value of $\gamma$ of .91 and a discount rate of $\beta$ of 0.99 match these moments. Our calibrated value of $\gamma$ falls within the range wage rigidity estimated by Schmitt-Grohé and Uribe (2016). The value $\beta$ is also consistent with common estimates from the OLG literature (see Appendix N).

Figure 7 shows the aggregate demand and aggregate supply curves of the secular stagnation stationary equilibrium. The two curves cross at an output gap of $-15 \%$. The natural interest rate in this calibration is $-2.2 \%$, and therefore an inflation target of $2 \%$ is too low to allow the nominal interest rate to remain above zero. As a result, the economy is drawn into the secular stagnation steady state. The equilibrium real interest is $-1.62 \%$ and the inflation rate is $1.62 \%-40$ basis points below target. Investment to output, bequests to output, labor share, and consumer debt to output continue to closely match the US moments. ${ }^{56}$

Figure 7 represents the second key quantitative finding of the paper. It suggests that the model can replicate a permanent stagnation with a standard parameterization of precisely the same form we have shown in the simple model. As in the three-period model, a surplus of savings over investment opportunities pushes the equilibrium interest rate negative. If the inflation target is insufficient to prevent the zero lower bound from binding and nominal wage rigidities bind, a secular stagnation emerges.

\subsection{Decline in Interest Rates Since 1970}

We use our model to quantitatively analyze the fall in the real interest rate observed since 1970 and to assess the relative contribution of different factors. 1970 is a natural starting point, for it

\footnotetext{
${ }^{56}$ The investment-to-output ratio, consumer debt-to-output ratio, labor share, and bequests-to-output remain very close to their values in Table 3; hence, we choose not to reparameterize the model for $\mu, \alpha, D$, and $\theta$ relative to the benchmark calibration.
} 
Figure 7: Secular stagnation equilibrium

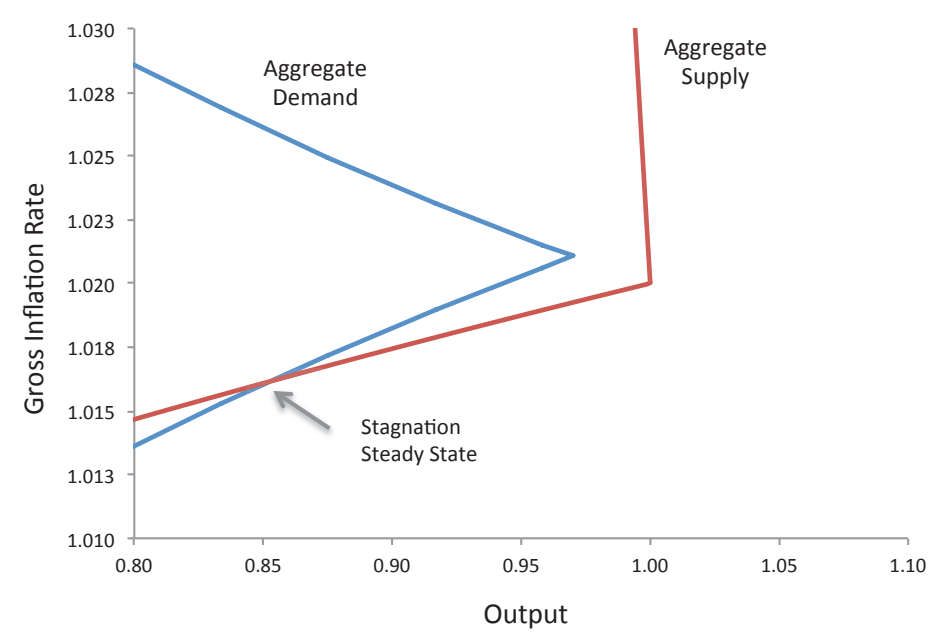

is the point at which a number of economic trends began shifting. Briefly, they are (i) children of the baby boom generation (born beginning in 1945) begin to enter the labor force; (ii) mortality rapidly falls with life expectancy increasing from an average of 70.8 in 1970 to 78.7 in 2010; (iii) according to Gordon (2016), the fall in the rate of productivity growth began in the 1970s; (iv) Greenwood, Hercowitz and Krusell (1997) and Fernald (2012) have documented that the relative price of investment goods has fallen by 30\% since 1970; and (v) Karabarbounis and Neiman (2014) have documented a significant drop in the labor share since 1970. Also, this period saw a significant rise in government and personal debt. For a full description of the changes in the economy since 1970, see Appendix M. For the data series used for these variables, see the Data Appendix.

We begin by targeting our calibration of the US economy to 1970 as shown in Table 4. All type 1 parameters (those taken directly from the data) we adjust to their 1970 counterparts (see Panel A) with the exception of the life cycle income profile, which remains unchanged. All type 2 parameters (those taken from the literature) are kept the same with the exception of the relative price of investment goods (Panel B). For the type 3 parameters (those we take to match moments), we keep the utility and production parameters $(\beta, \alpha, \mu)$ unchanged. We adjust the collateral constraint $D$, to match the lower consumer-debt-to-output ratio observed in 1970, and the profit share $\theta$ to match the higher labor share observed in the 1970s (Panel C). The respective 1970 values for these two parameters are then $D=0.144$ and $\theta=7.93$.

Table 5 shows the results of the simulation. The simulated 1970 real interest rate is $2.55 \%$, extremely close to the $2.62 \%$ observed in the data. This is an important quantitative result; our model is able to match the entire size of the decline in real interest rates over the past 45 years. The model predicts an investment-to-output ratio (which we did not explicitly target) slightly higher than what is observed in the data. By our choice of $D$ and $\theta$ the model matches the consumerdebt-to-output ratio exactly as well as the labor share. Overall, the model does a reasonable job 
Table 4: Change in parameters from 1970 to 2015

\begin{tabular}{lcc}
\hline \hline Panel A: Data & 1970 & 2015 \\
\hline Life expectancy & 70.7 & 78.7 \\
Total fertility rate & 2.8 & 1.9 \\
Productivity growth & $2.02 \%$ & $0.65 \%$ \\
Government debt (\% of GDP) & $42 \%$ & $118 \%$ \\
& & \\
Panel B: Relative price of investment & & \\
\hline Relative price of investment (index 100=2015) & 130 & 100 \\
& & \\
Panel C: Change in targets & & \\
\hline Consumer-debt-to-output ratio & $4.2 \%$ & $6.3 \%$ \\
Labor share & $72.4 \%$ & $66.0 \%$ \\
\hline
\end{tabular}

Table 5: Simulation results for 1970

\begin{tabular}{lcc}
\hline \hline Moment & Model & US data \\
\hline Natural rate of interest & $2.55 \%$ & $2.62 \%$ \\
Investment-to-output ratio & $19.0 \%$ & $16.8 \%$ \\
Consumer-debt-to-output ratio & $4.2 \%$ & $4.2 \%$ \\
Labor share & $72.4 \%$ & $72.4 \%$ \\
\hline
\end{tabular}

of explaining the fall in the real interest rate observed over the past 45 years by using observed changes in productivity, demographics, the relative price of investment goods, credit constraints, and changes in the labor share.

Table 6 decomposes the contribution of each of these factors to the decline in interest rates. We change each parameter from its steady-state value in 2015 to its steady-state value in 1970, holding all other parameters constant. We then examine the effect of this change on the real interest rate. For example, changing productivity growth from its 2015 level of $0.65 \%$ per year to its 1970 level of $2.02 \%$ results in an increase in the steady-state real interest rate of 1.9 percentage points. The table shows a decomposition of the relative importance of all the other factors. ${ }^{57}$ The reductions in fertility, mortality, and the rate of productivity growth play the largest role in the decrease in real interest rates. The main factor that has tended to counterbalance these forces is an increase in government debt. Changes in the labor share and the relative price of investment

\footnotetext{
${ }^{57}$ The decomposition is calculated by first adding up the total change in the real interest rate from all these factors and then dividing the effect of changing a particular forcing variable by the entire change. Numbers may not sum to unity due to interaction effects.
} 
Table 6: Decomposition of the decline in the natural rate of interest: 1970-2015

\begin{tabular}{lcc}
\hline \hline Forcing variable & $\Delta$ in $r$ & $\%$ of total $\Delta$ \\
\hline Total interest rate change & $-4.02 \%$ & $100 \%$ \\
Mortality rate & -1.82 & $43 \%$ \\
Total fertility rate & -1.84 & $43 \%$ \\
Productivity growth & -1.90 & $44 \%$ \\
Government debt (\% of GDP) & +2.11 & $-49 \%$ \\
Labor share & -.52 & $12 \%$ \\
Relative price of investment goods & -0.44 & $10 \%$ \\
Change in debt limit & +.13 & $-3 \%$ \\
\hline
\end{tabular}

goods play a smaller role in explaining the decline in real interest rates. Similarly, the increase in the consumer debt limit does not have a significant effect on the evolution of the interest rate in this parameterization. ${ }^{58}$

\subsection{Raising the Natural Rate of Interest}

If the natural rate of interest is indeed $-1.47 \%$ (the level in our baseline analysis), this poses a challenge for policymakers. With a $2 \%$ inflation target, small decreases in the natural rate will cause the zero lower bound to bind, implying that downturns may be sharper and more persistent. We now consider an alternative thought experiment, taking as given that the natural rate is $-1.47 \%$ in 2015. We ask, what economic conditions would be needed to increase the steady-state real interest rate to a positive territory of $1 \%$ ? While this target is somewhat arbitrary, we find it to be a useful benchmark. With the Federal Reserve's inflation target of $2 \%$, a natural rate of $1 \%$ would give policymakers a reasonable amount of room to respond to negative shocks that otherwise would lead to a binding ZLB. It also corresponds with the current expectations of the FOMC about longrun real interest rates. An alternative way of formulating our quantitative experiment is to ask, which forcing variables in 2015 would one need to change to be consistent with the current FOMC projections?

Table 7 provides the results of this experiment and shows that substantial changes in the underlying fundamentals are needed in order to increase the natural rate to $1 \%$. Given current demographic trends, it is implausible that fertility will reverse its decline and dramatically increase

\footnotetext{
${ }^{58}$ As our calibration takes account of only consumer debt, we suspect that this force may play a substantially larger role once one takes account of housing purchases and the associated debt, along with firms borrowing and lending. Together, these forces would have tended to increase the real interest rate in the past 45 years and lowered rates during the crisis. The increase in inequality observed during this period may have also been working to reduce interest rates; we have not taken account of this factorin the quantitative section and leave it for future research.
} 
Table 7: Raising the natural rate of interest to $1 \%$

\begin{tabular}{lcc}
\hline \hline Forcing variable & 2015 Value & Counterfactual value \\
\hline Total fertility rate & 1.88 & 3.28 \\
Government debt (\% of GDP) & $118 \%$ & $215 \%$ \\
Productivity growth & $0.65 \%$ & $2.43 \%$ \\
Relative price of investment goods & 1.00 & 2.43 \\
\hline
\end{tabular}

to 3.28 births per woman. An increase in immigration could make up a portion of the difference. It would also be challenging to increase productivity growth to $2.43 \%$ per year given the headwinds to productivity noted by Gordon (2016) and the fact that productivity growth has rarely exceeded $2 \%$ since 1970.

Of particular interest is the potential impact of an increase in government debt on interest rates, given that a higher public debt is an obvious policy lever. As Table 7 shows, government debt would need to double to roughly $215 \%$ of GDP to increase the natural rate to $1 \%$. Such a large level of debt raises questions about the feasibility of this policy for we have not modeled any costs or limits on the government's ability to issue risk-free debt - an assumption that may be strained at such high levels. While these results suggest that several reforms would tend to increase the natural rate of interest, the menu of options does not paint a particularly rosy picture relative to the alternative of raising the inflation target of the central bank.

\subsection{Transition Dynamics}

So far, we have confined our analysis to stationary equilibria. While this is one natural benchmark, we can also consider transition dynamics. This requires taking a strong stance on agents' expectations during the transition. Here, we document numerical experiments in which it is assumed that the economy was at a stationary equilibrium in 1970, and then project the model forward, assuming agents have perfect foresight about the path of exogenous processes.

We feed into the model the dynamic paths for each of the forcing variables in Table 6 and calculate the resulting transition path. We document the time series for each forcing variable in the Data Appendix. On impact in 1970, agents have perfect foresight about each of the exogenous and endogenous variables. For example, in 1970 all living agents will realize that there will be a productivity slowdown over the next 40 years and will adjust their optimal decisions accordingly. The forcing variables are set to their final steady-state values after the year 2015.

Since agents enter the labor force at the age of 26, the birthrates from 1945 to the 1970s are key state variables that will affect the real interest rate beginning in the 1970s. Since individuals entering the labor force in 1970 (age 26) were born in 1945, we use as model inputs data on fertility from 1945 onward to measure the size of each incoming generation. The birthrate data from 1945 
Figure 8: Transition path of the natural rate of interest

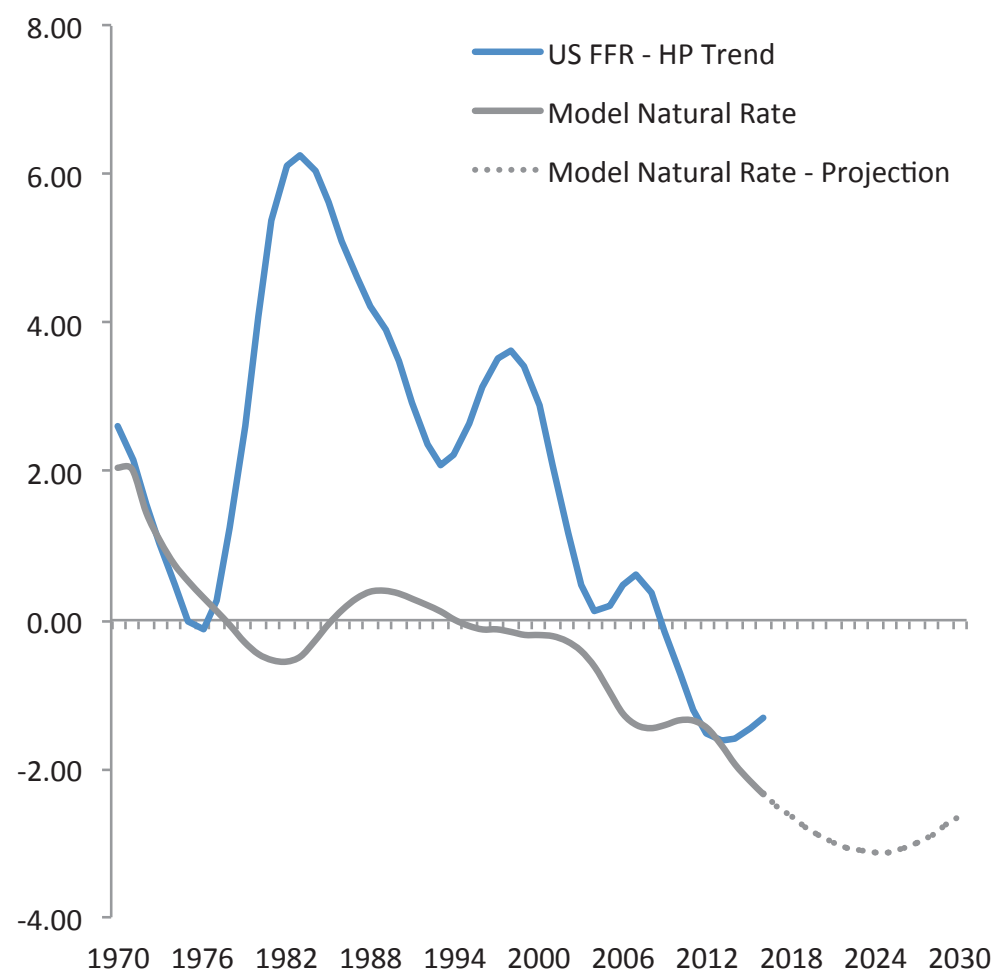

are reflected below the solid line in the age pyramid for the US economy in Figure 9, but, in 1970, those generations are economically inactive, entering the labor force only gradually.

Figure 8 shows the full transition path for the real interest rate. The 1970 real interest rate is $2.55 \%$ and declines non-monotonically throughout the period until it reaches $-1.0 \%$ in 2015 . The interest rate exhibits a brief recovery in the mid-to-late 1990s as productivity growth increases, but this subsides by the mid-2000s. Note that the model projects that the interest rate will continue to decrease until it hits a nadir in 2020. After 2020, there are cycles in the real interest rate due to the echo effects of the baby boom. The economy gradually converges to the final steady-state interest rate of $-1.47 \%{ }^{59}$

One interesting observation is that our model predicts a more rapid decline in the real interest rate than that observed in the data. A possible explanation for this, which we leave for future research, is offered by Summers (2014). He hypothesizes that the decline in the natural rate of interest since the late 1990s was masked by both the tech and housing bubble so that the true natural interest rate has only been observed post crisis. This could be modeled as exogenous

\footnotetext{
${ }^{59}$ One factor we do not focus on in these transition paths is debt deleveraging. While the evidence and theory certainly suggest there was a significant deleveraging shock in 2008, our model as of yet does not include a housing sector. Since housing debt is a significant portion of consumer debt, we leave the effect of debt deleveraging on interest rates to future quantitative work.
} 
fluctuations in the collateral constraint $D$ in our model.

One interesting aspect of our model is that it does not generate an investment boom even though real interest rates are declining. In fact, investment actually falls in our model, from 19.0\% in 1970 to $15.9 \%$ in 2015. Although lower interest rates will tend to lead to a higher capital-tooutput ratio and thus a higher investment rate, there are several counterbalancing forces in the model. In particular, decreases in the rate of population growth and productivity growth lead directly to a lower investment-to-output ratio, holding constant the capital-to-output ratio. Finally, our relatively inelastic production CES parameter means that the steady-state $\mathrm{K} / \mathrm{Y}$ ratio stays relatively constant for a given interest rate, which also dampens the effect on investment.

\subsection{Effects of the Baby Boom}

We now study the effects of the baby boom on real interest rates. The baby boom started in 1945, so the children of the baby boom did not enter economic maturity until 1970, when they reached age 26. Thus, we are able to look at the impact of these demographic changes on the evolution of interest rates starting from our model economy in 1970.

The left-hand panel of Figure 9 shows the demographic pyramid for the model during the transition years. In 1970, the economically active population is assumed to be in steady state; thus the pyramid above the solid line is a triangle. The younger generation of the baby boom, not yet in the labor force, bulges the distribution and will soon enter the labor force. Twenty-five years later, in 1995, the bulge now shows up in the working-age population. Fifty years later, in 2020, the baby boom generation is retired. There is also a second bulge in the population pyramid due to the children of the baby boomers (the millennials). By the year 2170, the population pyramids are approaching steady state.

The right-hand panel of Figure 9 shows the interest rate transition for the baby boom simulation. From 1970 until 2000, the baby boom tends to increase real interest rates owing to an increase in the rate of population growth. Following the baby boom comes the baby bust, and fertility rates drop as the boomers enter retirement, which leads to a sharp drop in real interest rates. The echo effects result in cycles in the real interest rate until it reaches its final steady-state value of around $1 \%$.

\section{Conclusion}

This paper builds a quantitative theory of negative interest rates and secular stagnation. We show how a low natural rate of interest can lead to a secular stagnation: a persistent output slump, inflation below target, and a chronically binding ZLB. Our message is not that the ZLB will be binding forever with certainty. A world of low natural rates admits business cycles in which the 
Figure 9: Baby boom and bust
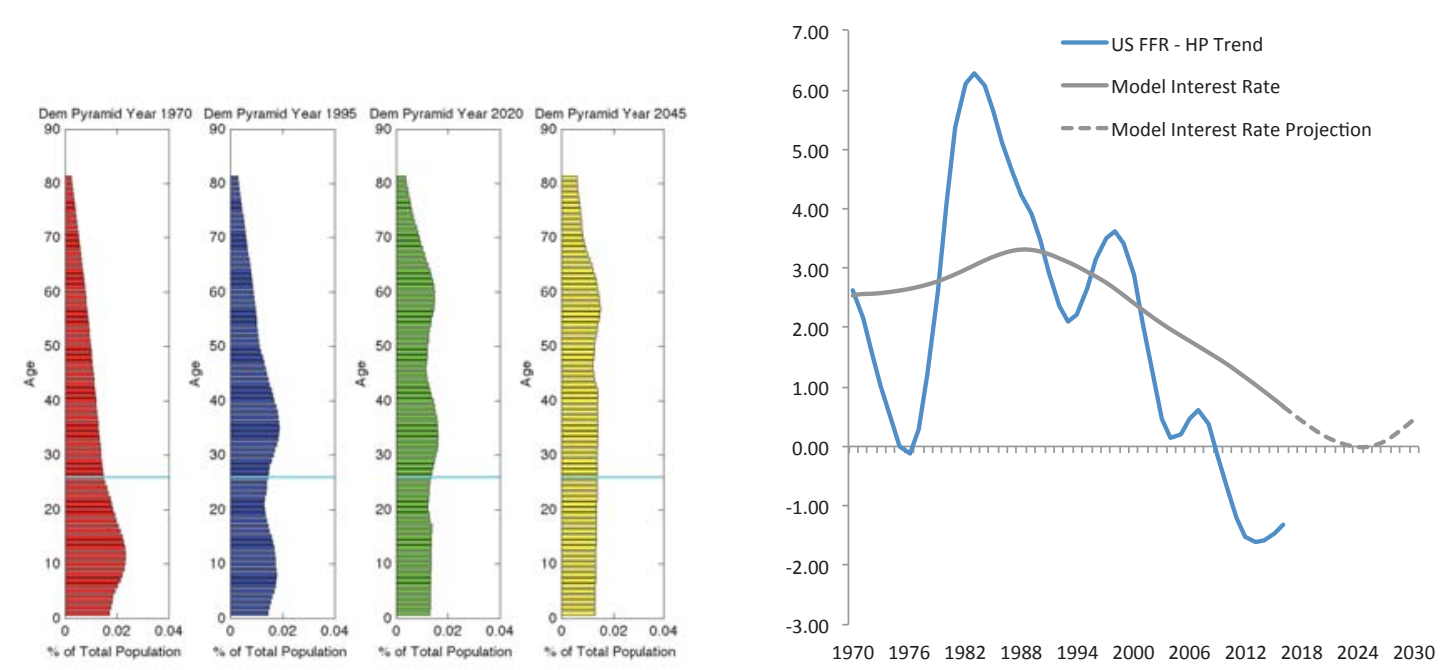

short-term rate can still be temporarily positive. Instead, it is a world characterized by a "new normal," in which real interest rates need on average to be negative to achieve full employment. As in the case of Hansen's prediction in 1938, we hope that this gloomy outlook will prove to be wrong. If negative rates persist, our analysis has identified several measures that could eliminate secular stagnation via appropriate policy.

A serious challenge, however, is that our policy recommendations advocate in favor of policies that were considered vices rather than virtues in macroeconomic theory: a higher inflation target, persistent increases in the debt-to-GDP ratio, or even more generous pay-as-you-go Social Security. This poses a conundrum for policymakers who cannot know with certainty if we are indeed in a "new normal" or just in a prolonged period of low interest rates that will abate in the near future. If the "new normal" hypothesis is incorrect, then those very policies that are desirable in order to eliminate secular stagnation are likely to be as counterproductive and costly as existing economic theory suggests. Given the uncertainty about the future, this creates new trade-offs for optimal policy, which we have not touched upon but hope that future research considers.

In closing, we briefly discuss some of the main arguments against the hypothesis of permanently negative interest rates, leaving a more detailed analysis to future research. The first argument, stated by Paul Samuelson and recently recapitulated by Ben Bernanke, is that negative real interest rates are a theoretical impossibility:

As ... Paul Samuelson taught me in graduate school at MIT, if the real interest rate were expected to be negative indefinitely, almost any investment is profitable. For example, at a negative (or even zero) interest rate, it would pay to level the Rocky Mountains to save even the small amount of fuel expended by trains and cars that currently must climb steep grades. It's therefore questionable that the economy's equilibrium real rate 
can really be negative for an extended period.

Samuelson's argument did not take into account two factors: monopoly rents and risk. In particular, under monopolistic competition, the rental rate of capital is given by $r^{k}=\frac{1}{\text { markup }} \cdot M P K$. With positive markups, the marginal product of capital is higher than the rental rate of capital. Thus, in equilibrium, there can be positive social returns to capital (even net of depreciation) while the rental rate (net of depreciation) and hence the real interest rate is negative. This is indeed the case in our quantitative model. Moreover, even though our calibrated model produces negative real interest rates, it can be shown that the economy is not dynamically inefficient. ${ }^{60}$

Adding risk to our model is another rejoinder to Samuelson's argument. As Abel et al. (1989) show, adding aggregate risk can lead to a negative risk-free interest rate, while the average and marginal return from capital (net of depreciation) remains positive. While adding aggregate risk to our economy is beyond the scope of this paper, we can illustrate this mechanism in a reducedform way. In Appendix K, we extend the model by including an additional financial friction: All borrowing and lending must now occur through a bank, which charges a spread between the borrowing and lending rates of interest. With a spread of $2 \%$, for example, it is possible to have a borrowing rate of interest that is positive while the lending rate of interest is negative. Since firms borrow at the higher rate, the marginal product of capital in excess of depreciation is positive in this economy.

The second argument against the presence of secular stagnation conditions in the US is that the measured return on capital is stable (see, for example, Gomme, Ravikumar and Rupert (2015)). The argument is that the most relevant measure of return is not the return on government debt but the return on productive capital. One problem with that argument is that business income does not just measure capital income, but also pure profits. ${ }^{61}$ And over the past decades, there is some evidence that competition has decreased and monopoly rents have risen. ${ }^{62}$ If an increase in monopoly rents cancels out the decrease in competitive returns to capital, this would lead to a stable measured average return on capital. ${ }^{63}$ This tends to increase the measured average return in our model through two channels: higher pure profits, and a higher marginal product of capital relative to the rental rate of capital. Although our economy exhibits a decline in the marginal product of capital over time, profits increase enough to almost completely offset this decline, and

\footnotetext{
${ }^{60}$ The condition for dynamic inefficiency, following Abel et al. (1989), is that the economy spends more on investment in capital than it gets out of it in terms of production: $I>M P K * K$.

${ }^{61}$ It is also possible that the NIPA accounts systematically understate the capital stock by mismeasuring intangible capital, as discussed in McGrattan and Prescott (2010). To the extent that this bias has increased over time, the true return on capital may be declining as our model would suggest.

${ }^{62}$ See, for example, Philippon and Gutierrez (2016), CEA (2016), and Decker et al. (2016).

${ }^{63} \mathrm{An}$ increase in monopoly rents is one possible explanation for the measured decrease in the labor share over the past 30 years. See in particular Barkai (2016), who finds that an increase in markups is responsible for a decrease in both the labor and the capital share.
} 
thus the measured average return on capital stays constant. Future research will consider alternative measures of the return on capital and evidence from firm-level data on whether returns have fallen over time. 


\section{References}

Abel, Andrew B., N. Gregory Mankiw, Lawrence H. Summers, and Richard J. Zeckhauser. 1989. “Assessing Dynamic Efficiency: Theory and Evidence." Review of Economic Studies, 56(1): 1-19.

Aiyagari, S. Rao. 1994. "Uninsured Idiosyncratic Risk and Aggregate Saving." Quarterly Journal of Economics, 109(3): 659-684.

Akerlof, George A., William T. Dickens, and George L. Perry. 1996. "The Macroeconomics of Low Inflation." Brookings Papers on Economic Activity, 27(1): 1-76.

Altig, David, Alan J. Auerbach, Laurence J. Kotlikoff, Kent A. Smetters, and Jan Walliser. 2001. "Simulating Fundamental Tax Reform in the United States." American Economic Review, 91(3): 574-595.

Alvarez-Cuadrado, Francisco, Ngo Van Long, and Markus Poschke. 2014. "Capital Labor Substitution, Structural Change, and the Labor Income Share." CIRANO-Scientific Publications 2014s02.

Antras, Pol. 2004. "Is the US Aggregate Production Function Cobb-Douglas? New Estimates of the Elasticity of Substitution." Contributions in Macroeconomics, 4(1): 1-34.

Asriyan, Vladimir, Luca Fornaro, Alberto Martin, and Jaume Ventura. 2016. "Monetary Policy for a Bubbly World." National Bureau of Economic Research 22639.

Auerbach, Alan J., and Laurence J. Kotlikoff. 1987. Dynamic Fiscal Policy. Vol. 11, Cambridge University Press Cambridge.

Autor, David, and David Dorn. 2013. "The Growth of Low-Skill Service Jobs and the Polarization of the US Labor Market." American Economic Review, 103(5): 1553-1597.

Barattieri, Alessandro, Susanto Basu, and Peter Gottschalk. 2014. "Some Evidence on the Importance of Sticky Wages." American Economic Journal: Macroeconomics, 6(1): 70-101. National Bureau of Economic Research.

Barkai, Simcha. 2016. "Declining Labor and Capital Shares." Mimeo. University of Chicago.

Barro, Robert J., and Herschel I. Grossman. 1971. "A General Disequilibrium Model of Income and Employment." American Economic Review, 61(1): 82-93.

BEA. 2004. "BEA Depreciation Estimates."

Bénassy, Jean-Pascal. 1993. "Nonclearing Markets: Microeconomic Concepts and Macroeconomic Applications." Journal of Economic Literature, 31(2): 732-761. 
Benhabib, Jess, Stephanie Schmitt-Grohé, and Martın Uribe. 2001. “The Perils of Taylor Rules." Journal of Economic Theory, 96(1): 40-69.

Benigno, Gianluca, and Luca Fornaro. 2015. "Stagnation Traps." Mimeo, London School of Economics.

Benigno, Pierpaolo, and Luca Antonio Ricci. 2011. “The Inflation-Output Trade-off with Downward Wage Rigidities." American Economic Review, 101(4): 1436-1466.

Bernanke, Ben S. 2005. "The Global Saving Glut and the US Current Account Deficit."

Berndt, Ernst R. 1976. "Reconciling Alternative Estimates of the Elasticity of Substitution." Review of Economics and Statistics, 58(1): 59-68.

Berry, Steven, James Levinsohn, and Ariel Pakes. 1995. "Automobile Prices in Market Equilibrium." Econometrica, 63(4): 841-890.

Bewley, Truman F. 1999. Why Wages Don't Fall During a Recession. Harvard University Press.

Bhattarai, Saroj, Gauti B. Eggertsson, and Raphael Schoenle. 2014. "Is Increased Price Flexibility Stabilizing? Redux." National Bureau of Economic Research 19886.

Blanchard, Olivier, and Philippe Weil. 2001. "Dynamic Efficiency, the Riskless Rate, and Debt Ponzi Games under Uncertainty." Advances in Macroeconomics, 1(2).

Brynjolfsson, Erik, and Andrew McAfee. 2014. The Second Machine Age: Work, Progress, and Prosperity in a Time of Brilliant Technologies. WW Norton \& Company.

Bullard, James. 2010. "Seven Faces of the Peril." Federal Reserve Bank of St. Louis Review, 92(5): 33952.

Caballero, Ricardo, and Emmanuel Farhi. 2014. "The Safety Trap." 19927. National Bureau of Economic Research.

Carvalho, Carlos, and Andrea Ferrero. 2014. “What Explains Japan's Persistent Deflation." Mimeo, PUC-Rio.

CEA. 2016. "Benefits of Competition and Indicators of Market Power."

Christiano, Lawrence J., Martin Eichenbaum, and Benjamin K. Johannsen. 2016. "Does the New Keynesian Model Have a Uniqueness Problem?" Mimeo. Northwestern University.

Christiano, Lawrence, Martin Eichenbaum, and Sergio Rebelo. 2011. "When Is the Government Spending Multiplier Large?" Journal of Political Economy, 119(1): 78-121. 
Christiano, L.J., M. Eichenbaum, and C.L. Evans. 2005. "Nominal Rigidities and the Dynamic Effects of a Shock to Monetary Policy." Journal of Political Economy, 113(1).

Cochrane, John H. 2016. “Michelson-Morley, Occam and Fisher: The Radical Implications of Stable Inflation at Near-Zero Interest Rates." Mimeo. Stanford University.

Coeurdacier, Nicolas, Stephane Guibaud, and Keyu Jin. 2015. "Credit Constraints and Growth in a Global Economy." American Economic Review, 105(9): 2838-2881.

Coibion, Olivier, Yuriy Gorodnichenko, and Johannes Wieland. 2012. "The Optimal Inflation Rate in New Keynesian Models." Review of Economic Studies, 79(4): 1371-1406.

Constantinides, George M., John B. Donaldson, and Rajnish Mehra. 2002. “Junior Can't Borrow: A New Perspective on the Equity Premium Puzzle." Quarterly Journal of Economics, 117(1): 269_ 296.

Cooley, Thomas F., and Edward C. Prescott. 1995. "Frontiers of Business Cycle Research." , ed. Thomas F. Cooley, Chapter Economic Growth and Business Cycles, 1-38. Princeton University Press.

Daly, Mary C., and Bart Hobijn. 2014. “Downward Nominal Wage Rigidities Bend the Phillips curve." Journal of Money, Credit and Banking, 46(S2): 51-93.

Decker, Ryan A., John Haltiwanger, Ron S. Jarmin, and Javier Miranda. 2016. "Where Has All the Skewness Gone? The Decline in High-Growth (Young) Firms in the US." European Economic Review, 86: 4-23.

Del Negro, Marco, Marc P. Giannoni, and Christina Patterson. 2012. "The Forward Guidance Puzzle." Federal Reserve Bank of New York Staff Report.

De Nardi, Mariacristina. 2004. "Wealth Inequality and Intergenerational Links." Review of Economic Studies, 71(3): 743-768.

Dynan, Karen E., Jonathan Skinner, and Stephen P. Zeldes. 2004. "Do the Rich Save More?" Journal of Political Economy, 112(2): 397-444.

Eggertsson, Gauti B., and Michael Woodford. 2003. "The Zero Bound on Interest Rates and Optimal Monetary Policy." Brookings Papers on Economic Activity, 34(1): 139-234.

Eggertsson, Gauti B., and Paul Krugman. 2012. "Debt, Deleveraging, and the Liquidity Trap: A Fisher-Minsky-Koo Approach." Quarterly Journal of Economics, 127(3): 1469-1513.

Eggertsson, Gauti B., and Sanjay R. Singh. 2016. "Log-linear Approximation versus an Exact Solution at the ZLB in the New Keynesian Model." National Bureau of Economic Research 22784. 
Eggertsson, Gauti B., Neil R. Mehrotra, Sanjay R. Singh, and Lawrence H. Summers. 2016. "A Contagious Malady? Open Economy Dimensions of Secular Stagnation." IMF Economic Review, 64(4): 581-634.

Elsby, Michael, Bart Hobijn, and Ayşegül Şahin. 2013. "The Decline of the US Labor Share." Brookings Papers on Economic Activity, 44(2): 1-63.

Fagan, Gabriel, and Julián Messina. 2009. “Downward Wage Rigidity and Optimal Steady-State Inflation." ECB Working Paper.

Fallick, Bruce, Michael Lettau, and William Wascher. 2011. “Downward Nominal Wage Rigidity in the United States During the Great Recession." Mimeo, Federal Reserve Board.

Fernald, John. 2012. "A Quarterly, Utilization-adjusted Series on Total Factor Productivity." Mimeo. Federal Reserve Bank of San Francisco.

FOMC. 2016. "Economic Projections of the FOMC."

Gagnon, Etienne, Benjamin K. Johannsen, and David Lopez-Salido. 2016. “Understanding the New Normal: The Role of Demographics." Mimeo. Federal Reserve Board.

Galí, Jordi. 2014. "Monetary Policy and Rational Asset Price Bubbles." American Economic Review, 104(3): 721-752.

Galí, Jordi. 2015. Monetary Policy, Inflation, and the Business Cycle. . 2nd ed., Princeton University Press.

Garga, Vaishali, and Sanjay R. Singh. 2016. "Output Hysteresis and Optimal Monetary Policy." Mimeo. Brown University.

Gibbs, Christopher. 2017. "Learning to Believe in Secular Stagnation." Mimeo. University of New South Wales.

Glover, Andrew, Jonathan Heathcote, Dirk Krueger, and José-Víctor Ríos-Rull. 2011. “Intergenerational Redistribution in the Great Recession." National Bureau of Economic Research 16924.

Golosov, Mikhail, and Robert E. Lucas. 2007. "Menu Costs and Phillips Curves." Journal of Political Economy, 115(2): 171-199.

Gomme, Paul, B. Ravikumar, and Peter Rupert. 2015. "Secular Stagnation and Returns on Capital." Federal Reserve Bank of St. Louis Economic Synopses, , (19).

Goos, Maarten, Alan Manning, and Anna Salomons. 2009. "Job Polarization in Europe." American Economic Review, 99(2): 58-63. 
Gordon, Robert J. 2012. "Is US Economic Growth Over? Faltering Innovation Confronts the Six Headwinds." National Bureau of Economic Research 18315.

Gordon, Robert J. 2015. "Secular Stagnation: A Supply-Side View." American Economic Review, Papers and Proceedings, 105(5): 54-59.

Gordon, Robert J. 2016. The Rise and Fall of American Growth: The US Standard of Living Since the Civil War. Princeton University Press.

Gourinchas, Pierre-Olivier, and Jonathan A. Parker. 2002. "Consumption Over the Life Cycle." Econometrica, 70(1): 47-89.

Greenwood, Jeremy, Zvi Hercowitz, and Per Krusell. 1997. "Long-run Implications of Investment-Specific Technological Change." American Economic Review, 87(3): 342-362.

Guerrieri, Veronica, and Guido Lorenzoni. 2011. "Credit Crises, Precautionary Savings, and the Liquidity Trap." National Bureau of Economic Research 17583.

Hall, Robert E. 2016. “The Anatomy of Stagnation in a Modern Economy." Economica, 84(333): 115.

Hansen, Alvin. 1939. "Economic Progress and Declining Population Growth." American Economic Review, 29(1): 1-15.

Hausman, Joshua K., and Johannes F. Wieland. 2014. “Abenomics: Preliminary Analysis and Outlook." Brookings Papers on Economic Activity, 45(1): 1-63.

Hendricks, Lutz. 2001. "Bequests and Retirement Wealth in the United States." Mimeo. Arizona State University.

Herrendorf, Berthold, Christopher Herrington, and Akos Valentinyi. 2015. "Sectoral Technology and Structural Transformation." American Economic Journal: Macroeconomics, 7(4): 104-133.

Hur, Sewon. 2016. “The Lost Generation of the Great Recession.” Mimeo. University of Pittsburgh.

Iacoviello, Matteo, and Marina Pavan. 2013. "Housing and Debt over the Life Cycle and Over the Business Cycle." Journal of Monetary Economics, 60(2): 221-238.

Jorgenson, Dale W. 1996. “Empirical Studies of Depreciation.” Economic Inquiry, 34(1): $24-42$.

Kaplan, Greg. 2012. “Inequality and the Life Cycle.” Quantitative Economics, 3(3): 471-525.

Karabarbounis, Loukas, and Brent Neiman. 2014. "The Global Decline of the Labor Share." Quarterly Journal of Economics, 129(1): 61-103. 
Kim, Jinill, and Francisco J. Ruge-Murcia. 2009. "How Much Inflation is Necessary to Grease the Wheels?" Journal of Monetary Economics, 56(3): 365-377.

Klump, Rainer, Peter McAdam, and Alpo Willman. 2007. "Factor Substitution and Factoraugmenting Technical Progress in the United States." Review of Economics and Statistics, 89(1): 183-192.

Kocherlakota, Naryana. 2013. "Impact of a Land Price Fall when Labor Markets are Incomplete." Mimeo, Federal Reserve Bank of Minneapolis.

Krueger, Dirk, and Felix Kubler. 2006. "Pareto-Improving Social Security Reform when Financial Markets are Incomplete!?" American Economic Review, 96(3): 737-755.

Krugman, Paul R. 1998. “It's Baaack: Japan's Slump and the Return of the Liquidity Trap." Brookings Papers on Economic Activity, 29(2): 137-205.

Krugman, Paul R. 2014. “The Timidity Trap." The New York Times.

Krusell, Per, and Anthony A. Smith. 1998. "Income and Wealth Heterogeneity in the Macroeconomy." Journal of Political Economy, 106(5): 867-896.

Krusell, Per, Lee E. Ohanian, José-Víctor Ríos-Rull, and Giovanni L. Violante. 2000. “Capitalskill Complementarity and Inequality: A Macroeconomic Analysis." Econometrica, 68(5): 1029_ 1053.

Malthus, Thomas R. 1798. An Essay on the Principle of Population. J. Johnson, London.

Mankiw, N. Gregory, David Romer, and David N. Weil. 1992. "A Contribution to the Empirics of Economic Growth." Quarterly Journal of Economics, 107(2): 407-437.

McGrattan, Ellen R., and Edward C. Prescott. 2010. “Unmeasured Investment and the Puzzling US Boom in the 1990s." American Economic Journal: Macroeconomics, 2(4): 88-123.

McKay, Alisdair, Emi Nakamura, and Jón Steinsson. 2016. “The Power of Forward Guidance Revisited." American Economic Review, 106(10): 3133-3158.

Mehrotra, Neil. 2017. "Fiscal Policy Stabilization: Purchases or Transfers?" International Journal of Central Banking, Forthcoming.

Mian, Atif, and Amir Sufi. 2014. "What Explains the 2007-2009 Drop in Employment?" Econometrica, 82(6): 2197-2223.

Midrigan, Virgiliu. 2011. "Menu Costs, Multiproduct Firms and Aggregate Fluctuations." Econometrica, 79(4): 1139-1180. 
Nadiri, M. Ishaq, and Ingmar R. Prucha. 1996. "Estimation of the Depreciation Rate of Physical and R\&D Capital in the US Total Manufacturing Sector." Economic Inquiry, 34(1): 43-56.

Nakamura, Emi, and Jon Steinsson. 2009. "Monetary Non-Neutrality in a Multi-Sector Menu Cost Model." Quarterly Journal of Economics, 125(3): 961-1013.

Oberfield, Ezra, and Devesh Raval. 2014. "Micro Data and Macro Technology." National Bureau of Economic Research 20452.

Philippon, Thomas, and German Gutierrez. 2016. "Investment-less Growth: An Empirical Investigation." National Bureau of Economic Research 22897.

Piketty, Thomas. 2014. Capital in the 21st Century. Harvard University Press.

Ríos-Rull, José-Víctor. 1996. "Life-cycle Economies and Aggregate Fluctuations." Review of Economic Studies, 63(3): 465-489.

Ríos-Rull, José-Víctor, and Virginia Sánchez-Marcos. 2008. "An Aggregate Economy with Different Size Houses." Journal of the European Economic Association, 6(2-3): 705-714.

Samuelson, Paul A. 1958. "An Exact Consumption-Loan Model of Interest With or Without the Social Contrivance of Money." Journal of Political Economy, 66(6): 467-482.

Schmitt-Grohé, Stephanie, and Martin Uribe. 2011. "Pegs and Pain." National Bureau of Economic Research 16847. National Bureau of Economic Research.

Schmitt-Grohé, Stephanie, and Martın Uribe. 2013. "The Making of a Great Contraction with a Liquidity Trap and a Jobless Recovery." Mimeo, Columbia University.

Schmitt-Grohé, Stephanie, and Martın Uribe. 2016. “Downward Nominal Wage Rigidity, Currency Pegs, and Involuntary Unemployment." Journal of Political Economy, 124(5): 1466-1514.

Schmitt-Grohé, Stephanie, and Martin Uribe. 2017. "Liquidity Traps and Jobless Recoveries." American Economic Journal: Macroeconomics, 9(1): 165-204.

Shimer, Robert. 2012. "Wage Rigidities and Jobless Recoveries." Journal of Monetary Economics, 59(S): S65-S77.

Stock, James H., and Mark W. Watson. 2012. "Disentangling the Channels of the 2007-2009 Recession." National Bureau of Economic Research 18904.

Summers, Lawrence. 2013. "Why Stagnation Might Prove to be the New Normal." The Financial Times. 
Summers, Lawrence H. 2014. “US Economic Prospects: Secular Stagnation, Hysteresis, and the Zero Lower Bound." Business Economics, 49(2): 65-73.

Thwaites, Gregory. 2015. "Why are Real Interest Rates so Low? Secular Stagnation and the Relative Price of Investment Goods." Mimeo. London School of Economics.

Tobin, James. 1972. "Inflation and Unemployment." American Economic Review, 62(1/2): 1-18.

Werning, Ivan. 2012. "Managing a Liquidity Trap: Monetary and Fiscal Policy." Mimeo, Massachusetts Institute of Technology.

Williams, John C. 2016. "Monetary Policy in a Low R-star World." Federal Reserve Bank of San Francisco Economic Letter, 23.

Woodford, Michael. 1990. "Public Debt as Private Liquidity." American Economic Review, 80(2): 382-388.

Woodford, Michael. 2003. Interest and Prices: Foundations of a Theory of Monetary Policy. Princeton University Press. 


\title{
Online Appendix for
}

\section{A Model of Secular Stagnation: Theory and Quantitative Evaluation}

\author{
Gauti B. Eggertsson, Neil R. Mehrotra, Jacob A. Robbins
}

\section{A Derivation of Simple Model}

\section{A.1 Households' Problem}

In this section, we specify and solve the household's problem in the general case of income received in all periods and taxes paid in all periods. For household $i$, the objective function and budget constraints are given below:

$$
\begin{gathered}
\max _{C_{t}(i), C_{t+1}(i), C_{t+2}(i)} \mathbb{E}_{t}\left\{\log \left(C_{t}(i)\right)+\beta \log \left(C_{t+1}(i)\right)+\beta^{2} \log \left(C_{t+2}(i)\right)\right\} \\
\text { s.t. } \quad C_{t}(i)=w_{t} L_{t}(i)-T_{t}^{y}+B_{t}(i) \\
C_{t+1}(i)=Z_{t}+w_{t+1} L_{t+1}(i)-T_{t+1}^{m}+B_{t+1}(i)-\frac{\left(1+i_{t}\right)}{\Pi_{t+1}} B_{t}(i) \\
C_{t+2}(i)=w_{t+2} L_{t+2}(i)-T_{t+2}^{o}-\frac{\left(1+i_{t+1}\right)}{\Pi_{t+2}} B_{t+1}(i) \\
B_{t+j}(i) \leq \mathbb{E}_{t+j}\left(1+r_{t+j+1}\right) D_{t+j} \quad \text { for } j=0,1,
\end{gathered}
$$

where the household $i$ has exogenous labor supply endowments in each period of life, $D_{t+j}$ is an exogenous collateral constraint, and $T_{t+j}$ are lump-sum taxes imposed by the government. We allow taxes to differ across household types and taxes to change over time.

We restrict ourselves to cases in which the collateral constraint is binding in the first period of life and possibly binding in the second period of life. In particular, we will assume two types of households - a household that has sufficiently low labor endowment in its middle period of life and remains credit constrained, and a household that has sufficiently high labor endowment in its middle period of life and is unconstrained. For the former, borrowing in the young and middleaged generations is determined by the binding collateral constraints. For the latter, borrowing is determined by the collateral constraint only while young; in the middle-aged generation, an Euler equation determines the optimal level of saving:

$$
\frac{1}{C_{t}^{m, h}}=\beta \mathbb{E}_{t} \frac{1+i_{t}}{\Pi_{t+1} C_{t+1}^{o, h}} .
$$

Let $L^{y}$ be the labor endowment for the young generation, $L^{m, l}$ be the labor endowment for the poor middle-generation household, $L^{m, h}$ the labor endowment for the wealthy middle-generation household, and $L^{o}$ the labor endowment in the last period. We adopt the normalization that 
$L^{y}+\eta_{s} L^{m, l}+\left(1-\eta_{s}\right) L^{m, h}+L^{o}=1$. The budget constraints for each type of household alive at any point in time are given below:

$$
\begin{aligned}
C_{t}^{y} & =\alpha Y_{t} \frac{L^{y}}{L_{t}^{f l e x}}-T_{t}^{y}+\mathbb{E}_{t} \Pi_{t+1} \frac{D_{t}}{1+i_{t}} \\
C_{t}^{m, l} & =\alpha Y_{t} \frac{L^{m, l}}{L_{t}^{\text {flex }}}+(1-\alpha) Y_{t}-T_{t}^{m}-D_{t-1}+\mathbb{E}_{t} \Pi_{t+1} \frac{D_{t}}{1+i_{t}} \\
C_{t}^{m, h} & =\alpha Y_{t} \frac{L^{m, h}}{L_{t}^{f l e x}}+(1-\alpha) Y_{t}-T_{t}^{m}-D_{t-1}-B_{t}^{m, h} \\
C_{t}^{o, l} & =\alpha Y_{t} \frac{L^{o}}{L_{t}^{\text {flex }}}-T_{t}^{o}-D_{t-1} \\
C_{t}^{o, h} & =\alpha Y_{t} \frac{L^{o}}{L_{t}^{\text {flex }}}-T_{t}^{o}+B_{t-1}^{m, h} \frac{1+i_{t-1}}{\Pi_{t}},
\end{aligned}
$$

where $T_{t}^{i}$ are lump-sum taxes per capita and $Y_{t}$ is output per middle-generation household. ${ }^{64}$ Aggregate consumption in this economy is given by the following expression:

$$
C_{t}=N_{t} C_{t}^{y}+N_{t-1}\left(\eta_{s} C_{t}^{m, l}+\left(1-\eta_{s}\right) C_{t}^{m, h}\right)+N_{t-2}\left(\eta_{s} C_{t}^{o, l}+\left(1-\eta_{s}\right) C_{t}^{o, h}\right) .
$$

\section{A.2 Firms' Problem, Labor Supply, and Wage Determination}

In this section, we specify the firm's problem in the baseline case with no capital accumulation. Firms choose labor to maximize profits subject to a standard decreasing returns to scale production function, taking wages as given:

$$
\begin{aligned}
& Z_{t}=\max _{L_{t}} P_{t} Y_{t}-W_{t} L_{t}^{d} \\
\text { s.t. } \quad Y_{t} & =A_{t}\left(L_{t}^{d}\right)^{\alpha},
\end{aligned}
$$

where $L_{t}^{d}$ is the firm's labor demand. Firms' labor demand is determined by equating the real wage to the marginal product of labor:

$$
\frac{W_{t}}{P_{t}}=\alpha A_{t}\left(L_{t}^{d}\right)^{\alpha-1}
$$

Each middle-generation household operates a firm and collects profits from its operation. The total measure of firms in the economy is $N_{t-1}$ and therefore grows with the total population. All firms are identical, sharing the same labor share parameter $\alpha$.

Labor supply is exogenous and fixed over a household's lifetime. When population is constant $(g=0)$, then labor supply is constant and can be normalized to unity. In the absence of downward nominal wage rigidity, the real wage equalizes labor supply to labor demand:

$$
\left(N_{t} L^{y}+N_{t-1}\left(\eta_{s} L^{m, l}+\left(1-\eta_{s}\right) L^{m, h}\right)+N_{t-2} L^{o}\right)=N_{t-1} L_{t}^{f l e x},
$$

\footnotetext{
${ }^{64}$ Output is not expressed in per capita terms to avoid a proliferation of population growth rate terms. In this economy, aggregate output is $N_{t-1} Y_{t}$ while the total population is $N_{t}+N_{t-1}+N_{t-2}$.
} 
where $w_{t}^{f l e x}$ defines the market-clearing real wage.

In the presence of downward nominal wage rigidity, the real wage may exceed the marketclearing real wage. In this case, labor is rationed with a proportional reduction in labor employed across all households (i.e., if total labor demand is $10 \%$ below the full-employment level, then labor falls $10 \%$ for all cohorts).

We assume that nominal wages are downwardly rigid, implying that real wages exceed the market-clearing level in the presence of deflation. The process determining the real wage is given below:

$$
W_{t}=\max \left\{\tilde{W}_{t}, P_{t} w_{t}^{f l e x}\right\} \text { where } \tilde{W}_{t}=\gamma W_{t-1}+(1-\gamma) P_{t} w_{t}^{f l e x}
$$

\section{A.3 Monetary and Fiscal Policy}

Monetary and fiscal policies are straightforward. We assume a monetary policy rule of the following form:

$$
1+i_{t}=\max \left(1,\left(1+i^{*}\right)\left(\frac{\Pi_{t}}{\Pi^{*}}\right)^{\phi_{\pi}}\right),
$$

where $i^{*}$ is the targeted natural rate and $\Pi^{*}$ is the central bank's gross inflation target. If the central bank has the correct natural rate target $i^{*}$, then inflation is stabilized at $\Pi=1$ in steady state.

Taxation is determined by the government's budget constraint and exogenous processes for government spending, the public debt, and taxation of young households. We typically assume that the ratio of taxes between the old and middle-aged households satisfies the following rule:

$$
T_{t}^{o}=\beta \frac{1+i_{t-1}}{\Pi_{t}} T_{t}^{m}
$$

In steady state, this fiscal rule ensures that changes in taxation have no effect on loan supply. We consider exceptions to this fiscal rule where taxes are levied only on old or middle-aged households, respectively. The government's budget constraint, together with the fiscal rule, determines $T_{t}^{m}$ and $T_{t}^{o}$ in response to the other exogenous fiscal processes:

$$
B_{t}^{g}+T_{t}^{y}\left(1+g_{t}\right)+T_{t}^{m}+\frac{1}{1+g_{t-1}} T_{t}^{o}=G_{t}+\frac{1}{1+g_{t-1}} \frac{1+i_{t-1}}{\Pi_{t}} B_{t-1}^{g},
$$

where all fiscal variables are all normalized in terms of middle-generation quantities.

\section{A.4 Market Clearing and Equilibrium}

Asset market clearing requires that total lending from savers equals total borrowing from creditconstrained young households and poor middle-generation households. This condition is given 
below:

$$
\begin{aligned}
\left(1-\eta_{s}\right) N_{t-1} B_{t}^{m, h} & =N_{t} \frac{D_{t}}{1+r_{t}}+\eta_{s} N_{t-1} \frac{D_{t}}{1+r_{t}} \\
\left(1-\eta_{s}\right) B_{t}^{m, h} & =\left(1+g_{t}+\eta_{s}\right) \frac{D_{t}}{1+r_{t}} .
\end{aligned}
$$

It can be verified that asset market clearing implies that aggregate consumption equals aggregate output less aggregate government purchases:

$$
C_{t}=N_{t-1} Y_{t}-\left(N_{t}+N_{t-1}+N_{t-2}\right) G_{t}
$$

A competitive equilibrium is a set of aggregate allocations $\left\{Y_{t}, C_{t}^{m, h}, C_{t}^{o, h}, B_{t}^{m, h}, L_{t}^{f l e x}, T_{t}^{m}, T_{t}^{o}\right\}_{t=0}^{\infty}$, price processes $\left\{i_{t}, \Pi_{t}, w_{t}, w_{t}^{\text {flex }}\right\}_{t=0}^{\infty}$, exogenous processes $\left\{G_{t}, g_{t}, D_{t}, T_{t}^{y}, B_{t}^{g}\right\}_{t=0}^{\infty}$ and initial values of household saving, nominal interest rate, real wage, and the public debt $\left\{B_{-1}^{m, h}, i_{-1}, w_{-1}, B_{-1}\right\}$ that jointly satisfy:

1. Household Euler equation (A.6)

2. Household budget constraints $(A .9)$ and (A.11)

3. Asset market clearing $(A .21)$

4. Fiscal policy rule $(A .18)$

5. Government budget constraint (A.19)

6. Monetary policy rule $(A .17)$

7. Full-employment labor supply (A.15)

8. Full-employment wage rate: $w_{t}^{\text {flex }}=\alpha A_{t}\left(L_{t}^{\text {flex }}\right)^{\alpha-1}$

9. Labor demand condition: $w_{t}=\alpha A_{t}\left(\frac{Y_{t}}{A_{t}}\right)^{\frac{\alpha-1}{\alpha}}$

10. Wage process: $w_{t}=\max \left\{\tilde{w}_{t}, w_{t}^{\text {flex }}\right\}$, where $\tilde{w}_{t}=\gamma \frac{w_{t-1}}{\Pi_{t}}+(1-\gamma) w_{t}^{\text {flex }}$

\section{B Inequality and the Natural Rate}

There is no general result about how an increase in inequality affects the real rate of interest. This relationship will depend on how changes in income affect the relative supply and demand for loans. Here we show a simple example illustrating that there are relatively plausible conditions under which higher inequality will in fact reduce the natural rate of interest. 
Consider first one form of income inequality, that of inequality across generations. As we have seen in (11), the relative endowment of the old versus the middle-aged generation affects the real interest rate; moving resources from the old to the middle-aged will increase savings and thereby put downward pressure on the real interest rate. The conclusion here is that redistribution that raises savings increases downward pressure on the real rate. Consider now the alternative: If all generations receive the same endowment $Y_{t}^{y}=Y_{t}^{m}=Y_{t}^{o}$, then it is easy to see that there is no incentive to borrow or lend, and, accordingly, the real interest rate is equal to the inverse of the discount factor $1+r_{t}=\beta^{-1}$. It is thus inequality of income across generations that is responsible for our results and triggers possibly negative real interest rates.

Generational inequality, however, is typically not what people have in mind when considering inequality; instead, commentators often focus on unequal income of individuals within the working-age population. This type of inequality can also have a negative effect on the real interest rate. Before getting there, however, let us point out that this need not be true in all cases. Consider, for example, an endowment distribution $Y_{t}(z)$, where $z$ denotes the type of an individual who is known once he is born. Suppose further that once again $Y_{t}^{y}(z)=Y_{t}^{m}(z)=Y_{t}^{o}(z)$ for all $z$. Once again, income is perfectly smoothed across ages and the real interest rate is given by $\beta^{-1}$. The point is that we can choose any distribution of income $Y(z)$ to support that equilibrium so, in this case, income distribution is irrelevant for the type of preferences we have assumed. ${ }^{65}$

Let us now consider the case when inequality in a given cohort can in fact generate negative pressure on real interest rates. When authors attribute demand slumps to a rise in inequality, they typically have in mind - in the language of old Keynesian models - that income gets redistributed from those with a high propensity for consumption to those who instead wish to save their income. We have already seen how this mechanism works in the case of inequality across generations. But we can also imagine that a similar mechanism applies if income gets redistributed within a cohort as long as some of the agents in that cohort are credit constrained.

Again, let us assume that only the middle-aged and old generations receive an income endowment. Now, however, suppose that some fraction of households receives a larger endowment in their middle years (i.e., high-income households) while the remaining households (i.e., lowincome households) receive a very small endowment in the middle period of life. For simplicity, all households receive the same income endowment in old age (this could be thought of as some sort of state-provided pension like Social Security). For sufficiently low levels of the middle-period endowment and a sufficiently tight credit constraint, low-income households will remain credit constrained in the middle period of life. These households will roll over their debt in the middle years and repay their debts only in old age, consuming any remaining endowment. In this situation, only the high-income households will save in the middle period and will, therefore, supply savings to both credit-constrained middle-aged households and the youngest generation.

\footnotetext{
${ }^{65}$ More general preference specifications, however, can easily make a difference.
} 
As before, we can derive an explicit expression for the real interest rate in this richer setting with multiple types of households. Under the conditions described above, the only operative Euler equation is for the high-income households who supply loans in equilibrium. The demand for loans is obtained by adding together the demand from young households and from the credit constrained low-income households. The expression we obtain is a generalization of the case obtained in equation (11):

$$
1+r_{t}=\frac{1+\beta}{\beta} \frac{\left(1+g_{t}+\eta_{s}\right) D_{t}}{\left(1-\eta_{s}\right)\left(Y_{t}^{m, h}-D_{t-1}\right)}+\frac{1}{\beta} \frac{Y_{t+1}^{o}}{\left(Y_{t}^{m, h}-D_{t-1}\right)},
$$

where $\eta_{s}$ is the fraction of low-income households, $Y_{t}^{m, h}$ is the income of the high-income middle generation, and $Y_{t+1}^{o}$ is the income of these households in the next period (i.e., the pension income received by all households). If $\eta_{s}=0$, we recover the expression for the real interest rate derived in (11).

Total income for the middle-aged generation is a weighted-average of high-and low-income workers: $Y_{t}^{m}=\eta_{s} Y_{t}^{m, l}+\left(1-\eta_{s}\right) Y_{t}^{m, h}$. Let us then define an increase in inequality as a redistribution of middle-generation income from low-to high-income workers, without any change in $Y_{t}^{m}$. While this redistribution keeps total income for the middle generation constant by definition, it must necessarily lower the real interest rate by increasing the supply of savings, which is only determined by the income of the wealthy. This can be seen in equation $(A .23)$, where the real interest rate is decreasing in $Y_{t}^{m, h}$ without any offsetting effect via $Y_{t}^{m, l}{ }^{66}$

As this extension of our model suggests, the secular rise in wage inequality in recent decades in the US and other developed nations may have been one factor in exerting downward pressure on the real interest rate. Labor market polarization - the steady elimination of blue-collar occupations and the consequent downward pressure on wages for a large segment of the labor force - could show up as increase in income inequality among the working-age population, lowering the real interest rate in the manner described here (for evidence on labor market polarization, see, e.g., Autor and Dorn (2013) and Goos, Manning and Salomons (2009)). Several other theories have been suggested for the rise in inequality. To the extent that they imply an increase in savings, they could fit into our story as well.

\footnotetext{
${ }^{66}$ As emphasized earlier, not all forms of income inequality should be expected to have a negative effect on the real interest rate. If middle-generation income is drawn from a continuous distribution, a mean-preserving spread that raises the standard deviation of income could be expected to have effects on both the intensive and extensive margin. That is, the average income among savers would rise, but this effect would be somewhat offset by an increase in the fraction of credit-constrained households (i.e, an increase in $\eta_{s}$ ). The extensive margin boosts the demand for loans and would tend to increase the real interest rate. Whether inequality raises or lowers rates would depend on the relative strength of these effects.
} 


\section{Linearization and Solution}

In this section, we detail the linearization and general solution to the model without capital but with income received in all periods. For simplicity, we do not consider the effect of population growth shocks, which greatly complicate the linearization and the computation of analytical solutions.

The generalized model with income received in all three periods and credit-constrained middleaged households can be summarized by the following linearized AD curve and linearized AS curve:

$$
\begin{aligned}
i_{t} & =E_{t} \pi_{t+1}-s_{y}\left(y_{t}-g_{t}\right)+\left(1-s_{w}\right) E_{t}\left(y_{t+1}-g_{t+1}\right)+s_{w} d_{t}+s_{d} d_{t-1} \\
y_{t} & =\gamma_{w} y_{t-1}+\gamma_{w} \frac{\alpha}{1-\alpha} \pi_{t},
\end{aligned}
$$

where various coefficients are given in terms of their steady-state values:

$$
\begin{aligned}
\gamma_{w} & =\frac{\gamma}{\bar{\pi}} \\
s_{y} & =\frac{\bar{Y}_{m, h}}{\bar{Y}_{m, h}-\bar{D}} \\
s_{d} & =\frac{\bar{D}}{\bar{Y}_{m, h}-\bar{D}} \\
s_{w} & =\frac{1+\beta}{\beta} \frac{\left(1+\bar{g}+\eta_{s}\right) \bar{D}}{\bar{i} / \bar{\pi}\left(\bar{Y}_{m, h}-\bar{D}\right)} .
\end{aligned}
$$

The exogenous shocks are the collateral shock $d_{t}$ and the government spending shock $g_{t}$, which means that a solution to this linear system takes the form:

$$
\begin{aligned}
& y_{t}=\beta_{y} y_{t-1}+\beta_{g} g_{t}+\beta_{d} d_{t}+\beta_{d, l} d_{t-1} \\
& \pi_{t}=\alpha_{y} y_{t-1}+\alpha_{g} g_{t}+\alpha_{d} d_{t}+\alpha_{d, l} d_{t-1} .
\end{aligned}
$$

Solving by the method of undetermined coefficients, we obtain the following expressions for the coefficients that determine equilibrium output and inflation in response to collateral and gov- 
ernment spending shocks:

$$
\begin{aligned}
\beta_{y} & =0 \\
\alpha_{y} & =-\frac{1-\alpha}{\alpha} \\
\beta_{d, l} & =\frac{s_{d}}{s_{y}+\frac{1-\alpha}{\alpha}} \\
\alpha_{d, l} & =\frac{1-\alpha}{\gamma_{w} \alpha} \beta_{d, l} \\
\beta_{d} & =\frac{s_{w}+\beta_{d, l}\left(\frac{1-\alpha}{\gamma_{w} \alpha}+\left(1-s_{w}\right)\right)}{s_{y}+\left(1-s_{w}\right) \rho_{d}+\frac{1-\alpha}{\alpha}\left(1-1 / \gamma_{w} \rho_{d}\right)} \\
\alpha_{d} & =\frac{1-\alpha}{\gamma_{w} \alpha} \beta_{d} \\
\beta_{g} & =\frac{s_{y}+\left(1-s_{w}\right) \rho_{g}}{s_{y}+\left(1-s_{w}\right) \rho_{g}+\frac{1-\alpha}{\alpha}\left(1-1 / \gamma_{w} \rho_{g}\right)} \\
\alpha_{g} & =\frac{1-\alpha}{\gamma_{w} \alpha} \beta_{g} .
\end{aligned}
$$

By substituting (A.25) into (A.24), we can obtain a first-order difference equation in output. This forward-looking difference equation implies that inflation and output will be determinate if and only if the following condition obtains:

$$
s_{y}-\left(1-s_{w}\right)>\frac{1-\alpha}{\alpha} \frac{1-\gamma_{w}}{\gamma_{w}} .
$$

When $s_{w}=1$, this condition is the same determinacy condition as discussed in the main text. When the above condition holds, there is a unique rational expectations equilibrium in the deflation steady state. The left-hand side is always positive, so in the case of perfect price rigidity (i.e., $\left.\gamma_{w}=1\right)$, this condition is satisfied and the deflation steady state is locally unique.

\section{Properties of Secular Stagnation Equilibrium}

Here we provide a formal proof for various properties of the secular stagnation equilibrium described in the body of the text.

Proposition 1. If $\gamma>0, \Pi^{*}=1$, and $i^{*}=r^{f}<0$, then there exists a unique determinate secular stagnation equilibrium.

Proof. Under the assumptions of the proposition, the inflation rate at which the zero lower bound binds, given in equation (30), is strictly greater than unity. Let $Y_{A D}$ denote the level of output implied by the aggregate demand relation and $Y_{A S}$ denote the level of output implied by the 
aggregate supply relation. For gross inflation rates less than unity, $Y_{A D}$ and $Y_{A S}$ are given by

$$
\begin{array}{r}
Y_{A D}=D+\psi \Pi \\
Y_{A S}=\left(\frac{1-\frac{\gamma}{\Pi}}{1-\gamma}\right)^{\frac{\alpha}{1-\alpha}} Y^{f}
\end{array}
$$

where $\psi=\frac{1+\beta}{\beta}(1+g) D>0$. The AD curve is upward sloping because $\Pi<1<\Pi_{k i n k}$ under our assumptions and, therefore, the zero lower bound binds.

When $\Pi=\gamma, Y_{A D}>Y_{A S}=0$. When $\Pi=1$, the real interest rate equals $\Pi^{-1}=1>r^{f}$. Thus, when $\Pi=1, Y_{A D}<Y^{f}$. Furthermore, from the equations above, when $\Pi=1, Y_{A S}=Y^{f}$. Therefore, it must be the case that $Y_{A D}<Y_{A S}$ when $\Pi=1$. Since the AS and AD curves are both continuous functions of inflation, it must be the case that there exists a $\Pi_{s s}$ at which $Y_{A D}=Y_{A S}$.

To establish uniqueness, we first assume that there exist multiple distinct values of $\Pi_{s s}$ at which $Y_{A D}=Y_{A S}$. In inflation-output space (output on the x-axis), the AS curve lies above the AD curve when inflation equals $\gamma$ and the AS curve lies below the AD curve for inflation at unity - see equation (27). Thus, if multiple steady states exist, given that AS is a continuous function, there must exist at least three distinct points at which the AS and AD curves intersect.

At the first intersection point, the slope of the AS curve crosses the AD line from above and, therefore, at the second intersection the AS curve crosses the AD curve from below. Since the AD curve is a line, the AS curve as a function of output is locally convex in this region. Similarly, between the second and third intersections, the AS curve is locally concave. Thus, given an increase in $Y$, the AS curve must first have a positive second derivative followed by a negative second derivative.

We compute the second derivative of inflation with respect to output of the AS curve and derive the following expression:

$$
\begin{aligned}
\frac{d^{2} \Pi}{d Y^{2}} & =G(Y)\left((1+\phi)(1-\gamma)\left(\frac{Y}{Y^{f}}\right)^{\phi}+(\phi-1)\right) \\
G(Y) & =\frac{\phi \gamma(1-\gamma)\left(\frac{Y}{Y^{f}}\right)^{\phi}}{Y^{2}\left(1-(1-\gamma)\left(\frac{Y}{Y^{f}}\right)^{\phi}\right)} \\
\phi & =\frac{1-\alpha}{\alpha} .
\end{aligned}
$$

As can be seen, over the region considered, the function $G(Y)$ is positive and, therefore, the convexity of the AS curve is determined by the second term. This term may be negative if $\phi<1$, but this expression is increasing in $Y$ between 0 and $Y_{f}$. Therefore, the second derivative cannot switch signs from positive to negative. Thus, we have derived a contradiction by assuming multiple steady states. Therefore, there must exist a unique intersection point.

As established before, it must be the case that the AS curve has a lower slope than the AD 
curve at the point of intersection. The slope of the AS curve is

$$
\frac{d \Pi}{d Y}=\frac{1-\alpha}{\alpha} \frac{1}{\gamma} \frac{\Pi}{Y}(\Pi-\gamma) .
$$

If the slope of the AS curve is less than the slope of the AD curve at the intersection point, then it must be the case that

$$
\begin{aligned}
\frac{1-\alpha}{\alpha} \frac{\Pi}{Y}\left(\frac{\Pi}{\gamma}-1\right) & <\psi^{-1} \\
\frac{1-\alpha}{\alpha} \frac{\psi \Pi}{Y}\left(\frac{\Pi}{\gamma}-1\right) & <1 \\
\frac{1-\alpha}{\alpha} \frac{Y-D}{Y}\left(\frac{\Pi}{\gamma}-1\right) & <1 \\
s_{y} \frac{\alpha}{1-\alpha}+1 & >\frac{\Pi}{\gamma} \\
\frac{\gamma}{\Pi}\left(s_{y} \frac{\alpha}{1-\alpha}+1\right) & >1 .
\end{aligned}
$$

The last inequality here is precisely the condition for determinacy discussed in Section 6. Thus, the unique secular stagnation steady state is always determinate as required.

\section{E Calvo Pricing}

In this section, we modify the aggregate supply block of our model to consider product market frictions instead of downward nominal wage rigidity. As in our baseline model, we assume that middle-aged households supply a constant level of labor $\bar{L}$. However, wages adjust frictionlessly to ensure that labor is fully employed in all periods.

Monopolistically competitive firms produce a differentiated good $l$ and set nominal prices periodically. Households consume a Dixit-Stiglitz aggregate of these differentiated goods, implying that each firm faces the following demand schedule:

$$
\begin{aligned}
y_{t}(l) & =Y_{t}\left(\frac{p_{t}(l)}{P_{t}}\right)^{-\theta} \\
P_{t} & =\left(\int p_{t}^{1-\theta} d l\right)^{\frac{1}{1-\theta}},
\end{aligned}
$$

where $\theta$ is the elasticity of substitution in the Dixit-Stiglitz aggregator and $P_{t}$ is the price level of the consumption bundle consumed by households. Production depends only on labor, and labor market clearing requires total labor demand to equal labor supply:

$$
\begin{aligned}
y_{t}(l) & =L_{t}(l) \\
\bar{L} & =\int L_{t}(l) d l .
\end{aligned}
$$


Combining labor market clearing with the demand for each product $(A .44)$, we can derive an expression for output in terms of exogenous labor supply and a term that reflects losses due to misallocation from pricing frictions:

$$
\begin{aligned}
Y_{t} & =\frac{\bar{L}}{\Delta_{t}} \\
\Delta_{t} & =\int\left(\frac{p_{t}(l)}{P_{t}}\right)^{-\theta} d l,
\end{aligned}
$$

Under Calvo pricing, firms are periodically able to reset their prices and will choose a single optimal reset price irrespective of the time since their last price change. Under the Calvo assumption, we can derive dynamic expressions for inflation and the misallocation term $\Delta_{t}$ in terms of the reset price $p_{t}^{*}$ :

$$
\begin{gathered}
1=\chi \Pi_{t}^{\theta-1}+(1-\chi)\left(\frac{p_{t}^{*}}{P_{t}}\right)^{1-\theta} \\
\Delta_{t}=\chi \Pi_{t}^{\theta} \Delta_{t-1}+(1-\chi)\left(\frac{p_{t}^{*}}{P_{t}}\right)^{-\theta},
\end{gathered}
$$

where $\chi$ is the Calvo parameter - the fraction of firms that do not adjust prices in the current period. Equations (A.46), (A.48), and (A.49) collectively define the aggregate supply block of the model with monopolistic competition and price friction. The IS curve and monetary policy rule close the model.

We can derive the long-run Phillips curve by combining the steady-state cases of equations (A.46), (A.48), and (A.49). The steady-state AS curve is given below:

$$
Y=\bar{L} \frac{1-\chi \Pi^{\theta}}{1-\chi}\left(\frac{1-\chi}{1-\chi \Pi^{\theta-1}}\right)^{\underline{\theta} \theta-1}
$$

\section{F Incorporating Money}

In this section, we extend our baseline model to explicitly introduce a role for money and a money demand function. Households now have preferences for real money balances to capture the value of money in easing transactions frictions. For simplicity, we assume that households only hold money in the middle period of life and utility over real money balances is separable. We also assume that there exists a level of real money balances $\bar{m}$ at which households are satiated: that is, $v^{\prime}(\bar{m})=0$.

We specify and characterize the household's problem in the case of income received in the middle period only and taxes paid in all periods. For household $i$, the objective function and 
budget constraints are given below:

$$
\begin{aligned}
\max _{C_{t}(i), C_{t+1}(i), M_{t+1}(i), C_{t+2}(i)} & \mathbb{E}_{t}\left\{\log \left(C_{t}(i)\right)+\beta \log \left(C_{t+1}(i)\right)+\beta v\left(M_{t+1}(i)\right)+\beta^{2} \log \left(C_{t+2}(i)\right)\right\} \\
\text { s.t. } \quad C_{t}(i) & =B_{t}(i)-T_{t}^{y} \\
C_{t+1}(i) & =Y_{t+1}-T_{t+1}^{m}+B_{t+1}(i)-M_{t+1}(i)-\frac{\left(1+i_{t}\right)}{\Pi_{t+1}} B_{t}(i) \\
C_{t+2}(i) & =\frac{1}{\Pi_{t+1}} M_{t+1}(i)-T_{t+2}^{o}-\frac{\left(1+i_{t+1}\right)}{\Pi_{t+2}} B_{t+1}(i) \\
B_{t+j}(i) & \leq \mathbb{E}_{t+j}\left(1+r_{t+j+1}\right) D_{t+j} \quad \text { for } j=0,1
\end{aligned}
$$

where $M_{t+1}(i)$ are real money balances demanded by household $i$. Money earns zero interest and carries a liquidity premium on bonds away from the zero lower bound. The household's money demand condition is given below:

$$
C_{t+1}(i) v^{\prime}\left(M_{t+1}(i)\right)=\frac{i_{t+1}}{1+i_{t+1}} .
$$

The above expression implicitly defines a money-demand equation. The given monetary policy rule determines real money balances via (A.55). Given a representative middle-aged cohort and given that only the middle aged demand money, we can drop the $i$, and money demand per middle-generation household is

$$
M_{t}=v^{\prime-1}\left(\frac{i_{t}}{1+i_{t}} \frac{1}{C_{t}^{m}}\right) .
$$

The issuance of money by the central bank modifies the government's budget constraint in (A.19). The government's consolidated budget constraint expressed in real terms is given below:

$$
B_{t}^{g}+M_{t}+T_{t}^{y}\left(1+g_{t}\right)+T_{t}^{m}+\frac{1}{1+g_{t-1}} T_{t}^{o}=G_{t}+\frac{1}{1+g_{t-1}}\left(\frac{1+i_{t-1}}{\Pi_{t}} B_{t-1}^{g}+\frac{1}{\Pi_{t}} M_{t-1}\right) .
$$

We assume a fiscal policy that adjust taxes $T_{t}^{y}, T_{t}^{m}$, and $T_{t}^{o}$ to keep the government's consolidated liabilities, $M_{t}+B_{t}^{g}$, at some constant target level. In particular, this means that, in periods of deflation, the nominal stock of government liabilities is being reduced in proportion to the fall in the price level. In the steady state of a stagnation equilibrium featuring a constant rate of deflation, nominal government liabilities are contracting at the rate of deflation. Under a fiscal policy that keeps real government liabilities constant, the presence of money does not materially alter our conclusions.

\section{G Productivity Growth and Hysteresis}

In this section, we extend the baseline model to include trend productivity growth and offer a simple extension to model hysteresis - where output gaps feed back onto the productivity growth 
process. The extension of the model to include productivity growth does not greatly alter the basic features of the model, but will allow the model to better match the dynamics of real GDP per capita. The aggregate demand block is still summarized by an asset market clearing that relates middle-generation income and the real interest rate:

$$
\begin{aligned}
1+r_{t} & =\frac{1+\beta}{\beta} \frac{\left(1+g_{t}\right) D_{t}}{Y_{t}^{m}-D_{t-1}} \\
& =\frac{1+\beta}{\beta} \frac{\left(1+g_{t}\right) \tilde{D}_{t}}{\tilde{Y}_{t}^{m}-\tilde{D}_{t-1} \frac{A_{t-1}}{A_{t}}},
\end{aligned}
$$

where $\tilde{X}_{t}=X_{t} / A_{t}$ are detrended variables. So long as the collateral constraint grows at the same rate as productivity growth, there exists a balanced growth path with a constant real interest rate in steady state and quantities growing at the rate of productivity growth. Relative to the AD curve in the baseline model, the only difference is that higher productivity growth increases saving by lowering the value of debt incurred when young.

Trend productivity growth also impacts the wage norm as the flexible-price real wage rises over time. Now, deflation must exceed the rate of productivity growth for the wage norm to bind. More generally, if nominal wages are indexed to the inflation target, the shortfall of inflation below target must exceed the growth rate of productivity. The wage norm indexed to inflation is given below along with the flexible-price real wage:

$$
\begin{aligned}
W_{t} & =\max \left\{\gamma \Pi^{*} W_{t-1}+(1-\gamma) P_{t} w_{t}^{\text {flex }}, P_{t} w_{t}^{\text {flex }}\right\} \\
w_{t}^{f l e x} & =\alpha A_{t} \bar{L}^{\alpha-1} .
\end{aligned}
$$

Real wages and output can be detrended by productivity growth to obtain stationary variables. Trend stationary real wages are given by the following expression:

$$
\tilde{w}_{t}=\max \left\{\gamma \Pi^{*} \frac{\tilde{w}_{t-1}}{\Pi_{t}} \frac{A_{t-1}}{A_{t}}+(1-\gamma) \tilde{w}^{\text {flex }}, \tilde{w}^{\text {flex }}\right\},
$$

where $\tilde{w}_{t}$ are detrended real wages and $\tilde{w}^{f l e x}=\alpha \bar{L}^{\alpha-1}$. In steady state, the wage norm binds when $\Pi^{*}>\bar{\Pi} \mu$, where $\mu$ is the steady-state growth rate of productivity. The AS curve can be derived by substituting the following expressions for output and the full-employment level of output:

$$
\begin{aligned}
\tilde{w}_{t} & =\alpha \tilde{Y}_{t}^{\frac{\alpha-1}{\alpha}} \\
\tilde{w}^{f l e x} & =\alpha \tilde{Y}_{f e}^{\frac{\alpha-1}{\alpha}} .
\end{aligned}
$$

Equations $(A .59),(A .62)$, and $(A .63)$ along with the Fisher relation and the monetary policy rule jointly determine $\left\{\tilde{Y}_{t}, \tilde{w}_{t}, r_{t}, \Pi_{t}, i_{t}\right\} .67$

\footnotetext{
${ }^{67}$ Income for the middle-aged household $\tilde{Y}_{t}^{m}$ is assumed to be a constant fraction of total income.
} 
The modified equilibrium conditions presented in this section have simply taken productivity growth as an exogenous process. One possibility is that prolonged output gaps feed back into slower productivity growth. Productivity growth could be related to the output gap simply by positing a simple feedback process. This feedback process represents a reduced-form mechanism whereby prolonged output gaps reduced productivity growth by, for example, reducing investment, technology adoption, and expenditures in public or private research and development, or by limiting the degree of firm entry. We posit the following feedback rule:

$$
\frac{A_{t}}{A_{t-1}}=\mu_{0}\left(\frac{\tilde{Y}_{t}}{\tilde{Y}_{f e}}\right)^{\kappa},
$$

where $\kappa$ determines the strength of the hysteresis effect.

\section{H Quantitative Calibration: US, Europe, and Japan}

The simple three-period OLG model captures the salient features of secular stagnation: persistently low levels of inflation and interest rates and below-trend output. Though our model is obviously highly stylized, we still think it is of value to explicitly parameterize it and examine its capacity to explain recent stagnation episodes. Figure A.1 displays the key series whose behavior our theory is trying to explain. In all these episodes, we have witnessed a drop in the short-term nominal interest rate to close to zero and a decline in inflation below the implicit inflation target of the central bank. The size of the fall in inflation has varied. Japan has experienced outright deflation, but in the US and Europe, deflation was very short-lived while inflation has remained persistently below the target of the central banks. The size of the output gap is more controversial. Here, we calibrate the model to recent estimates, but, conceptually, even without any remaining output gap, low natural rates of interest pose an ongoing challenge for monetary policy.

To evaluate the capacity of our model to match the behavior of GDP per capita, interest rates, and inflation, we choose parameters to target steady-state output gaps and deviations of inflation from target for each region. As discussed in the previous section, we modify the equilibrium conditions of our model to allow for trend productivity growth and wage indexation to the inflation target. In the case of Japan and the Eurozone, we assume that trend productivity growth fell at the onset of secular stagnation to fit the slower trend rate of GDP growth in each region. We loglinearize the model around the secular stagnation steady state, and plot transition paths for output per capita, nominal interest rates, and inflation in response to a shock to the collateral constraint in each region. Given the three-period OLG structure, each period is taken to be 20 years. 
Figure A.1: Data versus model transition paths: US, Japan, and Eurozone
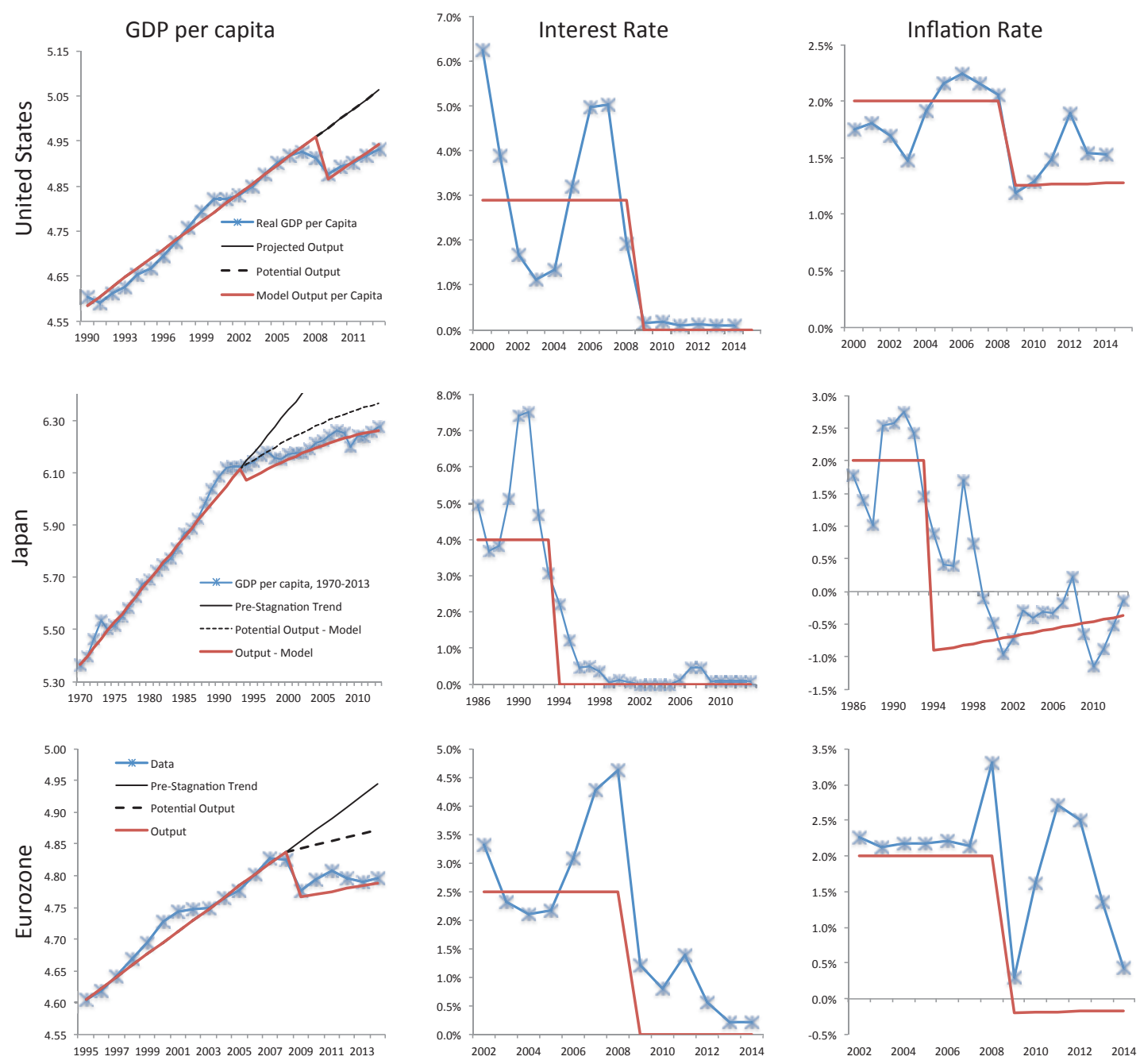

\section{H.1 US Calibration}

Table 1 shows parameters annualized for the US (hence in computing steady state, these values need to be converted to 20 years). We pick an inflation target of $2 \%$ per year, consistent with the Federal Reserve's implicit inflation target. Moreover, we assume that the wage norm is indexed at the inflation rate times the growth rate of productivity. In this case, the wage norm binds whenever inflation falls below target. We assume trend productivity growth of $2.1 \%$ per year to match average GDP per capita growth from 1990-2007. The rate of time preference $\beta$ is set at a conventional value of 0.96 . We set US population growth of $0.7 \%$ per year based upon UN population projections. We set $\alpha$ at 0.7 to match the labor share.

The two novel parameters to choose are the degree of wage rigidity determined by $\gamma$ and the collateral constraint on the young $D$. We must also set an initial value for the collateral constraint 
Table A.1: Parameter values for the US

\begin{tabular}{lcc}
\hline \hline Description & Parameter & Value \\
\hline Population growth & $g$ & $0.7 \%$ \\
Discount rate & $\beta$ & 0.96 \\
Labor share & $\alpha$ & 0.7 \\
Inflation target & $\Pi^{*}$ & $2.0 \%$ \\
Pre-shock collateral (\% of annual GDP) & $\frac{1+g}{1+r_{i n i}} \frac{D_{i n i}}{Y}$ & $126 \%$ \\
Post-shock collateral (\% of annual GDP) & $\frac{1+g}{1+r_{s s}} \frac{D_{s s}}{Y}$ & $100 \%$ \\
Wage adjustment & $\gamma$ & 0.94 \\
Youth income share & $Y_{y} / Y$ & 0.4 \\
\hline
\end{tabular}

as the initial point for the determining the transition path of the economy. To find realistic values of the collateral constraint, it is necessary to include other sources of demand. We do this by assuming that some income is received by the young, the government issues public debt, and the government absorbs some output through purchases that are financed by taxes levied on the middle aged. Government spending as a percentage of GDP is set at $20 \%$, and public debt as a percentage of annual GDP is set at $100 \%$. The government budget constraint determines the level of taxes.

Given government spending, taxes, and public debt, the collateral constraint $D$, the income distribution between young and old, and the wage rigidity parameter are set to match the following targets: an output gap of $13 \%$, an inflation rate of $1.4 \%$, and household debt of $100 \%$ of GDP in 2014. The output gap represents the deviation of output per capita from its 1990-2007 trendline. The inflation rate is based on the growth rate of core PCE in 2014. The household debt target is taken from the Federal Reserve Flow of Funds and is set at 100\% of GDP in order to match the sum of loans to households and nonprofits (13.7 trillion in 2014) and loans to nonfinancial noncorporate businesses ( $\$ 4.4$ trillion in 2014). Finally, the pre-shock level of the collateral constraint is set to match the average nominal interest of $2.9 \%$ between 2001 and 2007.

How reasonable are the values we set for these parameters? The implied weight on last-period wages ( $\gamma$ multiplied by the inflation target and productivity growth) is 0.98 per year. SchmittGrohé and Uribe (2016) provide an authoritative overview of the evidence on downward nominal wage rigidity and estimate a very similar wage adjustment curve to ours. The implied income distribution implies that $60 \%$ of national income is received by the middle aged while $40 \%$ of national income is received by the young. Our calibration implies an initial household debt level of $126 \%$ of GDP, which is quite close to the pre-2008 level of loans to households and small businesses of $121 \%$ of GDP. Therefore, the collateral shock we choose is quite close in magnitude to the contraction in lending experienced during the Great Recession. 
Table A.2: Parameter values for Japan and Eurozone

\begin{tabular}{lccc}
\hline \hline Description & Parameter & Japan & Eurozone \\
\hline Population growth & $g$ & $0 \%$ & $0 \%$ \\
Discount rate & $\beta$ & 0.96 & 0.96 \\
Labor share & $\alpha$ & 0.7 & 0.7 \\
Inflation target & $\Pi^{*}$ & $2.0 \%$ & $2.0 \%$ \\
Pre-shock collateral & $D_{0}$ & 0.37 & 0.27 \\
Post-shock collateral & $D_{1}$ & 0.23 & 0.21 \\
Wage adjustment & $\gamma$ & 0.90 & 0.89 \\
Hysteresis elasticity & $\kappa$ & 4.8 & 3.0 \\
\hline
\end{tabular}

The top row of Figure A.1 plots the transition paths for GDP per capita, inflation, and the interest rate over the relevant data series. A collateral shock can indeed explain the drop in inflation and the interest rate in our model. The nominal interest rate drops to the zero lower bound on impact while the inflation rate slightly overshoots, gradually rising towards its steady-state value of $1.4 \%$. Output per capita falls by less on impact than in the long-run. Therefore, the output gap is widening slightly along the transition path. Indeed, this behavior is consistent with that of US GDP per capita, which is drifting slightly away from the pre-recession trendline. Broadly speaking, our fairly simple model with a shock that matches the magnitude of the contraction in lending can capture the behavior of GDP per capita, inflation, and interest rates in the US during the Great Recession.

\section{H.2 Eurozone and Japan Calibration}

With hysteresis effects, we can calibrate the model to analyze stagnation episodes in the Eurozone and Japan. As with the US calibration, we set the rate of time preference $\beta$ and the labor share $\alpha$ to standard values. Population growth in both regions is set to zero to reflect recent population trends. The inflation target is set at $2 \%$ in both regions. The key remaining parameters are the collateral constraint $D$, the degree of wage rigidity $\gamma$, and the hysteresis parameter $\kappa$. For both regions, we set these parameters to match the output gap, inflation rate, and change in trend output growth. The pre-shock level of the collateral constraint is set to match the nominal interest rate prior to the stagnation episode. ${ }^{68}$ In each case, output is normalized to unity.

In the case of Japan, we target an output gap of $10 \%$, a rate of deflation of $-0.25 \%$, and a reduction in trend productivity growth from $3.3 \%$ to $0.7 \%$. The last value is determined by trend GDP per capita growth from 1970 to 1994 and from 1994 to 2008, respectively. Data on real GDP

\footnotetext{
${ }^{68}$ For this calibration, we set government debt/spending to zero, assume income is received only in the middle years, and do not seek to match the collateral constraint to measures of household debt in the Eurozone or Japan.
} 
per capita come from the World Economic Indicators. The output gap is based on estimates from Hausman and Wieland (2014), and the inflation rate is the growth rate of Japan's CPI as reported in the OECD main economic indicators. As Table A.2 shows, the implied degree of wage rigidity is low (relevant parameters are annualized). Because of hysteresis effects in our model, real wages are relatively flexible in comparison to the values found in Schmitt-Grohé and Uribe (2011). Hysteresis effects limit downward pressure on prices due to the paradox of toil, and therefore limit the degree of deflation despite a persistent output gap.

In the case of the Eurozone, we target an output gap of $10 \%$, an inflation rate of $0 \%$, and a slowdown in productivity growth from $1.8 \%$ to $0.2 \%$. The output gap is chosen to best fit the observed decline in output per capita during the Great Recession. The inflation rate reflects the growth rate of the harmonized CPI in the Eurozone during 2014. The slowdown in productivity growth is estimated by simple trendlines for GDP per capita growth from 1995 to 2008 and 2009 to 2014, respectively. The degree of wage rigidity in the Eurozone is comparable to values for Japan, and the hysteresis effects are about half as strong, reflecting the more modest slowdown in trend GDP growth before and after the stagnation episode. As in the US, the output gap in the Eurozone is gradually increasing over time along the transition path, consistent with the behavior of EU GDP per capita post Great Recession.

\section{Derivation of the Quantitative Life Cycle Model}

\section{I.1 Demographics and Labor Supply}

The economy consists of a large number of households with identical utility parameters. Households enter economic maturity at age 26, after which they work, consume, have children, and participate in markets. Finally they die at age $J$, which we take to be 81 years. Households have children at age 26 , and the population growth rate is determined by the total fertility rate $(\Gamma)$ of every family. Individuals have a probability of dying stochastically before reaching maximum age $J$. The probability of surviving between age $j$ and $j+1$ is denoted by $s_{j} .{ }^{69}$ The unconditional probability of reaching age $j$ is denoted with a superscript $s^{j} \cdot{ }^{70}$

The total population alive at any given time, $N_{t}$, is the sum of the population of the individual ages, $N_{j, t}$. The population size of a given generation $N_{j, t}$ is the population of the generation the previous year that has survived. But what about at age 26 (the first year of economic maturity in our model)? The total population of a generation entering economic majority at time $t$ is equal to the total population of their parents when they entered economic maturity at time $t-25$, times the total fertility rate of their parents' generation. Thus population evolves in the model according to

\footnotetext{
${ }^{69}$ Age-specific survival rates may also vary over time $t$; however, for notational simplicity we omit these additional subscripts.

${ }^{70}$ This can be calculated as the production on one-period survival probabilities: $s^{j}=\Pi_{m=26}^{j-1} s_{m}$.
} 
the law of motion given below:

$$
\begin{aligned}
N_{t} & =\sum_{j=26}^{J} N_{j, t} \\
N_{j+1, t+1} & =s_{j, t} N_{j, t} \text { for } j \in\{27, J\} \\
N_{26, t} & =N_{26, t-25} * \Gamma_{26, t-25} .
\end{aligned}
$$

The total fertility rate along with the age at which households have children determines the rate of population growth. In a steady state, for a given total fertility rate $\Gamma$, the rate of population growth $n$ is equal to

$$
n=\Gamma^{\frac{1}{25}}-1
$$

In a steady state with a rate of population growth $n$, each generation is $(1+n)$ times larger than the previous. Thus the total population size can be calculated as (normalizing the total population to 1 )

$$
\begin{aligned}
N & =\sum_{j=26}^{J} N_{j} \\
N_{j+1} & =s_{j} \frac{N_{j}}{(1+n)} \text { for } j \in\{27, J\} \\
N_{26}=N_{26}, &
\end{aligned}
$$

where $\bar{N}_{26}$ is the normalized population in period 1 , equal to

$$
\bar{N}_{1}=\frac{1}{\sum_{j=26}^{J} \frac{s^{j}}{(1+n)^{j-1}}} .
$$

Each household has an identical schedule of lifetime exogenous labor productivity, or human capital, denoted by $h c_{j}$, which varies by age. Households receive no wage income after retirement, which in our model occurs after age 65 (model age 40). We assume labor is supplied inelastically. Therefore, wage income at full employment is equal to the wage multiplied by the individual agespecific labor productivity $h c_{j}$ net of labor taxes $\left(1-\tau^{w}\right)$. In a secular stagnation, labor demand falls below labor supply, and labor is rationed proportionally for each cohort:

$$
L_{t}^{s}=\sum_{j=26}^{J} N_{j, t} h c_{j} .
$$

\section{I.2 Household's Problem}

Households receive utility from two sources: (i) consumption, which is given by a time-separable constant elasticity of substitution (CES) utility function $u(\cdot)$ with an elasticity of intertemporal substitution parameter $\rho$, and (ii) bequests, which are divided equally among all descendants. 
The bequest motive is also characterized by a CES function, $v(\cdot)$, whose argument is the amount of bequests left per descendent ${ }^{71}$, denoted by $x$. The utility of bequests is multiplied by a parameter $\mu \geq 0$ that determines the strength of the bequest motive. Denoting consumption of a household of age $j$ at time $t$ by $C_{j, t}$ and the discount rate by $\beta$, a household born at time $t$ then maximizes its lifetime expected utility:

$$
U_{t}=\sum_{j=26}^{J} s^{j} \beta^{j-1} u\left(C_{j, t+j-1}\right)+s^{J} \beta^{J-1} \mu v\left(x_{J, t+J-1}\right) .
$$

The household of age $j$ can purchase or borrow a real asset $a_{j, t}$ at price $\xi_{t}$ at time $t$, which is used as productive capital. At time $t+1$, it will pay the return $r_{t+1}^{k}$, which is the rental rate of capital, and has a resell value(net of depreciation) $(1-\delta) \xi_{t+1}$, where $\xi_{t+1}$ is the relative price of capital in terms of the consumption good. All households, prior to the terminal period, participate in a perfectly competitive one-period annuity market as in Ríos-Rull (1996). For a given cohort, the assets of households that die are distributed evenly to the surviving members of the cohort. Households also receive income from the pure profits from firms, denoted by $\Pi_{j, t}{ }^{72}$ Finally, the household may receive a bequest $q_{j, t}$. Bequest received are assumed to be zero at all times except at age $J-24$. Bequests given are zero at all times, except at age $J$.

The flow budget constraint of a household of age $j$ at time $t$ can then be written as $c_{j, t}+\xi_{t} a_{j+1, t+1}+\Gamma_{26, t-j+26} \cdot x_{j, t}=\left(1-\tau^{w}\right) w_{t} h c_{j}+\Pi_{j, t}+\left[r_{t}^{k}+\xi_{t}(1-\delta)\right]\left(a_{j, t}+q_{j, t}+\frac{1-s_{j}}{s_{j}} a_{j, t}\right)$.

Households may wish to borrow against future income and face a borrowing constraint of the same form as in the three-period model $^{73}$ :

$$
a_{j, t} \geq \frac{D_{t}}{1+r_{t}} .
$$

There is one further complication with bequests. Since mortality is stochastic, not all parents will survive to their maximum age and be able to give bequests to their children. Thus, absent any insurance markets, there would be stochastic within-generation inequality, as some households would receive bequests and others would not. In order to remove this channel, we assume all generations participate in a form of bequest insurance markets. At the maximum age, all surviving members of a generation pool their optimal bequests and divide them equally among their surviving children. Thus the relationship between bequests given (at age $J$ ) and those received by children (at model age $k$ ) at time $t$ is given by

$$
q_{k, t}=\frac{N_{J, t-1} x_{J, t-1} \cdot \Gamma_{26, t-J+26}}{N_{k, t}} .
$$

\footnotetext{
${ }^{71}$ Thus the total size of the bequest left by households is the bequest $x$ multiplied by the fertility of the household.

${ }^{72}$ We assume that these are distributed proportional to labor income.

${ }^{73}$ We assume that $D_{t}$ grows at the rate of productivity growth and is expressed in terms of consumption goods to ensure balanced growth.
} 


\section{I.3 Final Goods Firms}

There exists a continuum of final goods firms of type $i$ of measure one that costlessly differentiate an intermediate good and resell to the representative household. The final good composite is the CES aggregate of these differentiated final goods:

$$
Y_{t}=\left[\int_{0}^{1} y_{t}^{f}(i)^{\frac{\theta_{t}-1}{\theta_{t}}} d i\right]^{\frac{\theta_{t}}{\theta_{t}-1}} .
$$

These firms are monopolistically competitive, set prices in each period, and face a demand curve that takes the following form:

$$
y_{t}^{f}(i)=Y_{t}\left(\frac{p_{t}(i)}{P_{t}}\right)^{-\theta_{t}},
$$

where $\theta_{t}$ is a time-varying shock to the firm's market power. An increase in $\theta_{t}$ decreases a firm's market power and lowers equilibrium markups. Each final goods producer uses $y_{t}^{m}$ of intermediate goods to produce output, according to a linear technology function $y_{t}^{f}=y_{t}^{m}$. A final goods firm chooses real prices $\frac{p_{t}(i)}{P_{t}}$ and $y_{t}^{f}(i)$ to maximize real profits, subject to the production constraint:

$$
\begin{gathered}
\max \frac{p_{t}(i)}{P_{t}} y_{t}^{f}(i)-\frac{p_{t}^{i n t}}{P_{t}} y_{t}^{f}(i) \\
\text { subject to } y_{t}^{f}(i)=Y_{t}\left(\frac{p_{t}(i)}{P_{t}}\right)^{-\theta_{t}},
\end{gathered}
$$

where $\frac{p_{t}^{i n t}}{P_{t}}$ is the price of the intermediate good taken as given by the firm.

The optimality condition for the real price of the firm's good is a time-varying markup over the price of the intermediate good:

$$
\frac{p_{t}(i)}{P_{t}}=\frac{\theta_{t}}{\theta_{t}-1} \frac{p_{t}^{i n t}}{P_{t}}
$$

The nominal price index implies the following expression for the price of intermediate goods:

$$
P_{t}=\left(\int p_{t}(i)^{1-\theta_{t}} d i\right)^{\frac{1}{1-\theta_{t}}}
$$

Since the price of the intermediate good is the same, all final goods firms make the same pricing decisions (no pricing frictions), and thus $p_{t}(i)=P_{t}$, yielding

$$
\frac{p_{t}^{i n t}}{P_{t}}=\frac{\theta_{t}-1}{\theta_{t}}
$$

With a retail elasticity of substitution of $\theta_{t}$, aggregate profits in equilibrium will be given by

$$
\Pi_{t}=\frac{Y}{\theta} .
$$

Profits from monopolistically competitive firms are distributed according to wage income. In equilibrium, the total distributed profit must equal total profits:

$$
\frac{Y_{t}}{\theta_{t}}=\sum_{j=26}^{J} N_{j, t} \Pi_{j, t}
$$




\section{I.4 Intermediate Goods Firms}

There exists a perfectly competitive intermediate goods sector that sells its production to the final goods sector at real price $\frac{p_{t}^{\text {int }}}{P_{t}}$. These firms operate a CES production function with an elasticity of substitution $\sigma$, hire labor, and rent capital. The representative intermediate goods firms maximize static real profits given the following production function:

$$
\begin{aligned}
\Pi_{t}^{i n t} & =\max \frac{p_{t}^{i n t}}{P_{t}} Y_{t}-w_{t} L_{t}-r_{t}^{k} K_{t} \\
Y_{t} & =\left(\alpha\left(A_{k, t} K_{t}\right)^{\frac{\sigma-1}{\sigma}}+(1-\alpha)\left(A_{l, t} L_{t}\right)^{\frac{\sigma-1}{\sigma}}\right)^{\frac{\sigma}{\sigma-1}} .
\end{aligned}
$$

Labor productivity $A_{L, t}$ grows at each period at the rate of $g_{t}$.

The first-order conditions that determine labor and capital demand are given below:

$$
\begin{aligned}
w_{t} & =\frac{p_{t}^{\text {int }}}{P_{t}}(1-\alpha) A_{l, t}\left(\frac{Y_{t}}{L_{t}}\right)^{\frac{1}{\sigma}} \\
r_{t}^{k} & =\frac{p_{t}^{\text {int }}}{P_{t}} \alpha A_{k, t}\left(\frac{Y_{t}}{K_{t}}\right)^{\frac{1}{\sigma}} .
\end{aligned}
$$

The risk-free real rate is related to the return on capital by a standard no-arbitrage condition:

$$
1+r_{t}=\frac{r_{t}^{k}+(1-\delta) \xi_{t}}{\xi_{t-1}}
$$

\section{I.5 Relative Price of Capital Goods}

Investment-specific productivity is defined as the amount of capital goods that can be produced with one unit of investment. In particular, we will assume that capital goods are produced by perfectly competitive firms in an investment-specific production sector, which converts the final composite goods into capital goods. These firms maximize the following profit function subject to a linear production function:

$$
\begin{aligned}
\Pi^{K} & =\xi_{t} * K_{t}-Y_{t}^{K} \\
K_{t} & =z_{t} Y_{t}^{K},
\end{aligned}
$$

where $\xi_{t}$ is the relative price of capital goods. Here, $z_{t}$ is the productivity of the capital-producing sector. The zero profit conditions mean that, in equilibrium, $\xi_{t}=\frac{1}{z_{t}}$. Thus, the more productive the investment goods sector is, the lower the relative price of capital goods.

The aggregate capital stock evolves according to the standard law of motion:

$$
K_{t+1}=(1-\delta) K_{t}+\frac{I_{t}}{\xi_{t}},
$$

where $\delta$ is the rate of depreciation, $I_{t}$ is investment, and $\xi_{t}$ is the relative price of capital goods. 
The government spends an exogenous $G_{t}$ and may accumulate debt. The budget constraint is given by

$$
b_{g, t}=G_{t}+\left(1+r_{t}\right) b_{g, t-1}-T_{t}
$$

where the total tax bill is collected with labor income tax. For the purpose of our simulations, fiscal policy will be specified as an exogenous sequence of two variables: government debt to GDP and government spending to GDP. The wage income tax will then be endogenously determined by the model in order for the budget constraint to hold.

We have economized on notation by omitting real and nominal bonds as assets; they enter in the same way as in the simpler model, so there is both a well-defined real interest rate $r_{t}$ on a risk-free one-period bond and a nominal interest rate $i_{t}$.

\section{I.6 Equilibrium}

A competitive equilibrium is a set of household allocations: $\left\{\left\{c_{j, t}, a_{j, t}, \Pi_{j, t}, q_{j, t}, x_{j, t}\right\}_{j=26}^{J}\right\}_{t=0}^{\infty}$, a set of aggregate quantities $\left\{Y_{t}, K_{t}, L_{t}, \Pi_{t}\right\}_{t=0}^{\infty}$, a set of prices $\left\{w_{t}, r_{t}^{k}, r_{t}, \frac{p_{t}^{i n t}}{P_{t}}, \xi_{t}\right\}_{t=0}^{\infty}$, a set of government variables $\left\{b_{t}, \tau_{t}^{w}, \tau_{t}^{r}\right\}_{t=0}^{\infty}$, and a set of exogenous processes $\left\{\left\{N_{j, t}, p_{j, t+1}\right\}_{j=0}^{J}\right\}_{t=0}^{\infty}$ that jointly satisfy:

1. Consumption and bequests maximizes (A.70) subject to (A.71) and (A.72).

2. Asset holdings satisfy (A.71), with $a_{1}=0$ given.

3. Profits are distributed proportionally to labor income.

4. Bequests received equal bequests given by the surviving parents according to (A.73).

5. Output is given by aggregate production function (A.78).

6. Population by age group is given by (A.66).

7. Aggregate labor supply is given by (A.69).

8. Aggregate profits are given by (A.76).

9. There are perfect factor markets, and thus (A.81), (A.80), and (A.82) hold.

10. Markup condition: (A.74).

11. The government satisfies budget equation (A.86).

12. Asset markets clear, and thus

$$
\sum_{j=1}^{J} N_{j, t} \xi_{t} a_{j, t}=\xi_{t} K_{t}+b_{t} \forall t
$$




\section{I.7 Stationary Equilibrium}

A steady-state equilibrium is the same as the above definition, except that all variables are constant rather than subscripted by time. With productivity and population growth greater than zero, however, the economy is not stationary. However, since preferences are of the CRRA variety, the economy can be rewritten as stationary by applying a transformation. All cohort level variables are divided by $(1+g)^{t}$, aggregate variables are divided by $(1+g)^{t}(1+n)^{t}$, and wages are divided by $(1+g)^{t}$.

In a steady-state equilibrium, there are $4 * J+12$ unknowns: J consumption demands $c_{j}$, J asset demands $a_{j}$, J shares of aggregate profits $\Pi_{j}, J$ age-specific population sizes $N_{j}, 1$ bequest given $x$, 1 bequest received $q$, aggregate output $Y$, aggregate capital $K$, aggregate labor $L$, aggregate profits $\Pi$, wage rate $w$, return on capital $r^{k}$, interest rate $r$, price of intermediate goods $\frac{p^{i n t}}{P}$, relative price of capital $\xi$, and tax rate $\tau^{w}$.

There are also $4 * J+12$ equations:

1. (J-1) Euler equations

2. (1) Optimal bequest given equation

3. (1) Equation determining size of bequest received

4. (J) Flow budget equations

5. (J) Profit share equations

6. (1) Initial assets are zero

7. (J) Population equations

8. (1) Aggregate production function

9. (1) Asset market clearing condition

10. (1) Aggregate labor supply equation

11. (1) Aggregate profit equation

12. (1) Wage equation

13. (1) Price of intermediate goods equation

14. (1) Rental rate of capital equation

15. (1) Relative price of capital is exogenously given

16. (1) Interest rate equation

17. (1) Government budget equation 


\section{J Computational Method}

Solving the quantitative model is implemented much along the lines as described in chapter 4 of Auerbach and Kotlikoff (1987). We begin by describing how to solve for variables in the stationary equilibrium. In solving for the stationary equilibrium, the algorithm begins with a guess for a subset of endogenous variables. For the purposes of the rest of the iteration, this subset of variables is treated as exogenous. This simplification makes the resulting system easier to solve for the endogenous variables, including the variables for which guesses were made.

We begin with a guess for the aggregate capital stock, the wage tax, and bequests received. Given the aggregate capital and labor stock, we can calculate interest rates and wages, as well as aggregate output and profits. This allows us to calculate optimal household behavior for consumption, asset holdings, and bequests given. Since the optimization problem of the household includes a debt limit, we cannot solve the household's optimal decisions analytically, as in Auerbach and Kotlikoff (1987). Instead, we use Matlab's convex optimization solver "fmincon."

In the steady state, the population of each age group is given by equation (A.66). Using the population sizes of each age group, we aggregate the optimal asset supply to obtain a new value of the aggregate capital stock. Using aggregate capital and labor, we calculate aggregate output and profits in the economy. We also update the tax rate to satisfy the government's budget constraint. Finally, we set bequests received to be equal to total bequests given by the individuals that survive to 81 divided by the number of children who survived to the bequest age of 57 . Typically, 20 to 30 iterations are necessary to converge to the stationary equilibrium.

The approach used to solve for the transition path is similar to solving for the initial and final steady states of the model. We assume that the economy will be in a steady state after 150 years in the transition. In the years between the initial and final steady state, we must solve for all endogenous variables, including the optimal consumption and bequests choices for individuals of all generations. We assume the year 1 is in steady state and that, in the year 2, agents are surprised by an unexpected change in the path of key economic variables, such as productivity growth, total fertility rate, mortality profiles, etc. Their asset choices were made previously in

period 1, and they must now adjust their consumption and saving choices to the path of these variables. At the time of the shock, households have perfect foresight.

Our algorithm now begins with a guess for the same subset of endogenous variables, but now the guess for each variable is a $150 \times 1$ vector for each year of the transition path. Given the vector of guesses for the capital stock, we can calculate a vector of prices and wages and thus optimally solve for consumption and bequests of each generation in the transition period. After the year 151, agents assume the economy will be in the final steady state. We then aggregate the individual asset supply decisions to get a new value for capital supply and repeat the algorithm until convergence. 


\section{K Extension with Financial Frictions}

All borrowing and lending is done through a perfectly competitive banking system. The banking system takes lending from individuals and matches them with borrowers, who can be either firms or other individuals. For every 1 unit of either investment or final good that is lent, it costs the bank $\phi$. Because there is perfect competition in the banking industry, the rate the bank charges to borrowers, $r_{b}$, and the rate the bank gives to lenders, $r_{l}$ are related by the following arbitrage equation:

$$
r_{b}=r_{l}+\phi
$$

\section{K.1 Individuals}

Individuals have the same utility function, budget constraint, and borrowing limit as they previously did. However, now the interest rate they face depends on whether they are a borrower or a lender: If $a_{t}<0$, they face the borrowing interest rate $r_{b}$. If $a_{t}>0$, they face the lending interest rate $a_{l}$.

\section{K.2 Firms}

Intermediate goods firms face the same profit maximization and production function as before. However, now all borrowing of capital (paying the rental rate $r^{k}$ ) must be intermediated through a bank as well. Firms rent capital services at rate $\rho_{b}$, and individuals can lend capital at rate $\rho_{l}$. The arbitrage equation for the real interest rate is now given by

$$
1+r_{t, b}=\frac{r_{t, b}^{k}+(1-\delta) \xi_{t}}{\xi_{t-1}}
$$

with a similar arbitrage equation for the interest rate for lending.

\section{K.3 General Equilibrium}

In general equilibrium, the supply for loanable funds must equal the demand:

$$
S\left(r_{l}\right)=D\left(r_{b}\right)
$$

\section{Supplemental Figures and Tables}

We perform several robustness exercises. The first alternate specification holds all variables at the levels in the main specification, but sets depreciation at $8 \%$. The second alternate specification 
Figure A.2: Consumption profile in stationary equilibrium

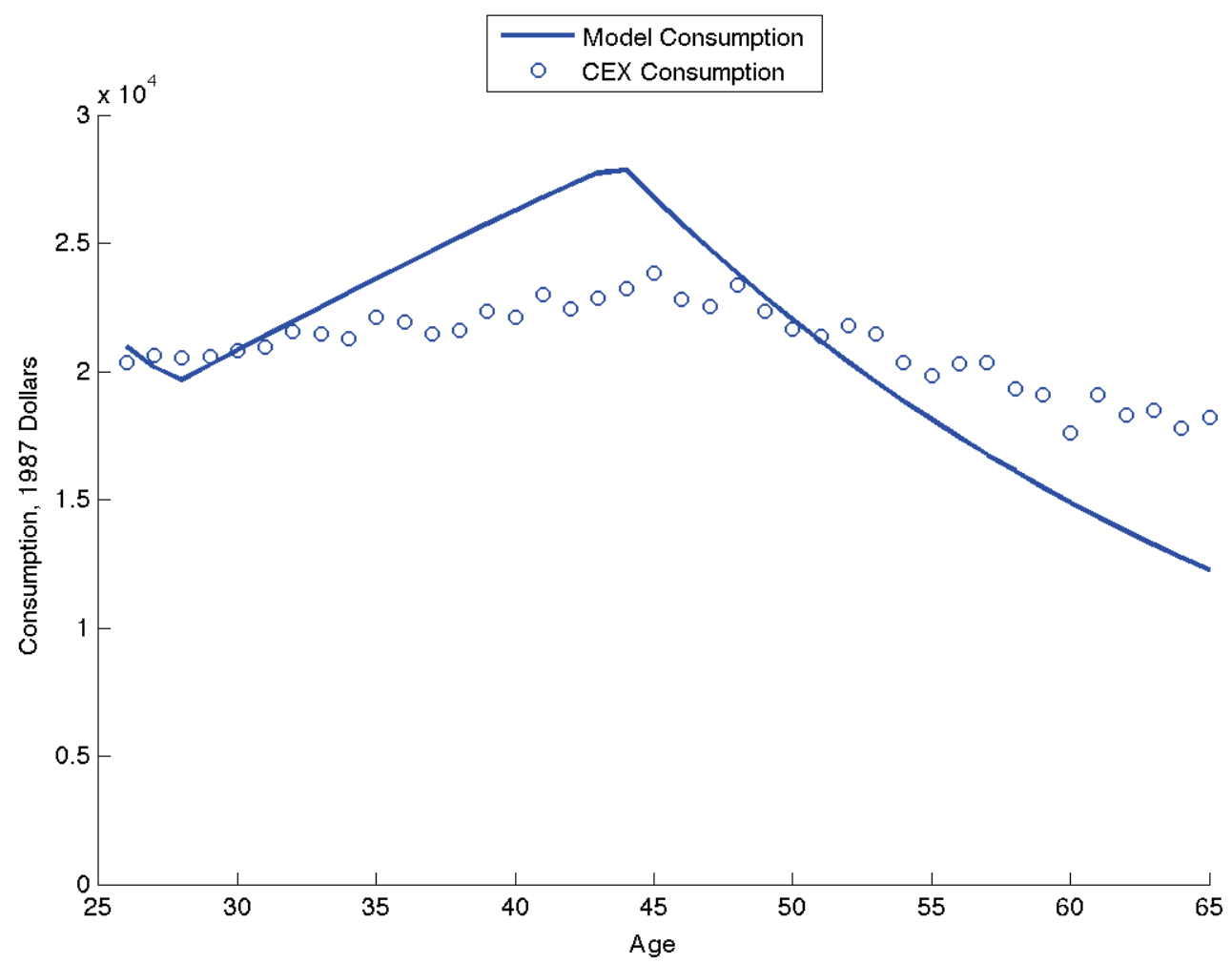


Figure A.3: Population pyramid in stationary equilibrium
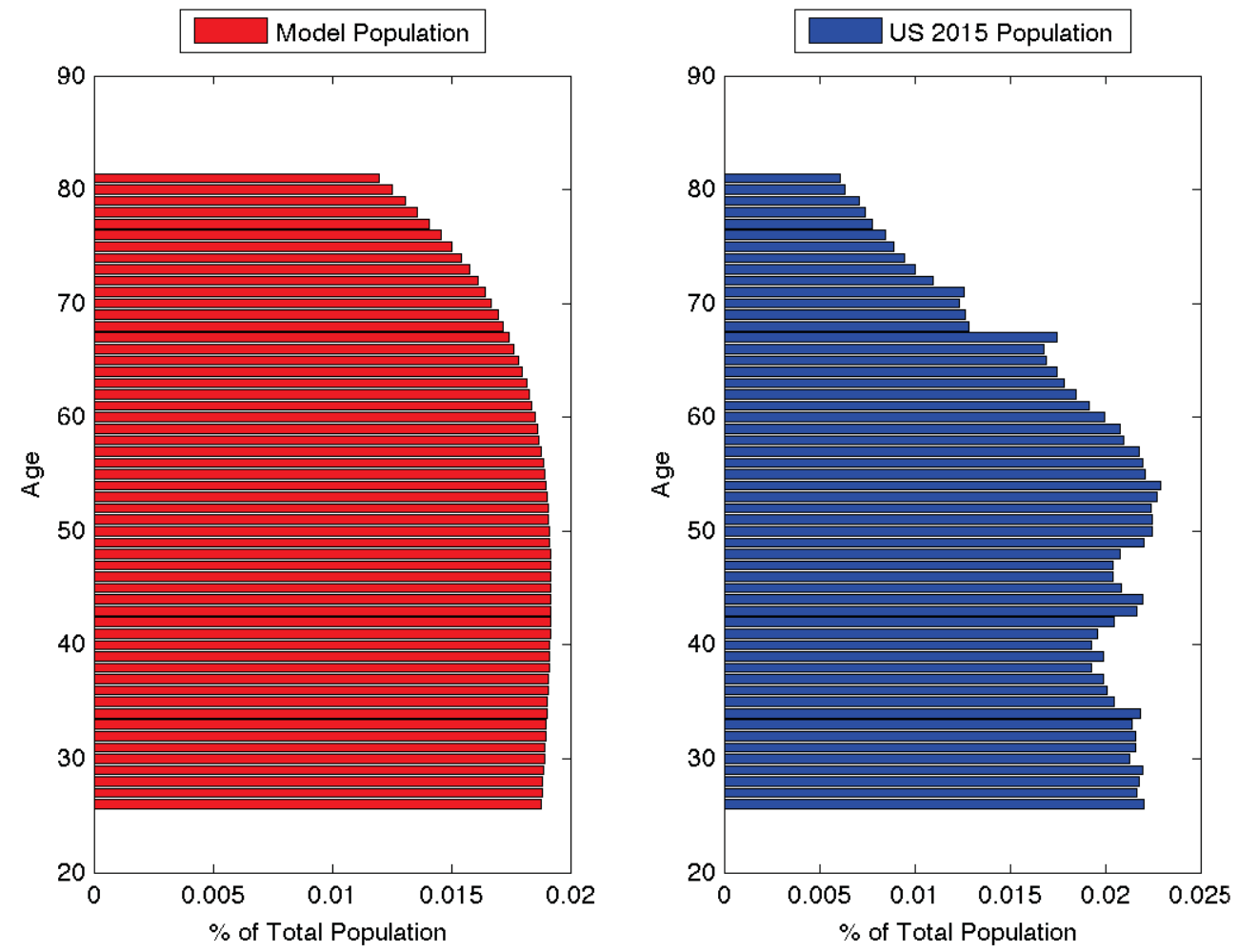
Table A.3: 2015 steady-state results, alternate specification 1

\begin{tabular}{lcc}
\hline \hline Moment & Model & US data \\
\hline Natural rate of interest & $-1.47 \%$ & $-1.47 \%$ \\
Investment-to-output ratio & $15.9 \%$ & $15.9 \%$ \\
Consumer-debt-to-output ratio & $6.3 \%$ & $6.3 \%$ \\
Labor share & $65.99 \%$ & $65.99 \%$ \\
Bequests-to-output & $3 \%$ & $3 \%$ \\
\hline
\end{tabular}

Table A.4: Decomposition, alternate specification 1

\begin{tabular}{lcc}
\hline \hline Forcing variable & $\Delta$ in $r$ & $\%$ of total $\Delta$ \\
\hline Total interest rate change & $-3.60 \%$ & $100 \%$ \\
Mortality rate & -1.28 & $34 \%$ \\
Total fertility rate & -1.19 & $32 \%$ \\
Productivity growth & -1.67 & $45 \%$ \\
Government debt (\% of GDP) & +1.13 & $-30 \%$ \\
Labor share & -.45 & $12 \%$ \\
Relative price of investment goods & -0.36 & $10 \%$ \\
Change in debt limit & +.08 & $-2 \%$ \\
\hline
\end{tabular}

holds all variables at the level in the main specification, but sets the utility elasticity of substitution equal to 1 . The third alternate specification holds all parameters at the level in the main specification, but sets the production elasticity equal to 1 (Cobb-Douglas). The fourth alternate specification sets the intertemporal elasticity of substitution to 0.5 .

\section{Changes in the US Economy Since 1970}

Our choice of 1970 as a starting point for our analysis is motivated primarily by the fact that there have been substantial changes in the fundamentals of the US economy since the 1970s. The baby

Table A.5: Raising the rate of interest to $1 \%$, alternate specification 1

\begin{tabular}{lcc}
\hline \hline Forcing variable & 2015 Value & Counterfactual value \\
\hline Total fertility rate & 1.88 & 5.40 \\
Government debt (\% of GDP) & $118 \%$ & $285 \%$ \\
Productivity growth & $0.65 \%$ & $2.65 \%$ \\
Relative price of investment goods & 1.00 & 2.22 \\
\hline
\end{tabular}


Table A.6: 2015 steady-state results, alternate specification 2

\begin{tabular}{lcc}
\hline \hline Moment & Model & US data \\
\hline Natural rate of interest & $-1.47 \%$ & $-1.47 \%$ \\
Investment-to-output ratio & $15.9 \%$ & $15.9 \%$ \\
Consumer-debt-to output ratio & $6.3 \%$ & $6.3 \%$ \\
Labor share & $65.99 \%$ & $65.99 \%$ \\
Bequests-to-output & $3.01 \%$ & $3 \%$ \\
\hline
\end{tabular}

Table A.7: Decomposition, alternate specification 2

\begin{tabular}{lcc}
\hline \hline Forcing variable & $\Delta$ in $r$ & $\%$ of total $\Delta$ \\
\hline Total interest rate change & $-2.86 \%$ & $100 \%$ \\
Mortality rate & -1.22 & $43 \%$ \\
Total fertility rate & -1.36 & $47 \%$ \\
Productivity growth & -1.28 & $45 \%$ \\
Government debt (\% of GDP) & +1.54 & $-54 \%$ \\
Labor share & -.33 & $12 \%$ \\
Relative price of investment goods & -0.30 & $10 \%$ \\
Change in debt limit & +.08 & $-3 \%$ \\
\hline
\end{tabular}

Table A.8: Raising the rate of interest to $1 \%$, alternate specification 2

\begin{tabular}{lcc}
\hline \hline Forcing variable & 2015 Value & Counterfactual value \\
\hline Total fertility rate & 1.88 & 4.35 \\
Government debt (\% of GDP) & $118 \%$ & $279 \%$ \\
Productivity growth & $0.65 \%$ & $3.29 \%$ \\
Relative price of investment goods & 1.00 & 1.78 \\
\hline
\end{tabular}

Table A.9: 2015 steady-state results, alternate specification 3

\begin{tabular}{lcc}
\hline \hline Moment & Model & US data \\
\hline Natural rate of interest & $-.81 \%$ & $-1.47 \%$ \\
Investment-to-output ratio & $18.03 \%$ & $15.9 \%$ \\
Consumer-debt-to-output ratio & $6.3 \%$ & $6.3 \%$ \\
Labor share & $65.40 \%$ & $65.99 \%$ \\
Bequests-to-output & $3 \%$ & $3 \%$ \\
\hline
\end{tabular}


Table A.10: Decomposition, alternate specification 3

\begin{tabular}{lcc}
\hline \hline Forcing variable & $\Delta$ in $r$ & $\%$ of total $\Delta$ \\
\hline Total interest rate change & $-2.85 \%$ & $100 \%$ \\
Mortality rate & -1.45 & $46 \%$ \\
Total fertility rate & -1.41 & $45 \%$ \\
Productivity growth & -1.70 & $54 \%$ \\
Government debt (\% of GDP) & +1.58 & $-50 \%$ \\
Labor share & -.3 & $10 \%$ \\
Relative price of investment goods & 0 & $0 \%$ \\
Change in debt limit & +.13 & $-4 \%$ \\
\hline
\end{tabular}

Table A.11: Raising the rate of interest to 1\%, alternate specification 3

\begin{tabular}{lcc}
\hline \hline Forcing variable & 2015 Value & Counterfactual value \\
\hline Total fertility rate & 1.88 & 3.18 \\
Government debt (\% of GDP) & $118 \%$ & $208 \%$ \\
Productivity growth & $0.65 \%$ & $2.11 \%$ \\
Relative price of investment goods & 1.00 & $\nexists$ \\
\hline
\end{tabular}

Table A.12: 2015 steady-state results, alternate specification 4

\begin{tabular}{lcc}
\hline \hline Moment & Model & US data \\
\hline Natural rate of interest & $-1.43 \%$ & $-1.47 \%$ \\
Investment-to-output ratio & $15.9 \%$ & $15.9 \%$ \\
Consumer-debt-to-output ratio & $6.3 \%$ & $6.3 \%$ \\
Labor share & $65.99 \%$ & $65.99 \%$ \\
Bequests-to-output & $2.34 \%$ & $3 \%$ \\
\hline
\end{tabular}


Table A.13: Decomposition, alternate specification 4

\begin{tabular}{lcc}
\hline \hline Forcing variable & $\Delta$ in $r$ & $\%$ of total $\Delta$ \\
\hline Total interest rate change & $-7.07 \%$ & $100 \%$ \\
Mortality rate & -3.36 & $38 \%$ \\
Total fertility rate & -3.10 & $35 \%$ \\
Productivity growth & -4.0 & $45 \%$ \\
Government debt (\% of GDP) & +3.27 & $-37 \%$ \\
Labor share & -1.11 & $13 \%$ \\
Relative price of investment goods & -0.83 & $9 \%$ \\
Change in debt limit & +.29 & $-3 \%$ \\
\hline
\end{tabular}

Table A.14: Raising the rate of interest to 1\%, alternate specification 4

\begin{tabular}{lcc}
\hline \hline Forcing variable & 2015 Value & Counterfactual value \\
\hline Total fertility rate & 1.88 & 2.56 \\
Government debt (\% of GDP) & $118 \%$ & $163 \%$ \\
Productivity growth & $0.65 \%$ & $1.51 \%$ \\
Relative price of investment goods & 1.00 & 1.95 \\
\hline
\end{tabular}

boom began soon after World War II, increasing fertility from 2.5 children per woman to a peak of 3.62 children per woman in $1960 .{ }^{74}$ Although the baby boom started in 1945, the children of the baby boom did not enter economic maturity (age 26) until 1970; thus we are able to look at the impact of the baby boom on the evolution of interest rates in our model starting in 1970. Mortality has also changed substantially. In 1970 life expectancy at birth was 70.8 years, growing to 78.7 in 2010. The combination of a slower fertility rate and a decrease in mortality leads to the aging population we see today. This data on fertility and mortality are the raw data we put into the model. For every year from 1970 to 2015, we input the exact total fertility rate from UN fertility data, along with the exact age-specific mortality rate from CDC life tables. After 2015, we assume a steady state with respect to birth rates and mortality.

Gordon (2016) argues that productivity growth in the future will likely stagnate and that longrun growth rates might be half that of the $1.9 \%$ annual rate from 1960 to 2007 . This prediction does not rely on a forecast of a future growth slowdown, for over the past four decades productivity growth has already slowed; since the 1970s, worker productivity has been slower by 0.8 percentage point per year than during the eight decades before. We incorporate this by using estimated

\footnotetext{
${ }^{74}$ After the well known "baby boom" came the less well-known "baby bust," in which total fertility in the US gradually fell to 1.88 children per woman, below the replacement rate, before recovering roughly to the replacement rate seen today.
} 
series for productivity growth rates from Fernald (2012). The exact productivity data are used as input in the model from the 1970s to present day, while from 2015 onward we hold it constant at 0.65 .

Other important factors driving the real interest rate are the relative price of investment goods, the labor share of output, and government debt. Greenwood, Hercowitz and Krusell (1997) and Fernald (2012) have documented that the relative price of investment goods has fallen by $30 \%$ since 1970. Since the relative price of investment goods directly affects capital accumulations, this could potentially have a substantial effect on real interest rates. We set the relative price of capital goods in our model to match the decline since the 1970s. Karabarbounis and Neiman (2014) and Elsby, Hobijn and Şahin (2013) provide data indicating that the labor share has declined substantially since 1970. We model the declining labor share in our model very simply, through an increase in the profit share $\frac{1}{\theta_{t}}$. We choose the path for $\theta_{t}$ to match the decline in the labor share from Elsby, Hobijn and Şahin (2013). Government debt is also an important factor that has changed over the period. Since 1970, total government debt (including state and local debt) has increased to $118 \%$ of GDP. We set government debt to exactly match the data over the period.

\section{N Literature Estimates}


Table A.15: Literature estimates of parameters, Part A

\begin{tabular}{l}
\hline Parameter \\
Beta \\
$0.988-0.990$ \\
$0.956-0.960$ \\
1.011 \\
0.92 \\
$0.96-1.04$ \\
\\
Intertemporal Elasticity of Substitution \\
$0.54-0.62$ \\
$0.71-2.00$ \\
0.40 \\
$0.25-1.00$ \\
0.50 \\
$0.167-0.250$
\end{tabular}

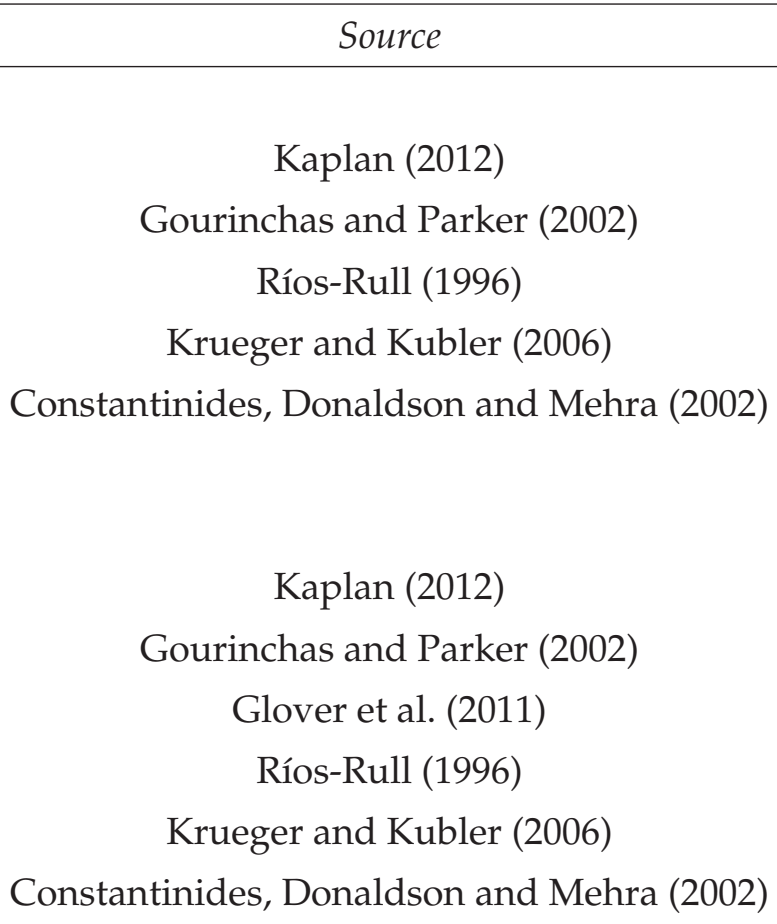
Source

\section{Capital Share}

0.36

0.25

0.33

0.30

$0.30-0.34$
Guerrieri and Lorenzoni (2011) Kaplan (2012)

Gourinchas and Parker (2002)

Hur (2016)

Ríos-Rull (1996)

Krueger and Kubler (2006)

Constantinides, Donaldson and Mehra (2002)

Ríos-Rull and Sánchez-Marcos (2008)

Aiyagari (1994)

Krusell and Smith (1998)

Iacoviello and Pavan (2013)
Ríos-Rull (1996)
Auerbach and Kotlikoff (1987)
Mankiw, Romer and Weil (1992)
Krueger and Kubler (2006)
antinides, Donaldson and Mehra (2002) 
Table A.16: Literature estimates of parameters, Part B

\begin{tabular}{|c|c|}
\hline Parameter & Source \\
\hline \multicolumn{2}{|l|}{ Depreciation } \\
\hline $0.10-0.15$ & Jorgenson (1996) \\
\hline 0.05 & Ríos-Rull (1996) \\
\hline $0.06-0.12$ & Nadiri and Prucha (1996) \\
\hline \multicolumn{2}{|l|}{ Production Elasticity of Substitution } \\
\hline $0.67-0.70$ & Oberfield and Raval (2014) \\
\hline 1.00 & Berndt (1976) \\
\hline $0.40-0.90$ & Antras (2004) \\
\hline $0.50-0.60$ & Klump, McAdam and Willman (2007) \\
\hline 1.25 & Karabarbounis and Neiman (2014) \\
\hline $1.30-1.60$ & Piketty (2014) \\
\hline 0.84 & Herrendorf, Herrington and Valentinyi (2015) \\
\hline 0.78 & Alvarez-Cuadrado, Van Long and Poschke (2014) \\
\hline \multicolumn{2}{|l|}{ Retailer Elasticity of Substitution } \\
\hline 6.00 & Christiano, Eichenbaum and Evans (2005) \\
\hline 6.00 & Galí (2015) \\
\hline 7.87 & Woodford (2003) \\
\hline 4.00 & Nakamura and Steinsson (2009) \\
\hline 4.00 & Berry, Levinsohn and Pakes (1995) \\
\hline 3.00 & Midrigan (2011) \\
\hline 7.00 & Golosov and Lucas (2007) \\
\hline \multicolumn{2}{|l|}{ Bequest Parameter } \\
\hline Based on bequests as a percent of permanent income & Altig et al. (2001) \\
\hline Based on a wealth transfer share of $60 \%$ & De Nardi (2004) \\
\hline
\end{tabular}

